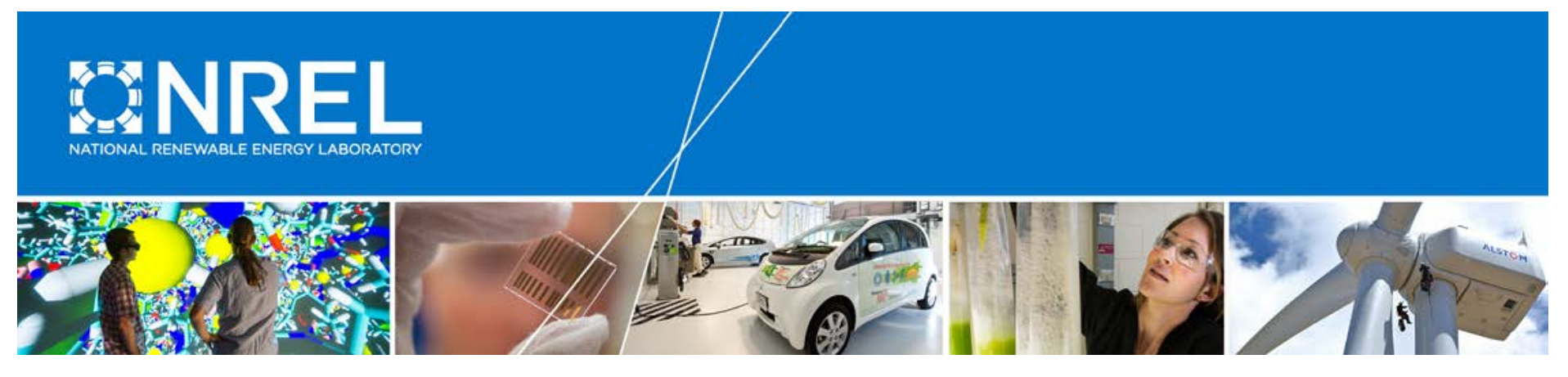

\title{
Tall Tower Wind Energy Monitoring and Numerical Model Validation in Northern Nevada
}

D. Koračin, M. Kaplan, C. Smith, G. McCurdy, A. Wolf, T. McCord, and K. King Desert Research Institute Reno, Nevada

R. Belu

Drexel University

Philadelphia, Pennsylvania

K. Horvath

Croatian Meteorological and Hydrological Service Zagreb, Croatia

NREL Technical Monitor: Caroline Draxl

NREL is a national laboratory of the U.S. Department of Energy Office of Energy Efficiency \& Renewable Energy Operated by the Alliance for Sustainable Energy, LLC

This report is available at no cost from the National Renewable Energy Laboratory (NREL) at www.nrel.gov/publications.

\section{Subcontract Report}

NREL/SR-5000-62894

October 2015 


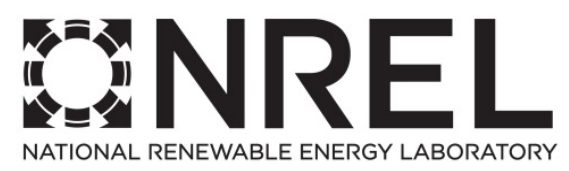

\section{Tall Tower Wind Energy Monitoring and Numerical Model Validation in Northern Nevada}

D. Koračin, M. Kaplan, C. Smith, G. McCurdy, A. Wolf, T. McCord, and K. King Desert Research Institute Reno, Nevada

R. Belu

Drexel University

Philadelphia, Pennsylvania

K. Horvath

Croatian Meteorological and Hydrological Service Zagreb, Croatia

NREL Technical Monitor: Caroline Draxl

Prepared under Subcontract No. NAX-9-66014-02

NREL is a national laboratory of the U.S. Department of Energy Office of Energy Efficiency \& Renewable Energy Operated by the Alliance for Sustainable Energy, LLC

This report is available at no cost from the National Renewable Energy Laboratory (NREL) at www.nrel.gov/publications.

National Renewable Energy Laboratory 15013 Denver West Parkway Golden, CO 80401

303-275-3000 • www.nrel.gov
Subcontract Report

NREL/SR-5000-62894

October 2015

Contract No. DE-AC36-08G028308 


\title{
This publication was reproduced from the best available copy submitted by the subcontractor and received minimal editorial review at NREL.
}

\begin{abstract}
NOTICE
This report was prepared as an account of work sponsored by an agency of the United States government. Neither the United States government nor any agency thereof, nor any of their employees, makes any warranty, express or implied, or assumes any legal liability or responsibility for the accuracy, completeness, or usefulness of any information, apparatus, product, or process disclosed, or represents that its use would not infringe privately owned rights. Reference herein to any specific commercial product, process, or service by trade name, trademark, manufacturer, or otherwise does not necessarily constitute or imply its endorsement, recommendation, or favoring by the United States government or any agency thereof. The views and opinions of authors expressed herein do not necessarily state or reflect those of the United States government or any agency thereof.
\end{abstract}

This report is available at no cost from the National Renewable Energy Laboratory (NREL) at www.nrel.gov/publications.

Available electronically at SciTech Connect http:/www.osti.gov/scitech

Available for a processing fee to U.S. Department of Energy and its contractors, in paper, from:

U.S. Department of Energy

Office of Scientific and Technical Information

P.O. Box 62

Oak Ridge, TN 37831-0062

OSTI http://www.osti.gov

Phone: 865.576.8401

Fax: 865.576.5728

Email: reports@osti.gov

Available for sale to the public, in paper, from:

U.S. Department of Commerce

National Technical Information Service

5301 Shawnee Road

Alexandria, VA 22312

NTIS http://www.ntis.gov

Phone: 800.553 .6847 or 703.605 .6000

Fax: 703.605.6900

Email: orders@ntis.gov 


\section{Foreword}

Assessment and forecasting of wind resources are of great importance for the community, especially in a time of global climate change. Wind turbines and associated technologies are rapidly advancing for both large and small scale facilities. Due to the high spatial and temporal variability of winds and turbulence, it is essential to understand wind structure and its evolution. More complex is to understand wind characteristics in complex terrain where topographic forcing can significantly alter wind magnitude and persistence (Koračin et al. 2014). As the turbine hub heights and blade sizes increase, it is important to analyze and predict 3-D wind and turbulence structure. From an observational point of view, surface measurements with approximate interpolation and extrapolation algorithms are in most cases insufficient and inaccurate to determine wind properties aloft. Efficient and recommended observations include in situ measurements with towers and remote sensing using acoustic sounders (hereafter sodars) and light detection and ranging systems (lidars).

Desert Research Institute (DRI) has been contracted in the past for comprehensive field programs, including towers and sodars as well as for modeling and forecasting studies of atmospheric dynamics for several research and application studies supported by various sponsors, including the U.S. Department of Energy's (DOE) National Renewable Energy Laboratory (NREL).

Considering this current project, the originally accepted proposal to NREL focused on installing a $120 \mathrm{~m}$ tower near Searchlight, Nevada to investigate the wind regime at hub-height elevations, assess wind energy at multiple heights, and evaluate high-resolution modeling of wind, wind shear, and turbulence in complex terrain. Because our business partner (Oak Creek Energy) decided to stop our joint intention to install and operate a $120 \mathrm{~m}$ tower in southern Nevada and we have not received a final permit from the Bureau of Land Management (BLM), we revised the original scope of work following communication with NREL. The revised statement of work was accepted by NREL under contract NAX-9-66014-02 (DE-AC36-08G028308). This project entitled, "Tall tower wind energy monitoring and numerical model validation in northern Nevada" consisted of more than a year-long measurement campaign and evaluation of Weather Research and Forecasting (WRF) and Operational Multiscale Environment Model with Grid Adaptivity (OMEGA) regional/mesoscale models with structured and unstructured grids, respectively. The field program included two $60-\mathrm{m}$ towers instrumented with standard and sonic anemometers and a deployment of sodar. The towers and the collocated sodar were located on ridges of the Virginia Hills between Reno and Carson City. All data were processed and posted on a public website for interactive use, including online calculation statistics and adjustable plotting. Tower data from the 17-month field program as well as modeling and forecasting results represent a great resource for research and application studies focused on assessing and predicting wind resources in complex terrain.

It should be noted that the investigators on this project outreached the research results and enhanced expertise in wind energy by publishing four peer-reviewed articles:

Belu R.G; Koračin, D. (2013). "Statistical and Spectral Analysis of Wind Characteristics Relevant to Wind Energy Assessment Using Tower Measurements in Complex Terrain." Journal of Wind Energy (739162); doi:10.1155/2013/739162. http://dx.doi.org/10.1155/2013/739162. 
Horvath, K.; Koračin, D.; Vellore, R.K.; Jiang, J.; Belu, R. (2012). "Sub-kilometer Dynamical Downscaling of Near-Surface Winds in Complex Terrain Using WRF and MM5 Mesoscale Models." Journal of Geophysical Research (117:D11111). doi:10.1029/2012JD017432.

Koračin, D.; Belu, R.; Canadillas, B.; Horvath, K.; Vellore, R.; Smith, C.; Jiang, J.; McCord, T. (2014). "A Review of Challenges in Assessment and Forecasting of Wind Energy Resources." Croat. Met. Journal. (47), pp. 13-33.

Smith, C. M.; Koračin, D.; Horvath, K. (2014). "Forecast Timing Errors Associated with the Washoe Zephyr. Part1: Dispersion Metrics." Weather and Forecasting (in print). 


\section{Preface}

This document is a final report for the DOE-funded project "Tall Tower Wind Energy Monitoring and Numerical Model Validation in Northern Nevada" under contract NAX-966014-02 (DE-AC36-08G028308). During the study, three NREL program managers were involved in discussions and reporting, namely Marc Schwartz, Dennis Elliot, and Caroline Draxl. The project consisted of a 17-month field program campaign in complex terrain and a modeling and forecasting component. The field program included two $60-\mathrm{m}$ towers equipped with standard and sonic anemometers as well as operation of an acoustic sounder. For the modeling component, the WRF and OMEGA regional/mesoscale models were used and evaluated.

The report is organized as follows. The first part describes performance of each task; the second part presents an additional study focused on dynamical downscaling using the MM5 and WRF models, and an analysis of wind shear. The Appendix lists all measured and processed parameters using tower measurements that are publicly available on DRI's website. 


\section{Acknowledgments}

This project entitled, "Tall Tower Wind Energy Monitoring and Numerical Model Validation in Northern Nevada" was supported by the DOE award NAX-9-66014-02 (DE-AC36-08G028308). DRI project number was 001523-008. The project was managed by NREL and we acknowledge assistance from the NREL project managers Marc Schwartz, Dennis Elliot, and Caroline Draxl. We thank Lycia Ronchetti and Maria Garretson for their help with administrative procedures. 


\section{List of Acronyms}

\begin{tabular}{ll} 
AGL & Above ground level \\
AVG & Average \\
BLM & Bureau of Land Management \\
DI & Diurnal \\
DOE & U.S. Department of Energy \\
DRI & Desert Research Institute \\
FNL & FiNaL analysis \\
LST & Local Standard Time \\
LTD & Longer-than-diurnal \\
MB & Megabyte \\
MM5 & Mesoscale Model 5 \\
MO & Monin-Obukhov \\
NREL & National Renewable Energy Laboratory \\
OMEGA & Operational Multiscale Environment Model with Grid Adaptivity \\
PBL & Planetary boundary layer \\
QC & Quality control \\
QNSE & Quasi-normal scale elimination \\
R & Coefficient of determination \\
RMSE & Root-mean-squared-error \\
SD & Sub-diurnal \\
STD & Standard deviation \\
SODAR & Sonic detection and ranging \\
TI & Turbulence intensity \\
TKE & Turbulent kinetic energy \\
UTC & Coordinated Universal Time (Greenwich Mean Time) \\
WRCC & Western Regional Climate Center \\
WRF & Weather Research and Forecasting \\
WT1 & Wind Tower 1 - McClellan Peak tower \\
WT2 & Wind Tower 2 - McClellan north saddle tower \\
YSU & YonSei University \\
& \\
\hline
\end{tabular}




\section{Executive Summary}

The main objectives of this project were to conduct a tall-tower and sodar field campaign in complex terrain, investigate wind properties relevant to wind energy assessment, and evaluate high-resolution models with fixed and adaptive grid structures. Two 60-m towers at Virginia Peak ridges near Washoe Valley, Nevada, were instrumented with cup and vane anemometers as well as sonic anemometers, and an acoustic sounder (hereafter sodar) was installed near one of the towers. The towers were located 2,700 m apart with a vertical distance of $140 \mathrm{~m}$ elevation between their bases. Each tower had a downhill exposure of rolling complex terrain, with the nearby valley floor 3,200 $\mathrm{m}$ to the west and $800 \mathrm{~m}$ below the summit. Cup anemometers were installed at both towers at 20, 40, and $60 \mathrm{~m}$, wind vanes at 20 and $60 \mathrm{~m}$, and sonic anemometers at 20 and $60 \mathrm{~m}$. The sodar measurements were nominally provided every $10 \mathrm{~m}$ in vertical distance from 40 to $200 \mathrm{~m}$ with the quality of the data generally decreasing with height. Surface air temperature, atmospheric pressure, and radiation measurements were conducted at $1.5 \mathrm{~m}$ AGL at both of the towers. Although the plan was to conduct a 1-year period of data collection, we extended the period (October 5, 2012 through February 24, 2014) to cover for possible data loss from instrument or communication problems.

We also present a preliminary analysis of the towers and sodar data, including a detailed inventory of available and missing data as well as outliers. The analysis additionally includes calculation of the Weibull parameters, turbulence intensity, and initial computation of wind power density at various heights.

Data from the campaign, including tower data and sodar, are on the Western Regional Climate Center website and are publicly available. The website links are as follows.

- http://www.wrcc.dri.edu/cgi-bin/rawMAIN.pl?nvncs1 McClellan Peak tower (Wind Tower 1, WT1)

- $\quad$ http://www.wrcc.dri.edu/cgi-bin/rawMAIN.pl?nvncs2 McClellan north saddle tower (Wind Tower 2, WT2)

- $\quad$ http://www.wrcc.dri.edu/cgi-bin/rawMAIN.pl?nvncs4 Sodar data from McClellan Peak.

In addition to allowing public access to the data, this website is interactive; i.e., a user can process the data online, produce statistics, and create and save plots.

Extensive numerical simulations of winds in the complex terrain of western Nevada were compared to the tower and sodar data. Two high-resolution regional/mesoscale models, the WRF and OMEGA models, were set up for the western Nevada area centered at the location of the towers and the sodar. The OMEGA simulations were unique in that they were performed with OMEGA, in which the grid resolution was adapted to the scale of the observed complex terrain geometry. This adaptive grid geometry represents a new and innovative design for numerical wind prediction models. Two clusters of simulations were performed: one cluster near Tonopah in southwestern Nevada and a second over northwestern Nevada. OMEGA performed better in southwestern Nevada than in northwestern Nevada. In southwestern Nevada the model performance was competitive with other structured grid numerical models. OMEGA performed much less accurately over northwestern Nevada. OMEGA performed better during the cold season over northwestern Nevada. During the warm season the performance over northwestern 
Nevada was much less accurate, with a substantial tendency to underpredict the wind velocity. This low velocity of the simulated winds represents the most significant model problem during the multi-month comparison with observations. The model accuracy of the simulation of wind direction was also somewhat disappointing, but not as poor as that of the wind velocity. Analyses of the simulated fields that did not verify accurately indicated a problem with the boundary layer in the numerical model in which the magnitude of the adjustments forced by diurnal heating and cooling was significantly underdone or misrepresented by the model. This ultimately caused problems with the wind velocity simulations, including the low velocity and weak response to diurnal forcing.

During the first part of the study, additional analysis and modeling using Mesoscale Model 5 and WRF were conducted using data from prior NREL-supported tower field programs in western Nevada. This part of the study investigated diurnal and seasonal wind properties in complex terrain and uncertainties and errors in simulations. The evaluated models will lead to improved estimates of the wind power density in Nevada and will provide guidance for wind facilities development.

It should be emphasized that the data collected during the current project for almost 17 months at two 60-m towers and 1 year of sodar data represent a great resource for wind power density assessment in complex terrain as well as for many subsequent data analyses, model evaluation, and model development studies. 


\section{Table of Contents}

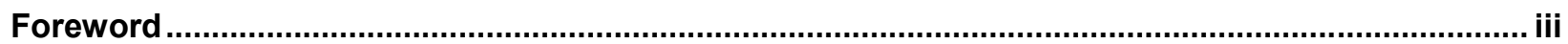

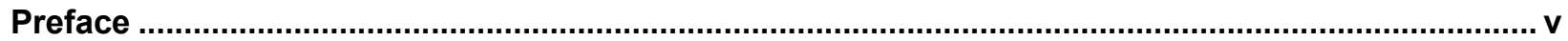

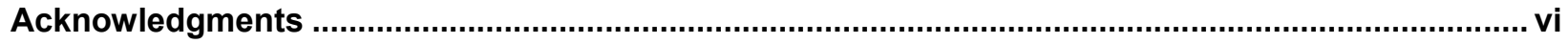

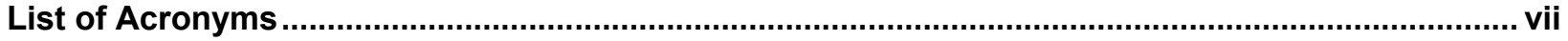

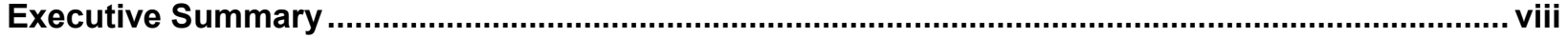

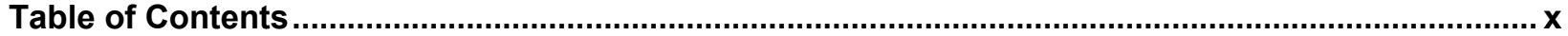

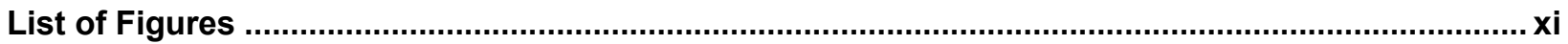

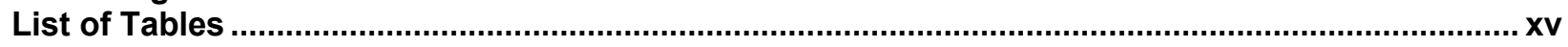

1 Report on Task 1: Planned Installation of the Tall Tower in Searchlight, Nevada ...................... 1

2 Report on Task 2: Installation of Measurement Equipment on 60-m Towers and Deployment of

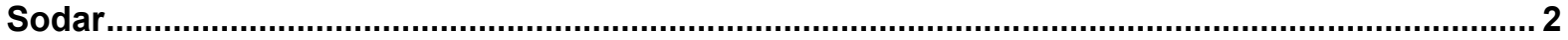

2.1 Topographical Setup of the Two 60 -m Towers and the Sodar.............................................. 3

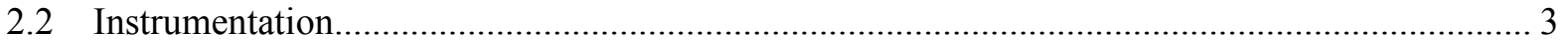

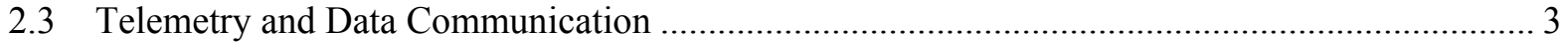

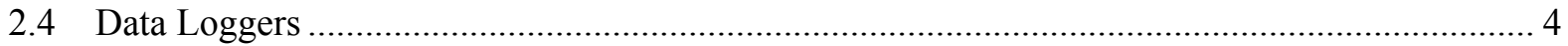

3 Report on Task 3: Operation and Maintenance of the 60-M Towers and Sodar .......................... 5

4 Report on Task 4: Data Acquisition, Web Presentation, and Analysis ........................................ 7

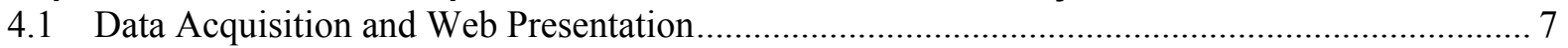

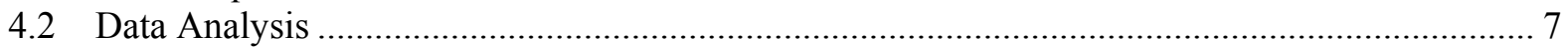

5 Report on Task 5: Evaluation of the OMEGA Numerical Model .............................................. 43

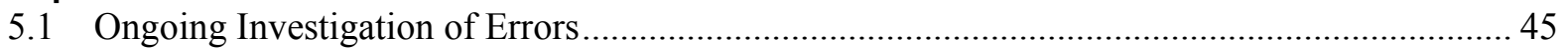

6 Report on Task 6: Evaluation of the Weather Research and Forecasting Numerical Model...... 50

6.1 Weather Research and Forecasting Deterministic Forecasting ........................................... 50

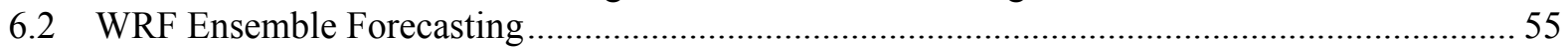

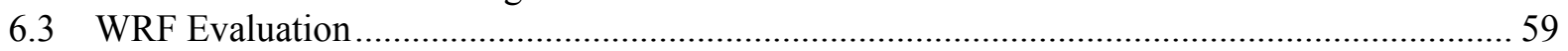

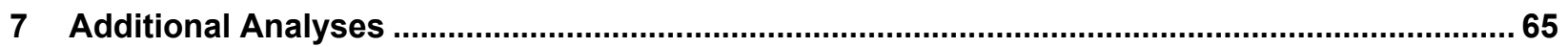

7.1 Subkilometer Dynamical Downscaling of Near-Surface Winds in Complex Terrain Using Weather Research and Forecasting and Mesoscale Model 5 ................................................... 65

7.2 Dynamical Downscaling of Wind Shear: Observational Analysis and Comparison of Mesoscale Model 5 and Weather Research and Forecasting Mesoscale Model Performance....................... 68

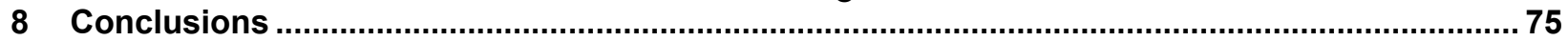

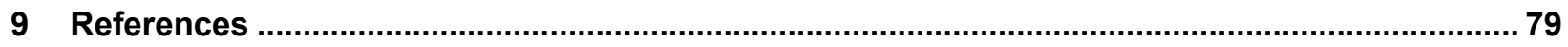

Appendix: List of Measured and Processed Parameters from Data Measured at WT1 and WT2 and

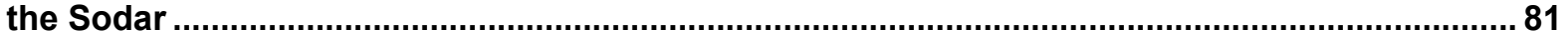




\section{List of Figures}

Figure 1. Topographical setup of wind towers in the Reno and Washoe Valley ridge areas. "2 NC WT1 CEC" and "3 NC WT2 CEC" are two towers that were operational and supported in this NREL project. Background map created using Google Earth software.....

Figure 2. Photographs of the southern tower WT1 (left); close-up of the 20-m instrumentation on tower WT2 (center), including sonic anemometer, wind vane oriented at $270 \mathrm{deg}$ and cup anemometers oriented at $000 \mathrm{deg}$ and $180 \mathrm{deg}$; and view of the Triton sodar from tower WT1. Photos courtesy of Greg McCurdy ....

Figure 3. Pictures of the NREL-owned Campbell CSAT-3 sonic anemometer on WT2, which was hit by lightning on June 10, 2013. This device was found on the ground near to the tower on July 24, 2013. We replaced the instrument on August 14, 2013. Photos courtesy of Greg McCurdy.

Figure 4. Data recovery rate as a function of height from the Triton Sodar for the entire period of deployment (October 31, 2012-November 1, 2013). Virtually all (>95\%) filtering of Triton sodar data is based on the QC factor output by the unit, and not vertical velocity or other any other factors. Recovery rates using filtering based on QC factor $>99 \%$ (red), $95 \%$ (blue), $90 \%$ (green - the manufacturer-recommended value), $85 \%$ (cyan), and 75\% (magenta) are shown.

Figure 5. Contours of: (left) - panels from the top down: wind direction, wind speed, turbulence intensity (TI), and vertical velocity; (right) - contours of QC parameter for wind speed (upper panel) and QC turbulence kinetic energy (TKE) parameter (lower panel) from the Triton sodar plotted versus height for one full week

Figure 6. Filtered wind velocity (top, QC $>90 \%$ ), unfiltered wind velocity (middle) $\left[\mathrm{m} \mathrm{s}^{-1}\right.$ ], and QC factor (bottom) as a function of height and date for the period October 31, 2012-March 14, 201316

Figure 7. Time series (October 5, 2012-February 24, 2014) of the wind speed and wind direction measured by the cup anemometers at $20 \mathrm{~m}$ (top), $40 \mathrm{~m}$ (middle), and $60 \mathrm{~m}$ (bottom panels) at WT1 18

Figure 8. Time series (October 8, 2012-February 24, 2014) of the wind speed and wind direction measured by the cup anemometers at $20 \mathrm{~m}$ (top), $40 \mathrm{~m}$ (middle), and $60 \mathrm{~m}$ (bottom panel) at WT2 20

Figure 9. Time series (October 5, 2012-February 24, 2014) of the raw wind speed data measured by the sonic anemometers at $20 \mathrm{~m}$ (top), and $60 \mathrm{~m}$ (bottom panel) at WT1

Figure 10. The same as Figure 9, but for the edited sonic wind speed time series .................................. 22

Figure 11. The same as Figure 9, but for WT2 tower (October 2, 2012-February 24, 2014) .................. 22

Figure 12. Same as Figure 11, but for the edited wind speed sonic data ................................................ 23

Figure 13. Sodar raw wind speed data at $40 \mathrm{~m}$ (red), $50 \mathrm{~m}$ (blue), and $60 \mathrm{~m}$ (green) Period: October 30,

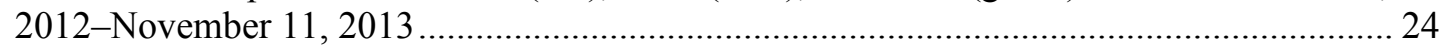

Figure 14. Same as Figure 13, but for sodar edited wind speed data, same levels and period .................. 24 Figure 15. Sodar raw wind speed data at $80 \mathrm{~m}$ (purple), $100 \mathrm{~m}$ (cyan), and $120 \mathrm{~m}$ (black) Period: October

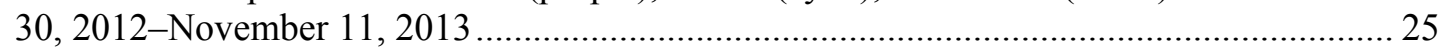

Figure 16. Same as Figure 15, but for sodar edited wind speed data, same levels and period .................. 25 Figure 17. Sodar raw wind direction data at $40 \mathrm{~m}$ (purple), $50 \mathrm{~m}$ (blue), and $60 \mathrm{~m}$ (green) Period: October

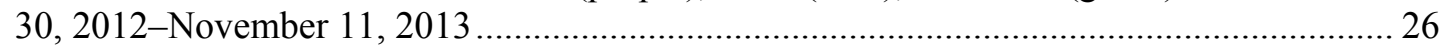

Figure 18. Same as Figure 17, but for sodar edited wind direction time series, same levels and period.... 26

Figure 19. Sodar raw wind direction data at $80 \mathrm{~m}$ (purple), $100 \mathrm{~m}$ (cyan), and $120 \mathrm{~m}$ (black) Period:

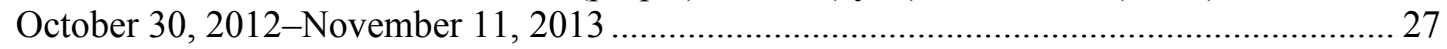

Figure 20. Same as Figure 19, but for sodar edited wind direction, same levels and period.................... 27

Figure 21. Percentage of data availability (d.a.: 100\% means no data were excluded) from the Triton sodar (using the manufacturer-recommended QC minimum of $90 \%$ ) for the full duration of 
the deployment (October 31, 2012-November 1, 2013) binned as a function of time of day (top), and mean wind speed $\left(\mathrm{m} \mathrm{s}^{-1}\right)$ from the co-located sonic anemometer at $60 \mathrm{~m}$ (bottom) 28

Figure 22. Scatter plots of cup (x-axis) versus sodar (y-axis) wind speed at $60 \mathrm{~m}$ (October 6, 2012-

November 1, 2013) at $60 \mathrm{~m}$ on tower WT1 for all sodar observations $(\mathrm{QC}=0$; slope $=0.82$;

$\mathrm{R} 2=0.63$; number of observations $=42,540)$ (left panel) and with $\mathrm{QC}>95 \%$ (slope $=0.93$;

$\mathrm{R} 2=0.91$; number of observations $=18,032$ ) (right panel)

Figure 23. Mean wind speed versus time of day from the 60-m cup anemometers at WT1 (red) and WT2

(blue) for the period November 1, 2012-June 1, 2013. Values are presented in such a way

that the mean wind speed during any given hour is plotted at the center of that hour........... 30

Figure 24. Scatter plot of wind speeds (October 6, 2012-March 14, 2013) at $60 \mathrm{~m}$ at WT1 for the sonic anemometer versus the cup anemometer (left), and filtered (QC minimum of 90\%) sodar velocity versus cup anemometer (middle) and versus sonic anemometer (right). The black line denotes a 1:1 correlation, and the best fit is denoted by the red line

Figure 25. TI (\%) at WT1 (top) and WT2 (bottom panel) at 20 (left), 40 (middle), and $60 \mathrm{~m}$ (right column). Period for WT1: October 5, 2012-February 24, 2014 and for WT2: October 30, 2012-November 11, 2013.

Figure 26. Autocorrelation functions for 10-min wind speed at all levels $(20,40$, and $60 \mathrm{~m})$ for WT1; the 2012-2014 composite dataset.

Figure 27. Same as Figure 26, but for WT2.

Figure 28. Autocorrelation functions for 10-min wind direction at 20 and $60 \mathrm{~m}$ levels for WT1; the 20122014 composite dataset.

Figure 29. Autocorrelation functions for 10-min wind direction at 20 and $60 \mathrm{~m}$ levels for WT2; the 20122014 composite dataset.

Figure 30. Same as Figure 26, but for sodar wind speed time series

Figure 31. OMEGA grid for simulations for December 2012 and June 2013

Figure 32. Wind direction (degrees) and wind speed $\left(\mathrm{m} \mathrm{s}^{-1}\right)$ at $60 \mathrm{~m}$ from WT1 observations (cup anemometer), WRF $2 \mathrm{~km}$ resolution simulations, and OMEGA $2 \mathrm{~km}$ resolution simulations over the period from December 10, 2012-December 17, 2012.

Figure 33. Wind direction (degrees) and wind speed $\left(\mathrm{m} \mathrm{s}^{-1}\right)$ at $60 \mathrm{~m}$ from WT1 observations (cup), WRF 2 $\mathrm{km}$ resolution simulations, and OMEGA $667 \mathrm{~m}$ resolution simulations over the period from December 10, 2012-December 17, 2012.

Figure 34. Wind direction (degrees) and wind speed $\left(\mathrm{m} \mathrm{s}^{-1}\right)$ at $60 \mathrm{~m}$ from WT1 observations (cup), WRF 2 $\mathrm{km}$ resolution simulations, and OMEGA $2 \mathrm{~km}$ resolution simulations over the period from June 10, 2013-June 17, 2013.

Figure 35. Wind direction (degrees) and wind speed $\left(\mathrm{m} \mathrm{s}^{-1}\right)$ at $60 \mathrm{~m}$ from WT1 observations (cup), WRF 2 $\mathrm{km}$ resolution simulations, and OMEGA $667 \mathrm{~m}$ resolution simulations over the period from June 10, 2013-June 16, 2013.

Figure 36. Full (left) and zoomed in (right) view of the WRF multiple-domain setup ...........................5 51

Figure 37. Topography [m] of the innermost WRF domain (left) and close-up of the Virginia Hills, Nevada. Also shown are the locations of nearby surface stations, and the $60-\mathrm{m}$ towers and the sodar.

Figure 38. Google view of the Virginia Hills looking north (left) and looking east (right), approximately toward the dominant wind direction. Also shown are the locations of the $60-\mathrm{m}$ towers and the sodar.

Figure 39. View of the WRF domains \#3 (left, $\Delta_{\mathrm{h}}=12 \mathrm{~km}$ ), and \#4 (right, $\Delta_{\mathrm{h}}=4 \mathrm{~km}$ ). Topography (m) is color contoured; and solid lines indicate the positions of the inner domains.

Figure 40. Close-up (partial) view of the Virginia Hills site in the WRF domains \#5 (left, $\Delta_{\mathrm{h}}=1.33 \mathrm{~km}$ ) and $\# 6$ (right, $\Delta_{\mathrm{h}}=444 \mathrm{~m}$ ). Topography $[\mathrm{m}]$ is color contoured. Also shown are the locations of nearby surface stations (white dots), the 60-m towers, the sodar (red dots), and the closest grid points in the WRF domains \#5 and \#6 for comparison (black circle and black dashed lines)...... 
Figure 41. Wind direction at $60 \mathrm{~m}$ (top), wind speed at $60 \mathrm{~m}$ (middle), and the near-surface temperature (bottom) from February 9, 2012 16:00 to February 11, 2012 16:00 (LST) from the WRF forecast (blue - 48-hour forecast, initialized with FNL at February 9, 2012 16:00), the sodar (red), cup, vane and temperature sensors (green) and sonic anemometer (cyan). WRF output is at hourly intervals, all other measurements are presented as 10-minute averages. .............54

Figure 42. Wind direction at $60 \mathrm{~m}$ (top), wind speed at $60 \mathrm{~m}$ (middle), and the near-surface temperature (bottom) for February 6, 2013-February 13, 2013 from the final 24 hours of the daily initialized (FNL) 48-hour WRF forecasts (blue), sodar (red), cup, vane and temperature sensors (green), and the sonic anemometer (cyan). WRF output is at hourly intervals, and all other measurements are presented as 10-minute averages.

Figure 43. Topography contours [m] of the Virginia Hills in the finest domain (\#6) of the high resolution $\left(\Delta_{\mathrm{h}}=100 \mathrm{~m}\right) \mathrm{WRF}$ runs using the standard $30 \mathrm{~s}$ topography (left) and $1 \mathrm{~s}$ topography (right). Solid lines indicate axes generally parallel and perpendicular to the ridge line. .57

Figure 44. Ten-m velocity quivers on February 5, 2013 at 19:30 LST and topography [m] from the WRF

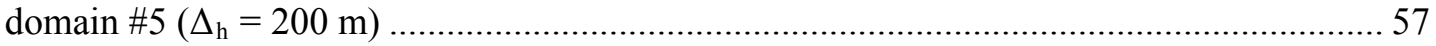

Figure 45. Cross-section velocity contours on February 5, 2013 at 19:30 LST. The near-longitudinal cross section is shown in Figure 37 (left to right).................................................................... 58

Figure 46. WRF forecast for all domains, data from the collocated sodar, and WT1 data for February 5, 2013 at 16:00 UTC to February 6, 2013 at 22:00 UTC. Plotted are the wind direction (top), wind speed (middle), and the surface temperature (bottom) from WT1 and the co-located sodar.

Figure 47. WT2 wind speed from the cup (blue) and sonic anemometers (red) at $60 \mathrm{~m}$ versus date for the WRF member 3 (MO Janjić Eta PBL option). Also plotted is the WRF 24-48 hour forecast wind speed (green) for the domain \#1 (top, $\Delta \mathrm{h}=18 \mathrm{~km}$ ), domain \#2 (middle, $\Delta \mathrm{h}=6 \mathrm{~km}$ ),

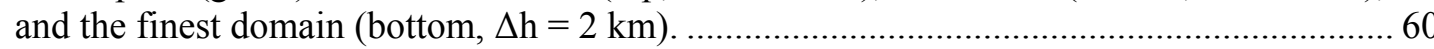

Figure 48. The WRF model RMSE (top) and bias (bottom) on WT1 at $60 \mathrm{~m}$ for all four members (\#1 red, \#2 blue, \#3 cyan, \#4 magenta) as a function of horizontal grid spacing of the domains for the

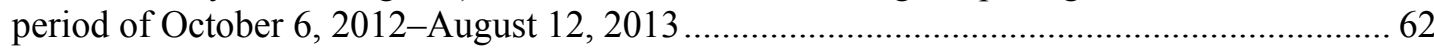

Figure 49. The WRF model RMSE (top) and bias (bottom) on WT2 at $60 \mathrm{~m}$ for all four members (\#1 red, \#2 blue, \#3 cyan, \#4 magenta) as a function of horizontal grid spacing of the domains for the period of October 6, 2012-August 12, 2013. A Y-axis range has been chosen to be consistent with the previous figure.

Figure 50. The WT1 (top) and tower WT2 (bottom) correlation coefficients between 60-m cup anemometer data and the WRF forecast as a function of grid spacing of the domains for all members (\#1 red, \#2 blue, \#3 cyan, \#4 magenta) for the period October 6, 2012-August 12, 2013.

Figure 51. Scatter plot with a linear correlation of the 60-m wind speed at tower WT1 (X-axis) and WRF forecast ( $\mathrm{Y}$-axis) used to calculate the correlation coefficient for member \#1, domain \#3 (2 $\mathrm{km}$ resolution) for the period of October 6, 2012-August 12, 2013

Figure 52. PSD of the $60-\mathrm{m}$ wind speed from the WT1 cup anemometer data (black) and WRF domains 1 (red $18 \mathrm{~km}$ ), 2 (blue $6 \mathrm{~km}$ ) and 3 (green $2 \mathrm{~km}$ resolution) at $60 \mathrm{~m}$ for the period of October 6 , 2012-August 12, 2013 for the WRF member $3(\mathrm{~m}=3)$ (MO Janjić Eta PBL option). Vertical black lines indicate periods of 1 week, 1 day, and aliased integer multiples of 1 day; and the vertical cyan lines indicate periods of 1 day \pm 2 hours.

Figure 53. DI variability of the RMSE (top) and bias (bottom) at $60 \mathrm{~m}$ on tower WT1 for member \#1 for all three domains (grid spacings of $18 \mathrm{~km}$ (red), $6 \mathrm{~km}$ (blue), and $2 \mathrm{~km}$ (green) resolution) for the period of October 6, 2012-August 12, 2013

Figure 54. Mean wind speed in (a) July and (b) December 2007 for all model domains for the MM5 and WRF models. On the X-axis in a) and b), "Obs" denotes observed values. .66 
Figure 55. Histograms of observed and modeled wind speed at $10 \mathrm{~m}$ AGL during daytime for (a) MM5 and (b) WRF in July 2007. D1 denotes domain \#1, D2 domain \#2, D3 domain \#3, D4 domain \#4, and D5 domain \#5.

Figure 56. Variability of the ratio (\%) of the modeled and observed integrated spectral kinetic energy (horizontally averaged over all measurements stations) for all computational domains for MM5 and WRF in (a) total range of frequencies (total, 2 hours $<\mathrm{t}<7$ days), (b) longer-thandiurnal range (LTD, 26 hours $<\mathrm{t}<7$ days), (c) DI (22 hours $<\mathrm{t}<26$ hours), and (d) SD (2 hours $<\mathrm{t}<22$ hours) at $10 \mathrm{~m}$ and $50 \mathrm{~m}$ AGL for July 2007. A perfect match (100\%) is plotted as a short-dashed line.

Figure 57. Time series of the measured mean wind shear for July 2007 during the daytime (top) and nighttime (bottom) at Tonopah, Kingston, Luning5N, and Luning7W towers for $20 \mathrm{~m}$ vertical separation between levels....

Figure 58. Time series of the measured wind shear during daytime (top) and nighttime (bottom) for July 2007 at the Tonopah $24-\mathrm{W}$ tower.....

Figure 59. Histograms of the measured wind shear (top row) and the directional wind shear (bottom row) between $50 \mathrm{~m}$ and $10 \mathrm{~m}$ measurement levels during daytime (left column) and nighttime (right column) for July 2007 at the Luning $5 \mathrm{~N}$ tower...

Figure 60. Measured, WRF-simulated (top), and MM5-simulated (bottom) time series of the wind shear during daytime (left column) and nighttime (right column) during July 2007 for the Tonopah tower. The models' results include five domains with different grid spacing ranging from 27 $\mathrm{km}$ to $333 \mathrm{~m}$.

Figure 61. Histograms of the measured and simulated wind shear for WRF and all five model domains for July 2007 during daytime (top) and nighttime (bottom) for the Tonopah tower 


\section{List of Tables}

Table 1. Location of the Two Wind Towers and Sodar in the Virginia Hills, Nevada*........................... 2

Table 2. Number of Missing Data and Outliers for Tower WT1, October 8, 2012-December 31, 2012 2... 8

Table 3. Number of Missing Data and Outliers for Tower WT1, 2013 …........................................... 8

Table 4. Number of Missing Data and Outliers for Tower WT1, January 1, 2014-February 24, 2014 ...... 9

Table 5. Number of Missing Data and Outliers for Tower WT2, October 22, 2012-December 31, $2012 \ldots 9$

Table 6. Number of Missing Data and Outliers for Tower WT2, 2013 ............................................ 10

Table 7. Number of Missing Data and Outliers for Tower WT2, January 1, 2014-February 24, 2014 .... 10

Table 8. Number of Missing Data and Outliers for Sodar, October 30, 2012-December 31, $2012 \ldots \ldots \ldots . . .11$

Table 9. Number of Missing Data and Outliers for Sodar, January 1, 2013-November 11, 2013 ............ 12

Table 10. Correlation Coefficient and Slope of Best-Fit Line Between Sodar and Cup Anemometer (October 6, 2012-November 1, 2013) at WT1 at $60 \mathrm{~m}$ Height for Various Filtering of Sodar

Data Based on the Minimum QC Factor*

Table 11. Coefficients $k$ and $c$ of the Weibull Distributions on Annual and Seasonal Scales From the Entire WT1 Cup Anemometer Datasets at All Levels (October 5, 2012-February 24, 2014).

Available Wind Power Density Was Calculated by Using the Weibull Parameters

Table 12. Coefficients $k$ and $c$ of the Weibull Distributions on Annual and Seasonal Scales From the Entire WT2 Cup Anemometer Datasets at All Levels (October 22, 2012-February 24, 2014)

Table 13. Coefficients $k$ and $c$ of the Weibull Distributions on Annual and Seasonal Scales From the Entire Sodar Dataset At All Levels (October 30, 2012-November 11, 2013)...................... 37

Table 14. Statistical Analysis of OMEGA Simulations at Grid Points Nearest to WT1 for December 2012

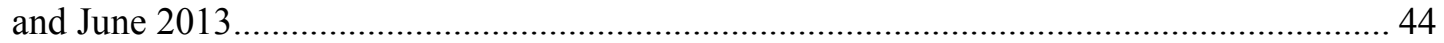

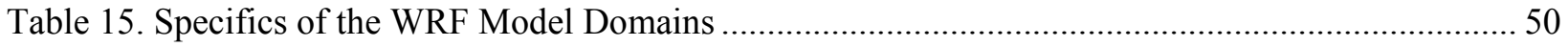

Table 16. Characteristics of the Ensemble Members* ........................................................................... 56

Table 17. Statistics of the a) MM5 and b) WRF Simulated Wind Shear for the Tonopah Tower During

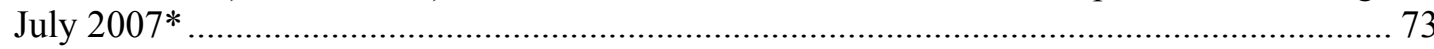




\section{Report on Task 1: Planned Installation of the Tall Tower in Searchlight, Nevada}

An original Desert Research Institute (DRI) proposal, which focused on installing a 120-m tower in Searchlight, Nevada, was accepted by the U.S. Department of Energy's (DOE) National

Renewable Energy Laboratory (NREL). The main purposes of the project were to investigate the wind regime at hub-height elevations, assess wind energy at multiple heights, and evaluate highresolution models in predicting wind, wind shear, and turbulence in complex terrain. During the permitting phase of the project, our business partner (Oak Creek Energy) decided to terminate our collaboration. In addition, as we had not received a final permit from the Bureau of Land Management (BLM), we revised the original scope of work following communication with NREL and discussed options with NREL. Based on NREL's suggestions, we wrote a revised statement of work, which was subsequently accepted for funding by NREL under the contract NAX-9-66014-02 (DE-AC36-08G028308). The main objectives were to conduct a tall-tower and sodar field campaign in complex terrain, investigate wind properties relevant to wind energy assessment, and evaluate high-resolution models with fixed and adaptive grid structures. Details are shown in the subsequent sections. 


\section{Report on Task 2: Installation of Measurement Equipment on 60-m Towers and Deployment of Sodar}

Two 60-m towers were instrumented in the Virginia Hills near Washoe Valley (Figure 1). Wind Tower 1 (WT1) was operational from October 6, 2012 to February 24, 2014, and Wind Tower 2 (WT2) was operational from October 22, 2012 to February 24, 2014. A Triton sodar was installed near tower WT1, and was operational from October 31, 2012 through November 4, 2013. See Table 1 and Figure 1 for details.

Table 1. Location of the Two Wind Towers and Sodar in the Virginia Hills, Nevada*

\begin{tabular}{ccccc}
\hline Application & $\begin{array}{c}\text { Latitude } \\
(\mathbf{N})\end{array}$ & $\begin{array}{c}\text { Longitude } \\
(\mathbf{E})\end{array}$ & $\begin{array}{c}\text { Elevation } \\
(\mathbf{m})\end{array}$ & Data Record \\
\hline Tower 1 & 39.26280 & -119.71694 & 2223 & $10 / 06 / 2012-02 / 24 / 2014$ \\
\hline Tower 2 & 39.28360 & -119.69970 & 2045 & $10 / 22 / 2012-02 / 24 / 2014$ \\
\hline Sodar & 39.26392 & -119.71709 & 2226 & $10 / 31 / 2012-11 / 04 / 2013$ \\
\hline
\end{tabular}

* Periods of data acquisition are also indicated.

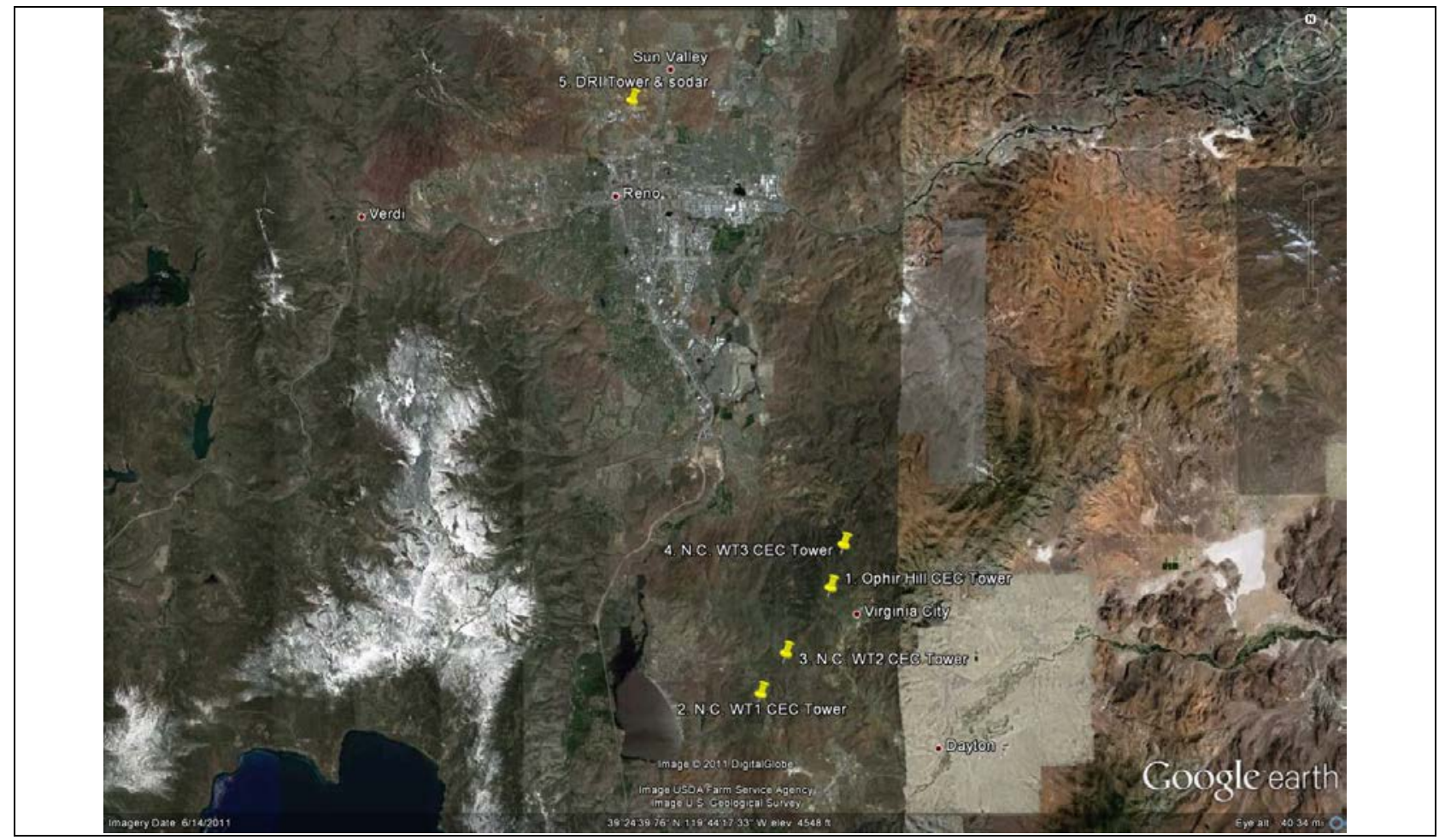

Figure 1. Topographical setup of wind towers in the Reno and Washoe Valley ridge areas. "2 NC WT1 CEC" and "3 NC WT2 CEC" are two towers that were operational and supported in this NREL project. Background map created using Google Earth software

Note: These towers were installed and operated initially by Clean Energy Center and later by Alton Energy. As information for possible future use and analysis, additional towers not related to this project were located in the area: one near the DRI campus in Reno "5 DRI \& sodar," and 
two additional towers "1 Ophir Hill CEC" and "4 NC WT3 CEC" originally owned and operated by CEC and later by Alton Energy.

\subsection{Topographical Setup of the Two 60-m Towers and the Sodar}

The WT1 and WT2 towers were owned formerly by Clean Energy Center. During this NREL project their ownership and operation were transferred to Alton Energy. Based on this NREL project, we received approval from Alton Energy to instrument the towers with standard and sonic instrumentation and deploy the sodar near WT1. The main objectives were to conduct a tall-tower and sodar field campaign in complex terrain, investigate wind properties relevant to the wind energy assessment, and evaluate high-resolution models with fixed and adaptive grid structures. The towers were located 2,700 m apart with a vertical distance of $140 \mathrm{~m}$ elevation between their bases. Each tower had a downhill exposure of rolling complex terrain, with the nearby valley floor $3,200 \mathrm{~m}$ to the west and $800 \mathrm{~m}$ below the summit.

\subsection{Instrumentation}

Instrumentation on both towers consisted of the following: two cup anemometers at $20 \mathrm{~m}, 40 \mathrm{~m}$, and $60 \mathrm{~m}$, sonic anemometers at $20 \mathrm{~m}$ and $60 \mathrm{~m}$, and wind vanes at $20 \mathrm{~m}$ and $60 \mathrm{~m}$. The sodar was measuring at 10 levels between $40 \mathrm{~m}$ and $200 \mathrm{~m}$. A list of all directly measured and processed parameters that are available on the websites listed above is given in the Appendix. Photos of the towers and sodar setup are shown in Figure 2.

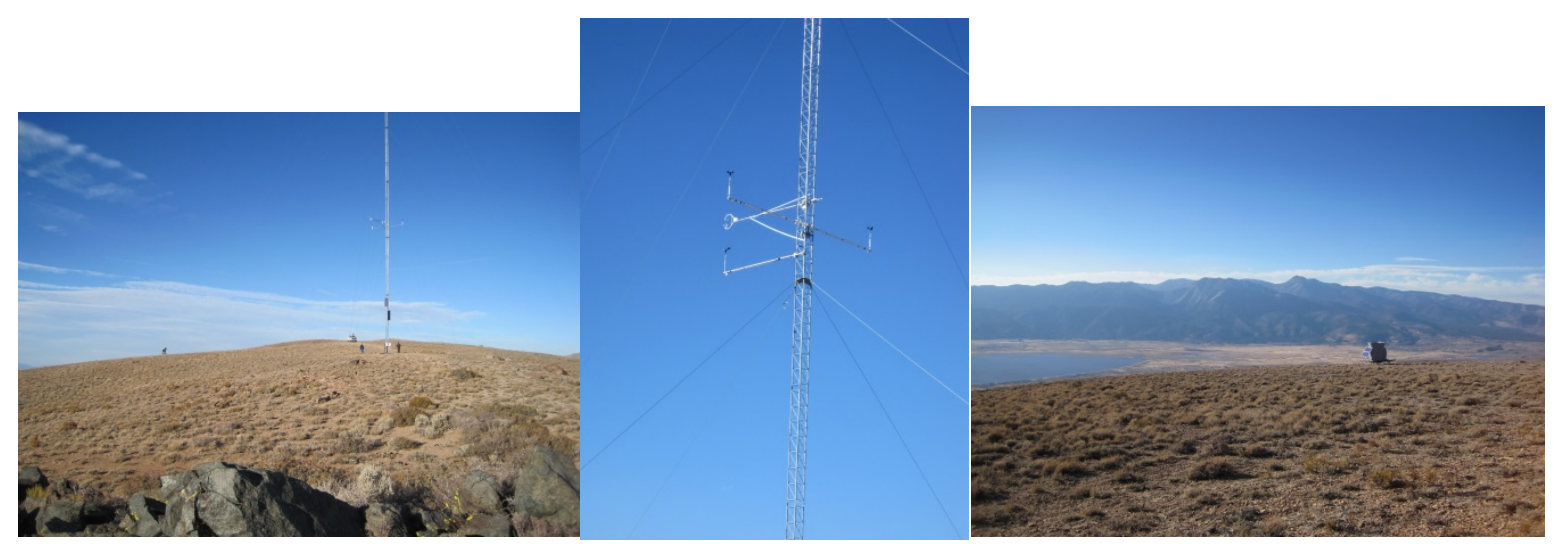

Figure 2. Photographs of the southern tower WT1 (left); close-up of the 20-m instrumentation on tower WT2 (center), including sonic anemometer, wind vane oriented at 270 deg and cup anemometers oriented at $000 \mathrm{deg}$ and $\mathbf{1 8 0} \mathrm{deg}$; and view of the Triton sodar from tower WT1. Photos courtesy of Greg McCurdy

\subsection{Telemetry and Data Communication}

During November 2012, high-speed data communication equipment was installed on both wind towers and the DRI facility in Reno. Data telemetry distances were about 20 miles for both towers. The data telemetry connection was used to telemeter the 20-hertz data from all four sonic sensors and the 10-minute averaged data every 10 minutes. The data system used microtik router/radios to establish the high-speed communications with parabolic dishes. The angular separation between the two towers from the DRI facility was small enough that a single parabolic receiver was able to handle the connection to both towers. Approximately $400 \mathrm{MB}$ of data were transferred each day. 


\subsection{Data Loggers}

The data loggers were augmented with additional memory storage. Two-gigabyte data cards were installed on the four data loggers that collect data from the 3-D sonic sensors. This increased the buffer amount that the data loggers can hold in case a communications problem develops. 


\section{Report on Task 3: Operation and Maintenance of the 60-M Towers and Sodar}

Some problems were encountered with communications once winter weather moved in, but with additional fine tuning, data throughput was maintained at optimum levels. Total number of data, number of missing data, as well as number of outliers for all instruments on both met towers are shown in Tables 2 and 3 in Section 4. The sonic anemometer at $20 \mathrm{~m}$ on WT1 broke shortly after installation on October 17, 2012, and was fixed on March 6, 2013. After ensuring that the problem with the sonic was not in the communication wiring, we found a spare sonic (borrowed from another project) to replace this malfunctioning sonic. The request for replacement was sent to a person from Alton Energy who is licensed to climb the tower. On April 4, 2013, two climbers from Swans Turbine Services inspected the sonic sensors at $20 \mathrm{~m}$ and $60 \mathrm{~m}$ on WT1. Nothing visually appeared to be wrong with either sensor, but they replaced the sonic sensor at $20 \mathrm{~m}$ while on site. The cause of malfunction of the 20 -m sonic anemometer on WT1 is not clear as post-replacement inspection revealed nothing wrong.

From installation (October 6, 2012) until February 8, 2013, all the wind vanes on WT1 were pegged for wind direction between $000^{\circ}$ and $090^{\circ}$. It was not possible to salvage these data based on any selective filtering. The cause of the problem appeared to be some faulty wiring at the base of the tower, which was fixed by a DRI technician on February 8, 2013. Snow accumulation at the remote site limited access before that date. After that all data from these wind vanes were recovered at a rate $>95 \%$, and data from all other cup and vane sensors on both towers were recovered at high rates. Inspection of the tower also found a broken guy wire, which was repaired by the tower maintenance team a few days later.

WT2, located in a gap in the Virginia Hills range just north of WT1, went operational on October 8,2012 , but the first data available are from October 22, 2012. This tower was hit by lightning on June 10, 2013, 15:10 Local Standard Time (LST). The lightning strike burned the 60-m sonic anemometer and the data logger for all instrumentation (Figure 3). All instrumentation besides the $60-\mathrm{m}$ sonic anemometer was fully functional and was not harmed by the lightning strike, but data from all instruments were lost from June 10, 2013 until the data logger was replaced on July 24,2013 . It is believed that the power supply for the $20-\mathrm{m}$ sonic also was damaged during the lightning strike. This power supply and the 60-m sonic anemometer were replaced successfully on August 14, 2013. 


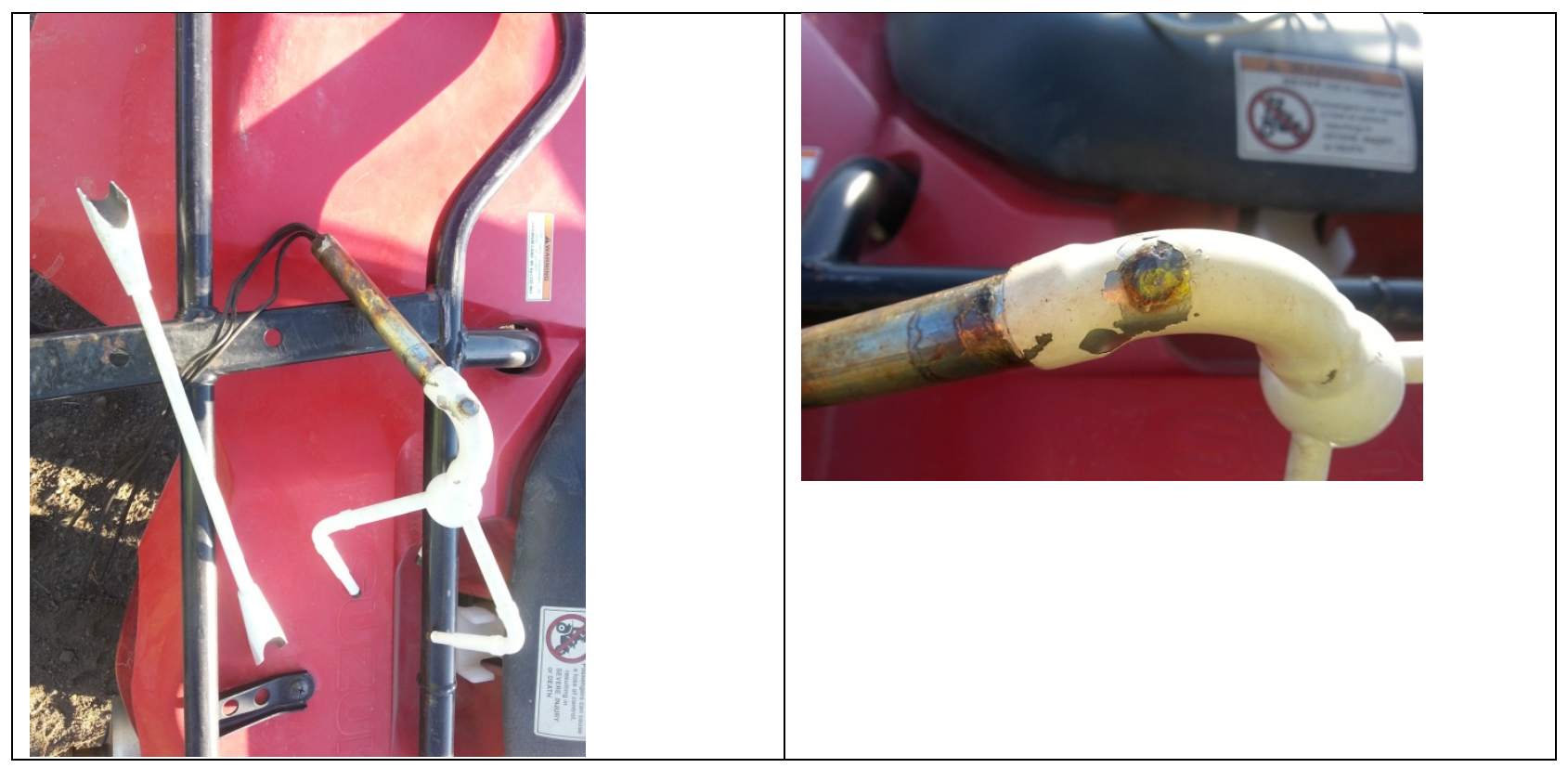

Figure 3. Pictures of the NREL-owned Campbell CSAT-3 sonic anemometer on WT2, which was hit by lightning on June 10, 2013. This device was found on the ground near to the tower on July 24, 2013. We replaced the instrument on August 14, 2013. Photos courtesy of Greg McCurdy 


\section{Report on Task 4: Data Acquisition, Web Presentation, and Analysis}

\subsection{Data Acquisition and Web Presentation}

Data from the campaign, including tower data and sodar, are on the Western Regional Climate Center (WRCC) website and publicly available. The websites are as follows.

- $\quad$ http://www.wrcc.dri.edu/cgi-bin/rawMAIN.pl?nvncs1 McClellan Peak tower (tower WT1)

- http://www.wrcc.dri.edu/cgi-bin/rawMAIN.pl?nvncs2 McClellan north saddle tower (tower WT2)

- $\quad$ http://www.wrcc.dri.edu/cgi-bin/rawMAIN.pl?nvncs4 Sodar data from McClellan Peak

Besides accessing the data, this website is interactive (i.e., a user can process the data online, produce statistics, and create plots).

\subsection{Data Analysis}

Detailed lists of missing data for all instruments at both towers as well as missing data for each measuring gate for the sodar are shown below in Sections 4.2.1 and 4.2.2. Section 4.2.3 discusses some of the data issues and shows some of the data examples. Table 2 through Table 9 show detailed analyses of the missing data and outliers for the towers and the sodar. The criteria for outliers are based on algorithms by Rothamsted et al. (1994), Cowen (1998), Hawkins (1980), and Ott and Longnecker (2008).

Quality control (QC) of all data was performed to reject outliers and to interpolate over any small data gaps. Overall, the corrected data are of sufficient quality, with $<1 \%$ of the data removed as outliers or considered unacceptable. A third-order polynomial fit was used to interpolate missing and rejected data. A 72-point (6 hours of measurements) sliding interval, centered on each data point, was used to detect the outliers. If the wind speed of a point was higher than four standard deviations of the 72-point interval, the data point was discarded and replaced with the interpolated values. For the whole population, most of the data $(>99 \%)$ are in a three-standard deviation interval. This suggests that each measurement in the 72-point interval outside of fourstandard deviation is questionable and can be discarded as outlier. This assumption is based on the references and guidelines found in the literature on data analysis and processing (see above). 


\subsubsection{Analysis of Missing Data and Outliers-Towers' Measurements (2012-2014)}

Table 2. Number of Missing Data and Outliers for Tower WT1, October 8, 2012-December 31, 2012

\begin{tabular}{c|lccc}
\hline \multicolumn{1}{c}{$\begin{array}{c}\text { Measurement } \\
\text { Level }\end{array}$} & \multicolumn{1}{c}{ Parameter } & $\begin{array}{c}\text { Total \# } \\
\text { Observations }\end{array}$ & $\begin{array}{c}\text { Missing } \\
\text { Data }\end{array}$ & $\begin{array}{c}\text { Outliers/ } \\
\text { Rejected Data }\end{array}$ \\
\hline \multirow{4}{*}{ 60-m Cup Anemometer I } & Wind Speed & 12,457 & 0 & 4 \\
\cline { 2 - 5 } & Wind Direction & 12,457 & 0 & 139 \\
\cline { 2 - 5 } & Standard Deviation & 12,457 & 0 & 67 \\
\cline { 2 - 5 } & Maximum Wind Gust & 12,457 & 0 & 14 \\
\hline \multirow{4}{*}{$60-m$ Cup Anemometer II } & Wind Speed & 12,457 & 0 & 4 \\
\cline { 2 - 5 } & Standard Deviation & 12,457 & 0 & 66 \\
\cline { 2 - 5 } & Maximum Wind Gust & 12,457 & 0 & 13 \\
\hline \multirow{3}{*}{ Surface Level } & Ux Sonic Anemometer & 12,457 & 149 & 159 \\
\cline { 2 - 5 } & Uy & 12,457 & 149 & 160 \\
\cline { 2 - 5 } & Uz & 12,457 & 149 & 160 \\
\hline & Air Temperature & 12,457 & 0 & 0 \\
\cline { 2 - 5 } & Atmospheric Pressure & 12,457 & 0 & 0 \\
\hline
\end{tabular}

Table 3. Number of Missing Data and Outliers for Tower WT1, 2013

\begin{tabular}{c|lccc}
\hline \multicolumn{1}{c}{$\begin{array}{c}\text { Measurement } \\
\text { Level }\end{array}$} & \multicolumn{1}{c}{ Parameter } & $\begin{array}{c}\text { Total \# } \\
\text { Observations }\end{array}$ & $\begin{array}{c}\text { Missing } \\
\text { Data }\end{array}$ & $\begin{array}{c}\text { Outliers/ } \\
\text { Rejected Data }\end{array}$ \\
\hline \multirow{4}{*}{ 60-m Cup Anemometer I } & Wind Speed & 49,982 & 0 & 44 \\
\cline { 2 - 5 } & Wind Direction & 49,982 & 0 & 410 \\
\cline { 2 - 5 } & Standard Deviation & 49,982 & 0 & 275 \\
\cline { 2 - 5 } & Maximum Wind Gust & 49,982 & 0 & 62 \\
\hline \multirow{4}{*}{ 60-m Cup Anemometer II } & Wind Speed & 49,982 & 0 & 46 \\
\cline { 2 - 5 } & Standard Deviation & 49,982 & 0 & 294 \\
\cline { 2 - 5 } & Maximum Wind Gust & 49,982 & 0 & 62 \\
\hline \multirow{3}{*}{ Surface Level } & Ux & 49,982 & 933 & 976 \\
\cline { 2 - 5 } & Uy & 49,982 & 933 & 1,048 \\
\cline { 2 - 5 } & Uz & 49,982 & 933 & 1,431 \\
\hline & Air Temperature & 49,982 & 0 & 0 \\
\cline { 2 - 5 } & Atmospheric Pressure & 49,982 & 0 & 0 \\
\hline
\end{tabular}


Table 4. Number of Missing Data and Outliers for Tower WT1, January 1, 2014-February 24, 2014

\begin{tabular}{c|lccc}
\hline \multicolumn{1}{c}{$\begin{array}{c}\text { Measurement } \\
\text { Level }\end{array}$} & \multicolumn{1}{c}{ Parameter } & $\begin{array}{c}\text { Total \# } \\
\text { Observations }\end{array}$ & $\begin{array}{c}\text { Missing } \\
\text { Data }\end{array}$ & $\begin{array}{c}\text { Outliers/Rejected } \\
\text { Data }\end{array}$ \\
\hline \multirow{4}{*}{$60-$ m Cup Anemometer I } & Wind Speed & 49,982 & 0 & 44 \\
\cline { 2 - 5 } & Wind Direction & 49,982 & 0 & 410 \\
\cline { 2 - 5 } & Standard Deviation & 49,982 & 0 & 275 \\
\cline { 2 - 5 } & Maximum Wind Gust & 49,982 & 0 & 62 \\
\hline \multirow{4}{*}{60 m - Cup Anemometer II } & Wind Speed & 49,982 & 0 & 46 \\
\cline { 2 - 5 } & Standard Deviation & 49,982 & 0 & 294 \\
\cline { 2 - 5 } & Maximum Wind Gust & 49,982 & 0 & 62 \\
\hline \multirow{3}{*}{ Surface Level } & Ux Sonic Anemometer & 49,982 & 933 & 976 \\
\cline { 2 - 5 } & Uy & 49,982 & 933 & 1,048 \\
\cline { 2 - 5 } & Uz & 49,982 & 933 & 1,431 \\
\hline & Air Temperature & 49,982 & 0 & 0 \\
\cline { 2 - 5 } & Atmospheric Pressure & 49,982 & 0 & 0 \\
\hline
\end{tabular}

Table 5. Number of Missing Data and Outliers for Tower WT2, October 22, 2012-December 31, 2012

\begin{tabular}{c|lccc}
\hline \multicolumn{1}{c}{$\begin{array}{c}\text { Measurement } \\
\text { Level }\end{array}$} & \multicolumn{1}{c}{ Parameter } & $\begin{array}{c}\text { Total \# } \\
\text { Observations }\end{array}$ & $\begin{array}{c}\text { Missing } \\
\text { Data }\end{array}$ & $\begin{array}{c}\text { Outliers/ } \\
\text { Rejected Data }\end{array}$ \\
\hline \multirow{4}{*}{ 60-m Cup Anemometer I } & Wind Speed & 10,154 & 0 & 0 \\
\cline { 2 - 5 } & Wind Direction & 10,154 & 0 & 84 \\
\cline { 2 - 5 } & Standard Deviation & 10,154 & 0 & 67 \\
\cline { 2 - 5 } & Maximum Wind Gust & 10,154 & 0 & 9 \\
\hline \multirow{4}{*}{ 60-m Cup Anemometer II } & Wind Speed & 10,154 & 0 & 0 \\
\cline { 2 - 5 } & Standard Deviation & 10,154 & 0 & 64 \\
\cline { 2 - 5 } & Maximum Wind Gust & 10,154 & 0 & 11 \\
\hline \multirow{3}{*}{ Surface Level } & Ux & 10,154 & 96 & 111 \\
\cline { 2 - 5 } & Uy & 10,154 & 96 & 104 \\
\cline { 2 - 5 } & Uz & 10,154 & 96 & 161 \\
\hline & Air Temperature & 10,154 & 0 & 0 \\
\cline { 2 - 5 } & Atmospheric Pressure & 10,154 & 0 & 0 \\
\hline
\end{tabular}


Table 6. Number of Missing Data and Outliers for Tower WT2, 2013

\begin{tabular}{c|lccc}
\hline \multicolumn{1}{c}{$\begin{array}{c}\text { Measurement } \\
\text { Level }\end{array}$} & Parameter & $\begin{array}{c}\text { Total \# } \\
\text { Observations }\end{array}$ & $\begin{array}{c}\text { Missing } \\
\text { Data }\end{array}$ & $\begin{array}{c}\text { Outliers/ } \\
\text { Rejected Data }\end{array}$ \\
\hline \multirow{4}{*}{ 20-m Cup Anemometer I } & Wind Speed & 43,640 & 0 & 38 \\
\cline { 2 - 5 } & Wind Direction & 43,640 & 0 & 419 \\
\cline { 2 - 5 } & Standard Deviation & 43,640 & 0 & 209 \\
\cline { 2 - 5 } & Maximum Wind Gust & 43,640 & 0 & 47 \\
\hline \multirow{4}{*}{$20-m$ Cup Anemometer II } & Wind Speed & 43,640 & 0 & 38 \\
\cline { 2 - 5 } & Standard Deviation & 43,640 & 0 & 226 \\
\cline { 2 - 5 } & Maximum Wind Gust & 43,640 & 0 & 44 \\
\hline \multirow{4}{*}{$40-m$ Cup Anemometer I } & Ux & 43,640 & 3,257 & 3,301 \\
\cline { 2 - 5 } & Uy & 43,640 & 3,257 & 3,384 \\
\cline { 2 - 5 } & Uz & 43,640 & 3,257 & 3,321 \\
\cline { 2 - 5 } & Wind Speed & 43,640 & 0 & 45 \\
\cline { 2 - 5 } & Standard Deviation & 43,640 & 0 & 243 \\
\hline & Maximum Wind Gust & 43,640 & 0 & 50 \\
\hline \multirow{4}{*}{$40-m$ Cup Anemometer II } & Wind Speed & 43,640 & 0 & 39 \\
\cline { 2 - 5 } & Standard Deviation & 43,640 & 0 & 238 \\
\cline { 2 - 5 } & Maximum Wind Gust & 43,640 & 0 & 56 \\
\hline
\end{tabular}

Table 7. Number of Missing Data and Outliers for Tower WT2, January 1, 2014-February 24, 2014

\begin{tabular}{c|lccc}
\hline \multicolumn{1}{c}{$\begin{array}{c}\text { Measurement } \\
\text { Level }\end{array}$} & \multicolumn{1}{c}{ Parameter } & $\begin{array}{c}\text { Total \# } \\
\text { Observations }\end{array}$ & $\begin{array}{c}\text { Missing } \\
\text { Data }\end{array}$ & $\begin{array}{c}\text { Outliers/ } \\
\text { Rejected Data }\end{array}$ \\
\hline \multirow{4}{*}{ 60-m Cup Anemometer I } & Wind Speed & 8,002 & 0 & 14 \\
\cline { 2 - 5 } & Wind Direction & 8,002 & 0 & 65 \\
\cline { 2 - 5 } & Standard Deviation & 8,002 & 0 & 43 \\
\cline { 2 - 5 } & Maximum Wind Gust & 8,002 & 0 & 14 \\
\hline \multirow{4}{*}{$60-$-m Cup Anemometer II } & Wind Speed & 8,002 & 0 & 17 \\
\cline { 2 - 5 } & Standard Deviation & 8,002 & 0 & 41 \\
\cline { 2 - 5 } & Maximum Wind Gust & 8,002 & 0 & 13 \\
\hline \multirow{3}{*}{ Surface Level } & Ux & 8,002 & 23 & 125 \\
\cline { 2 - 5 } & Uy & 8,002 & 23 & 44 \\
\cline { 2 - 5 } & Uz & 8,002 & 23 & 79 \\
\hline & Air Temperature & 8,002 & 0 & 0 \\
\cline { 2 - 5 } & Atmospheric Pressure & 8,002 & 0 & 0 \\
\hline
\end{tabular}




\subsubsection{Analysis of Missing Data and Outliers-Sodar Measurements (2012-2013)}

Table 8. Number of Missing Data and Outliers for Sodar, October 30, 2012-December 31, 2012

\begin{tabular}{|c|c|c|c|c|}
\hline \multicolumn{2}{|c|}{$\begin{array}{c}\text { Measurement } \\
\text { Level }\end{array}$} & \multirow{2}{*}{$\begin{array}{c}\begin{array}{c}\text { Total \# } \\
\text { Observations }\end{array} \\
8,970\end{array}$} & \multirow{2}{*}{$\begin{array}{c}\begin{array}{c}\text { Missing } \\
\text { Observations }\end{array} \\
0\end{array}$} & \multirow{2}{*}{$\begin{array}{c}\text { Rejected Data/ } \\
\text { Outliers } \\
61\end{array}$} \\
\hline $10 \mathrm{~m}$ & Wind Speed & & & \\
\hline 西 & Wind Direction & 8,970 & 0 & 39 \\
\hline \multirow{2}{*}{$50 \mathrm{~m}$} & Wind Speed & 8,970 & 0 & 90 \\
\hline & Wind Direction & 8,970 & 0 & 73 \\
\hline \multirow{2}{*}{$60 \mathrm{~m}$} & Wind Speed & 8,970 & 0 & 109 \\
\hline & Wind Direction & 8,970 & 0 & 98 \\
\hline \multirow{2}{*}{$80 \mathrm{~m}$} & Wind Speed & 8,970 & 0 & 109 \\
\hline & Wind Direction & 8,970 & 0 & 155 \\
\hline \multirow{2}{*}{$100 \mathrm{~m}$} & Wind Speed & 8,970 & 0 & 122 \\
\hline & Wind Direction & 8,970 & 0 & 212 \\
\hline \multirow{2}{*}{$120 \mathrm{~m}$} & Wind Speed & 8,970 & 0 & 98 \\
\hline & Wind Direction & 8,970 & 0 & 171 \\
\hline \multirow{2}{*}{$140 \mathrm{~m}$} & Wind Speed & 8,970 & 0 & 57 \\
\hline & Wind Direction & 8,970 & 0 & 158 \\
\hline \multirow{2}{*}{$160 \mathrm{~m}$} & Wind Speed & 8,970 & 0 & 29 \\
\hline & Wind Direction & 8,970 & 0 & 117 \\
\hline \multirow{2}{*}{$180 \mathrm{~m}$} & Wind Speed & 8,970 & 0 & 11 \\
\hline & Wind Direction & 8,970 & 0 & 92 \\
\hline \multirow{2}{*}{$200 \mathrm{~m}$} & Wind Speed & 8,970 & 0 & 50 \\
\hline & Wind Direction & 8,970 & 0 & 194 \\
\hline
\end{tabular}


Table 9. Number of Missing Data and Outliers for Sodar, January 1, 2013-November 11, 2013

\begin{tabular}{|c|c|c|c|c|}
\hline \multicolumn{2}{|c|}{$\begin{array}{c}\text { Measurement } \\
\text { Level }\end{array}$} & \multirow{2}{*}{$\begin{array}{c}\begin{array}{c}\text { Total \# } \\
\text { Observations }\end{array} \\
41,844\end{array}$} & \multirow{2}{*}{$\begin{array}{c}\begin{array}{c}\text { Missing } \\
\text { Observations }\end{array} \\
0\end{array}$} & \multirow{2}{*}{\begin{tabular}{|c|} 
Rejected Data \\
Outliers
\end{tabular}} \\
\hline \multirow{2}{*}{$40 \mathrm{~m}$} & Wind Speed & & & \\
\hline & Wind Direction & 41,844 & 0 & 329 \\
\hline \multirow{2}{*}{$50 \mathrm{~m}$} & Wind Speed & 41,844 & 0 & 257 \\
\hline & Wind Direction & 41,844 & 0 & 533 \\
\hline \multirow{2}{*}{$60 \mathrm{~m}$} & Wind Speed & 41,844 & 0 & 264 \\
\hline & Wind Direction & 41,844 & 0 & 652 \\
\hline \multirow{2}{*}{$80 \mathrm{~m}$} & Wind Speed & 41,844 & 0 & 336 \\
\hline & Wind Direction & 41,844 & 0 & 965 \\
\hline \multirow{2}{*}{$100 \mathrm{~m}$} & Wind Speed & 41,844 & 0 & 470 \\
\hline & Wind Direction & 41,844 & 0 & 993 \\
\hline \multirow{2}{*}{$120 \mathrm{~m}$} & Wind Speed & 41,844 & 0 & 373 \\
\hline & Wind Direction & 41,844 & 0 & 812 \\
\hline \multirow{2}{*}{$140 \mathrm{~m}$} & Wind Speed & 41,844 & 0 & 179 \\
\hline & Wind Direction & 41,844 & 0 & 584 \\
\hline \multirow{2}{*}{$160 \mathrm{~m}$} & Wind Speed & 41,844 & 0 & 82 \\
\hline & Wind Direction & 41,844 & 0 & 520 \\
\hline \multirow{2}{*}{$180 \mathrm{~m}$} & Wind Speed & 41,844 & 0 & 35 \\
\hline & Wind Direction & 41,844 & 0 & 374 \\
\hline \multirow{2}{*}{$200 \mathrm{~m}$} & Wind Speed & 41,844 & 0 & 178 \\
\hline & Wind Direction & 41,844 & 0 & 1,657 \\
\hline
\end{tabular}

\subsubsection{Sodar Issues}

The Second Wind Triton Sonic Wind Profiler was operational during the field program campaign (see Section 4.2.2). It provides remote wind measurement data. The Triton is a sonic detection and ranging (sodar) system capable of profiling the wind characteristics up to $200 \mathrm{~m}$ above the instrument. As mentioned earlier, we refer to this as sodar in this report. Sodar systems transmit acoustic chirps into the atmosphere and measure the backscattered signal returned to the device. The primary source of acoustic scattering is variations in air temperature, which cause changes in the refractive index of sound. By measuring the Doppler-shifted frequency of these returned signals, the Triton can calculate the wind speed and direction for the volume of air above the instrument, measured at 10 fixed heights known as station heights. The Triton is specifically designed to assess the wind energy resource, because it can remotely capture wind data at heights above ground where wind turbine rotors operate. This information can be used for energy assessment, turbine siting, model evaluation, comparison to reference stations, and many other applications. 
The Triton collects 10-minute averaged intervals of the following measurements at all 10 heights:

- Horizontal wind speed

- Vertical wind speed

- Horizontal wind direction

- Turbulence.

The data for each of these measurements are averaged and time-stamped at the end of the 10minute interval. For example, data with a timestamp of 11:10:00 are the averaged measurements from 11:00:00 to 11:09:59.

According to the User's Manual the amount of usable data available at any measurement height is a function of the quality of the shots collected at those heights. Each sample of data is assigned a QC factor between $0 \%$ and $100 \%$, which is based upon the signal to noise ratio of the shots within the chunk. Signal to noise ratio is the determining factor of how accurate the wind data are for each shot recorded by the Triton. High levels of atmospheric absorption or atmospheric stability at the measurement site can decrease the signal strength. Generally, there are diurnal (DI) and seasonal trends in the levels of absorption or stability in the atmosphere. Noise can be increased by active noise sources at the site (such as insects), or passive noise sources (such as echoes) caused by improper siting. Thus, at any single measurement height, the data availability can vary over time and from site to site. With the QC factor set to $90 \%$ (recommended by Second Wind), the Triton can deliver the following:

- Horizontal wind speed measurements accurate to $\pm 0.5 \mathrm{~m} \mathrm{~s}^{-1}$, range from $0 \mathrm{~m} \mathrm{~s}^{-1}$ to $25 \mathrm{~m} \mathrm{~s}^{-1}$

- Vertical wind speed measurements accurate to $\pm 0.5 \mathrm{~m} \mathrm{~s}^{-1}$, range from $-5 \mathrm{~m} \mathrm{~s}^{-1}$ to $5 \mathrm{~m} \mathrm{~s}^{-1}$

- Horizontal wind direction measurement accurate to $\pm 1.5^{\circ}$, range from $0^{\circ}$ to $359^{\circ}$

- According to Second Wind calibration studies, Triton correlates to within $\mathrm{R}=0.98$ compared to cup anemometers.

For more details, see the Second Wind website and the User's Manual (2.2): (http://secondwind.com/triton-user-documentation.html).

We have performed an analysis of data from the Triton sodar for the duration of the sodar deployment. Figure 4 shows vertical distribution of the data recovery for various QC factors for the entire period of the sodar deployment. Note that the recommended QC factor is $90 \%$. Data recovery rates using the manufacturer's suggested QC value minimum of $90 \%$ result in net data availability rates of $75 \%$ at $60 \mathrm{~m}$ (Figure 4 ). 


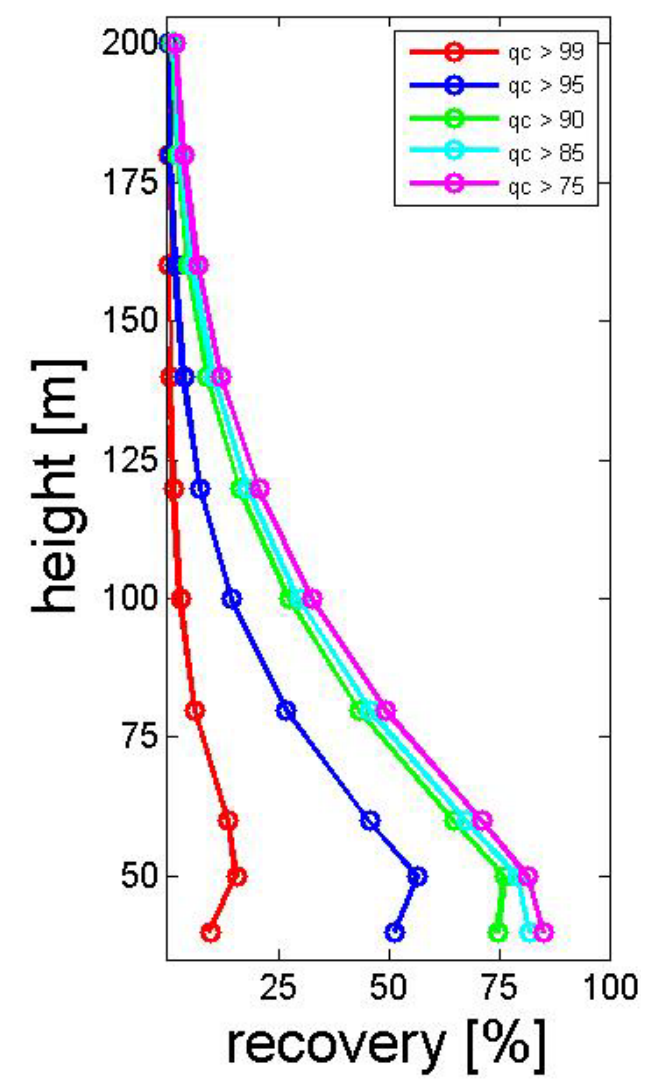

Figure 4. Data recovery rate as a function of height from the Triton Sodar for the entire period of deployment (October 31, 2012-November 1, 2013). Virtually all (>95\%) filtering of Triton sodar data is based on the QC factor output by the unit, and not vertical velocity or other any other factors. Recovery rates using filtering based on QC factor $>99 \%$ (red), $95 \%$ (blue), $90 \%$ (green the manufacturer-recommended value), $85 \%$ (cyan), and $75 \%$ (magenta) are shown.

Note that the recovery rate quickly decreases beyond $60 \mathrm{~m}$ and above $100 \mathrm{~m}$ is well below $50 \%$ for all QCs. The manufacturer (Barry Logue, Vaisala, barry.logue@vaisala.com) has vaguely suggested alternative filtering of data using something other than QC minimum value, but has failed to respond to our request to provide any specific details on suggested procedure. Overall data recovery rates from this platform (using the manufacturer recommended QC minimum of $90 \%$ ) are low and biased with respect to mean wind speed from the sonic anemometer and time of day (Figure 4).

Although results for QC $=90 \%$ are essentially the same as for the $95 \%$ and even $99 \%$, the highest recovered amount of data is below $50 \mathrm{~m}$ height and rapidly drops off with height similarly for all QCs $\geq 50 \%$. Maximum recovery rates from $75 \%$ to $80 \%$ are still lower than we expected. Figure 5 illustrates time-height contours of the main parameters measured by sodar together with the QC factors. 

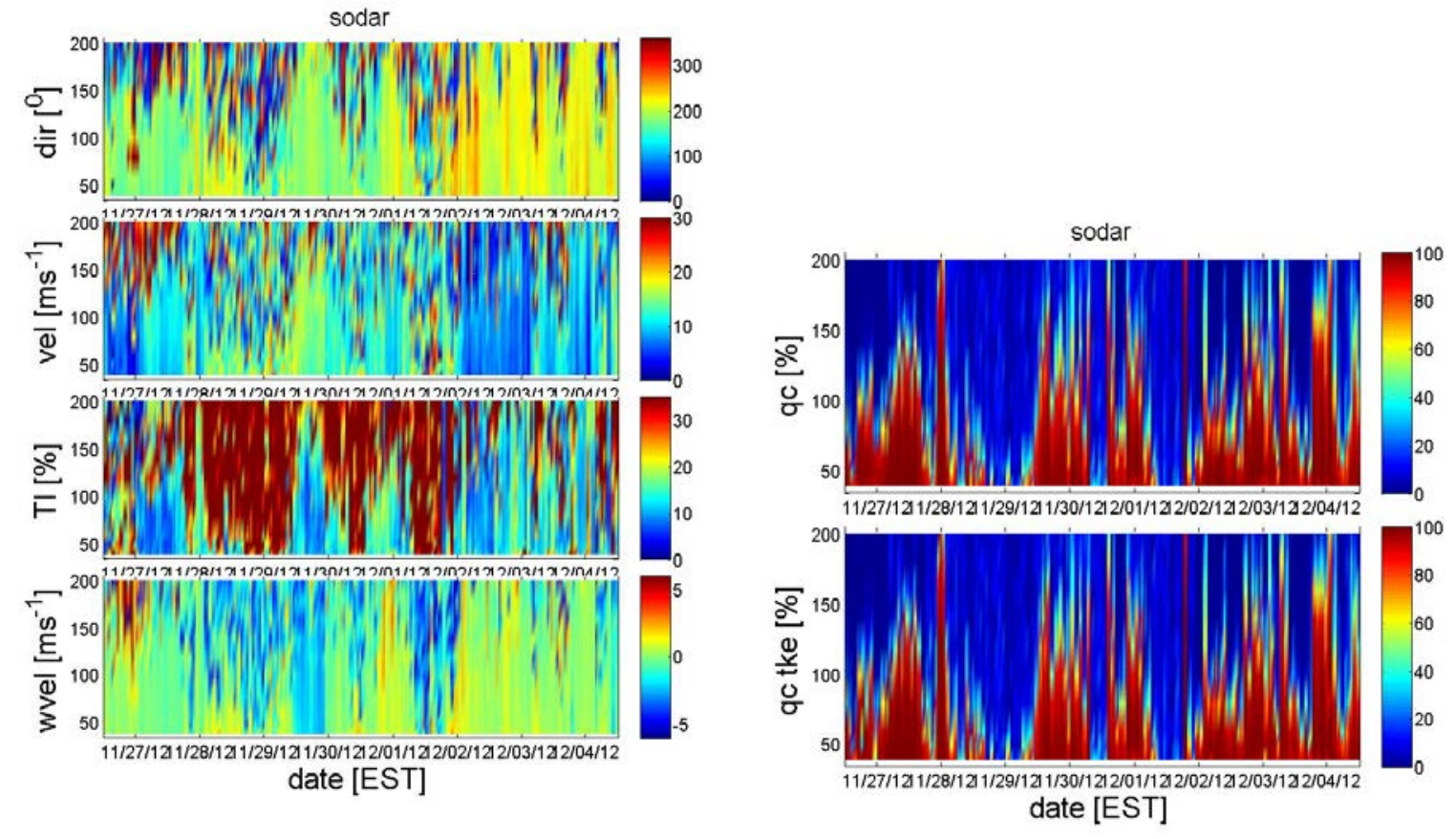

Figure 5. Contours of: (left) - panels from the top down: wind direction, wind speed, turbulence intensity (TI), and vertical velocity; (right) - contours of QC parameter for wind speed (upper panel) and QC turbulence kinetic energy (TKE) parameter (lower panel) from the Triton sodar plotted versus height for one full week

Note a drop of QC during high TI periods and low QC factors generally beyond approximately $100 \mathrm{~m}$. The output TKE QC factor is essentially identical to the QC factor, except that low $(<3$ $\left.\mathrm{m} \mathrm{s}^{-1}\right)$ and high $\left(>15 \mathrm{~m} \mathrm{~s}^{-1}\right)$ wind speeds are always filtered. The vast majority $(>95 \%)$ of all data to be excluded is done based on the QC factor, and not excessively low or high wind speeds, or large absolute vertical velocity. Using a QC minimum of $90 \%$, the percentage of data availability is rather poor at the lowest heights (40 and $60 \mathrm{~m}$ have availability of $\sim 75 \%$ ) and deteriorates rapidly with height (roughly $90 \%$ of all $200 \mathrm{~m}$ retrievals do not meet the Triton QC standards). The recovery rate is highly dependent on the minimum of the QC factor.

In Figure 6 we present filtered and unfiltered wind speed plotted as a function of height and date. Also shown is the QC factor-we have not been able to correlate the low recovery rates with any specific meteorological events, such as discrete periods of snowfall. Due to the remote nature of the site, we have not been able to observe and record snow accumulation in the unit. The unit is not being turned on and off periodically (because of insufficient photovoltaic supply). We have contacted Second Wind regarding this, but they did not have any input on how to increase the data recovery rate. Presumably it might be related to low aerosol loading in the high-desert sagebrush (and scattered juniper) environment, and could also be related to the very high elevation of the site $(\sim 7,500 \mathrm{ft}$, or $2,300 \mathrm{~m})$. 


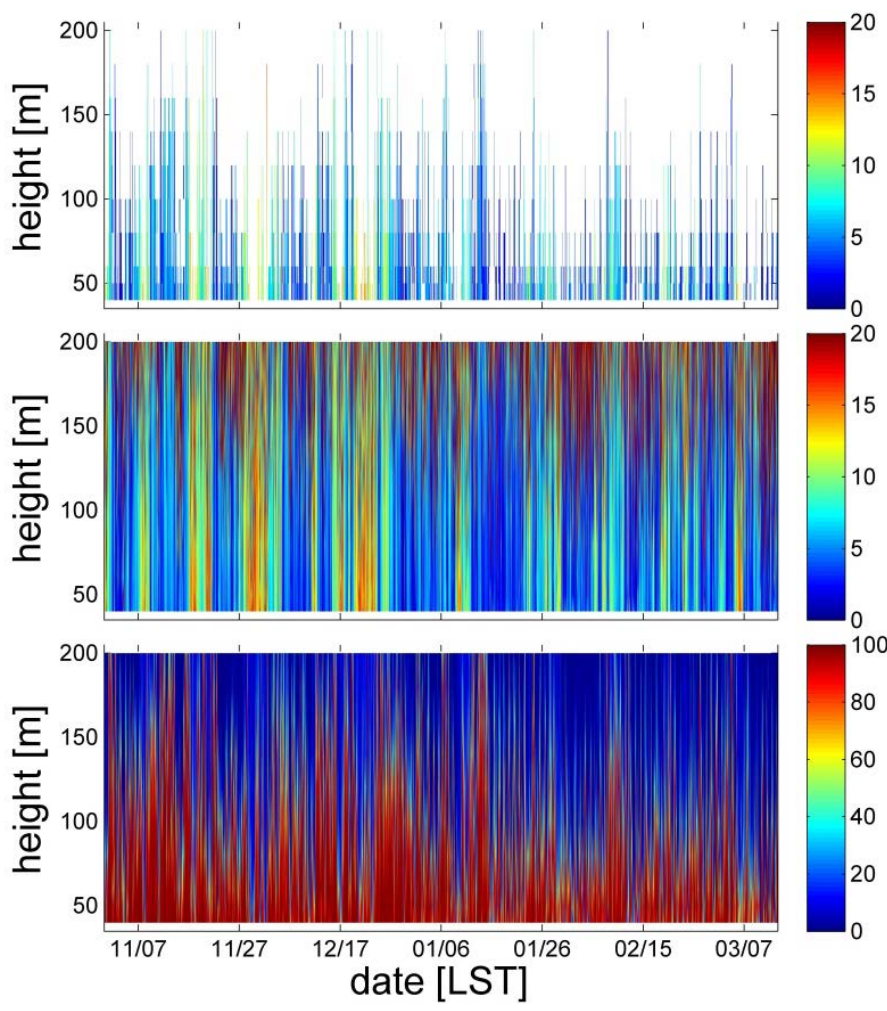

Figure 6. Filtered wind velocity (top, $Q C>90 \%$ ), unfiltered wind velocity (middle) [m $\left.\mathrm{s}^{-1}\right]$, and QC factor (bottom) as a function of height and date for the period October 31, 2012-March 14, 2013

\subsubsection{Long-Term Series of Tower Data-Cup Anemometer}

Figure 7 shows a 1-year time series of the wind speed measured by the cup anemometers at 20, 40 , and $60 \mathrm{~m}$ at WT1. All plots in this subsection were obtained using the interactive plotting on the http://wrcc.dri.edu website. A user can publicly access this website and produce graphics and statistics without graphical/numerical software. 


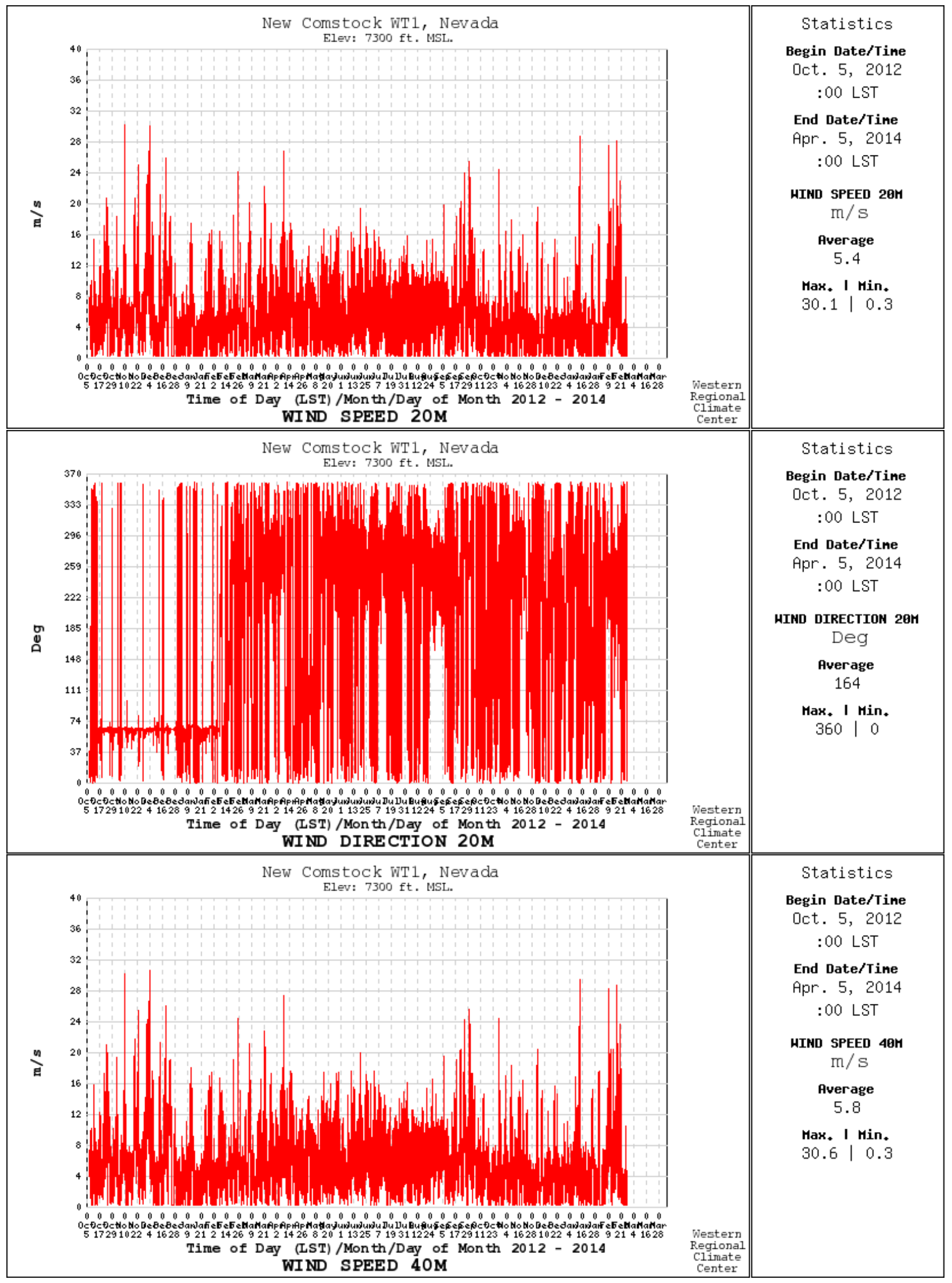




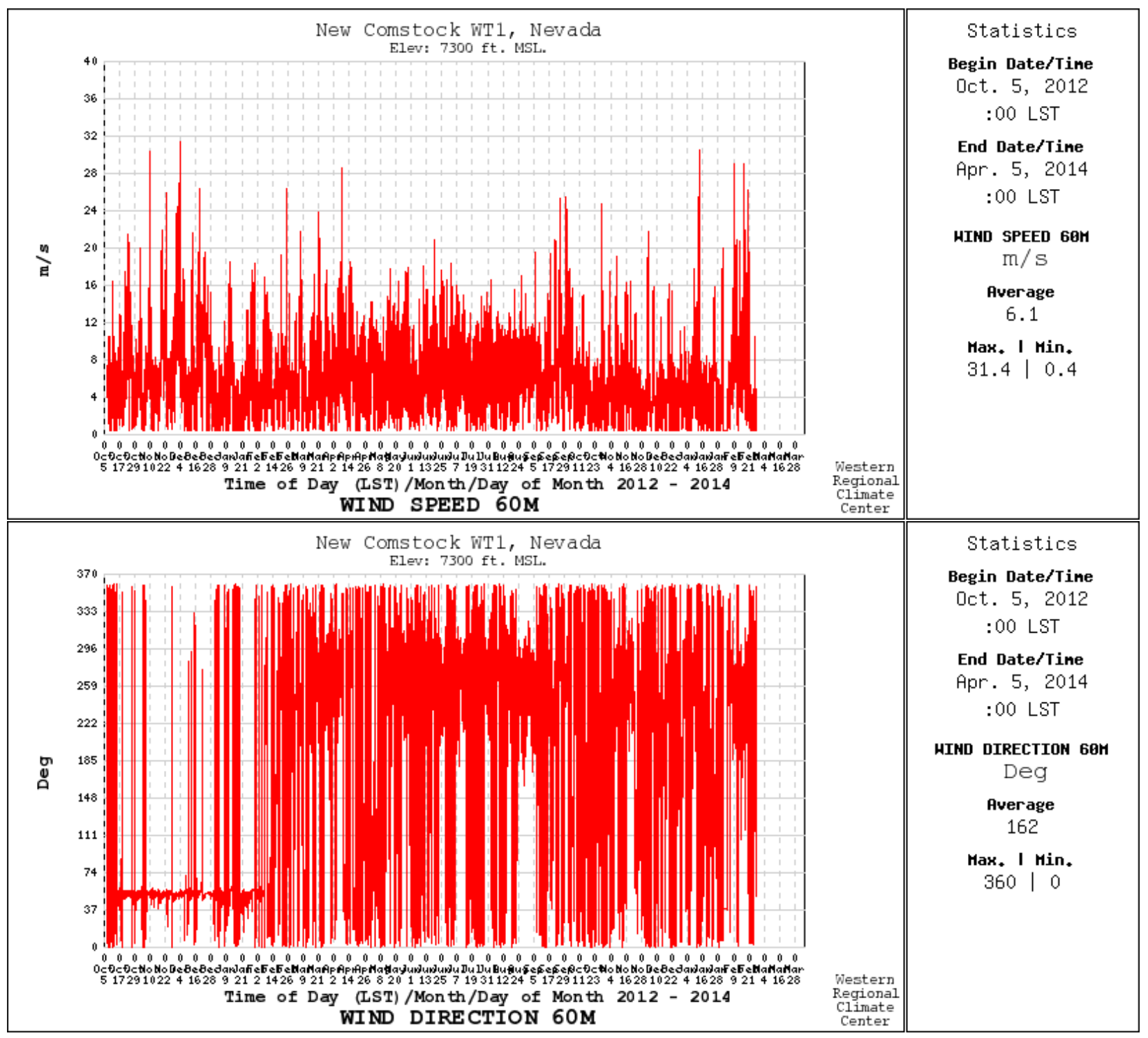

Figure 7. Time series (October 5, 2012-February 24, 2014) of the wind speed and wind direction measured by the cup anemometers at $20 \mathrm{~m}$ (top), $40 \mathrm{~m}$ (middle), and $60 \mathrm{~m}$ (bottom panels) at WT1

Note that the data gap at the end of the displayed period is caused by plot program limits beyond 1 year when a user can choose either 1 year and 6 months or 2 years. In this case, we chose 1 year and 6 months and the end of data on the X-axis is actually on February 24, 2014, when the tower field program ended. The figure also shows that the vanes at 20 and $60 \mathrm{~m}$ were pegged in the beginning of the period. This malfunction was repaired after analyzing the first buffer data and when the site became accessible in winter conditions.

Figure 8 shows a 1-year series of the wind speed and wind direction measured by the cup anemometers at 20,40, and $60 \mathrm{~m}$ at WT2. 


\begin{tabular}{|c|c|c|c|}
\hline$\overbrace{a}^{n}$ & 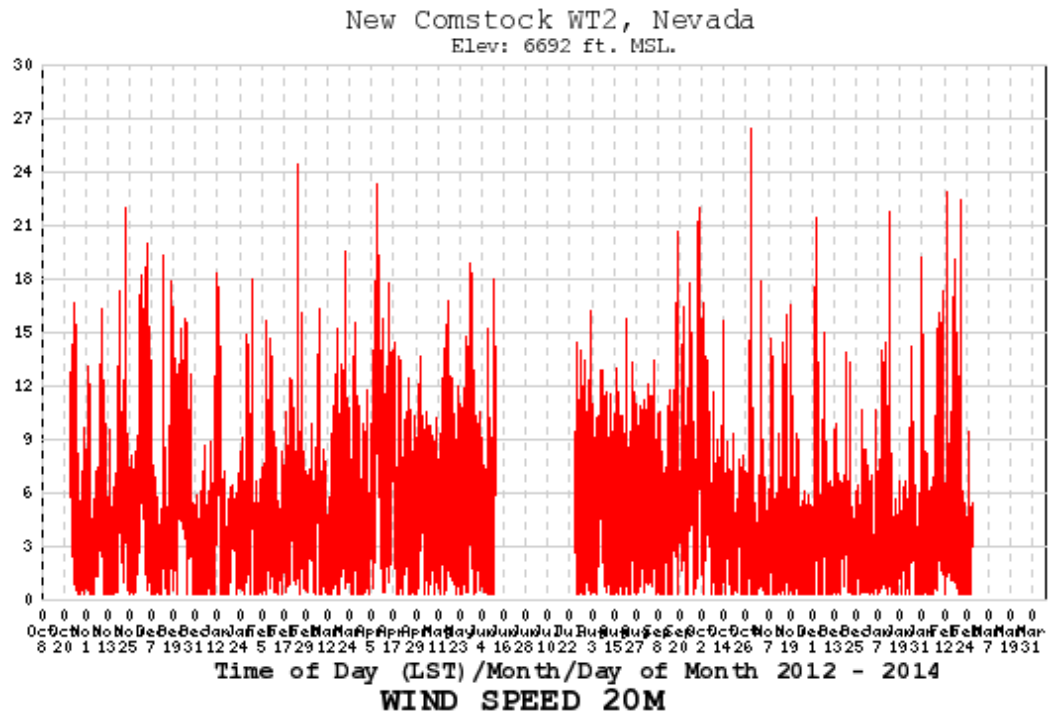 & $\begin{array}{l}\text { Western } \\
\text { Regional } \\
\text { Climate } \\
\text { Center }\end{array}$ & $\begin{array}{c}\text { Statistics } \\
\text { Begin Date/Tine } \\
\text { Oct. 8, 2012 } \\
\text { :00 LST } \\
\text { End Date/Tine } \\
\text { Apr. 8, 2014 } \\
: 00 \text { LST } \\
\text { HIMD SPEED 20M } \\
\text { m/s } \\
\text { Average } \\
5.1 \\
\text { Max. I Min. } \\
26.4 \text { | } 0.3\end{array}$ \\
\hline סூ & 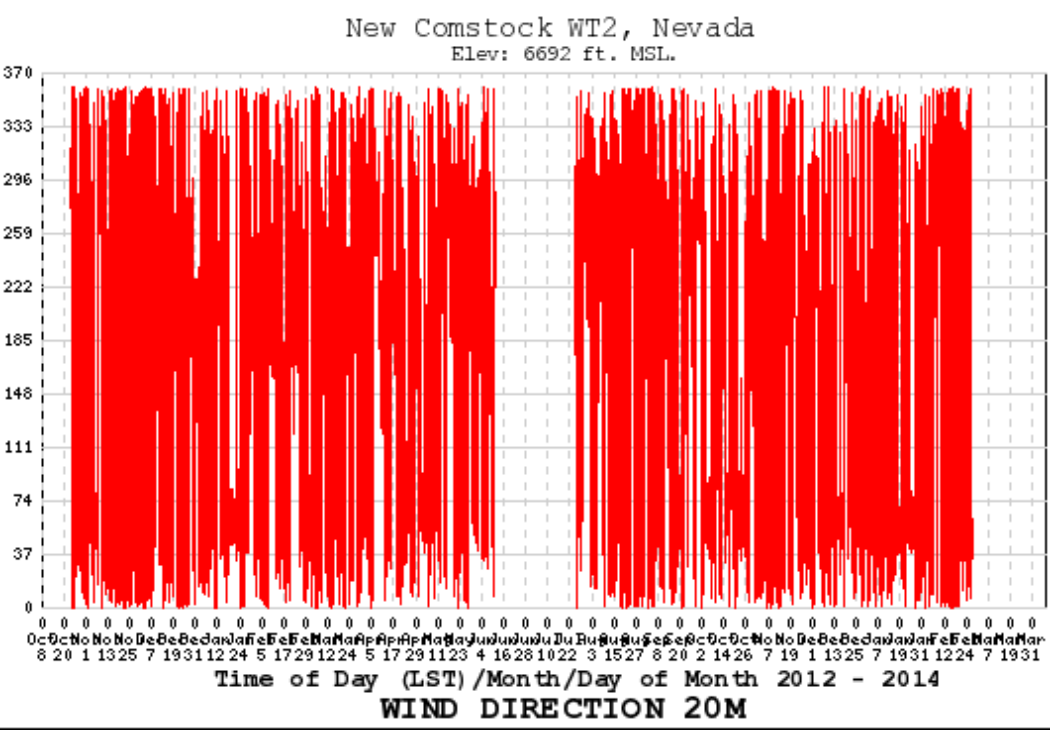 & $\begin{array}{l}\text { Western } \\
\text { Regional } \\
\text { Climate } \\
\text { Center } \\
\end{array}$ & $\begin{array}{c}\text { Statistics } \\
\text { Begin Date/Tine } \\
\text { Oct. 8, 2012 } \\
: 00 \text { LST } \\
\text { End Date/Tine } \\
\text { Apr. 8, 2014 } \\
: 00 \text { LST } \\
\text { HIND DIRECIION 20H } \\
\text { Deg } \\
\text { Average } \\
178 \\
\text { Mas. I Min. } \\
360 \text { | } 0\end{array}$ \\
\hline$\sum^{n}$ & $\begin{array}{c}\mid \\
0 \\
0\end{array}$ & $\begin{array}{l}\text { Western } \\
\text { Regional } \\
\text { Climate } \\
\text { Center }\end{array}$ & $\begin{array}{c}\text { Statistics } \\
\text { Begin Date/Tine } \\
\text { Oct. 8, 2012 } \\
: 00 \text { LST } \\
\text { End Date/Tine } \\
\text { Apr. 8, 2014 } \\
: 00 \text { LST } \\
\text { HIND SPEED 46H } \\
\text { m/s } \\
\text { Average } \\
5.4 \\
\text { Max. I Min. } \\
27 \text { | } 0.3\end{array}$ \\
\hline
\end{tabular}




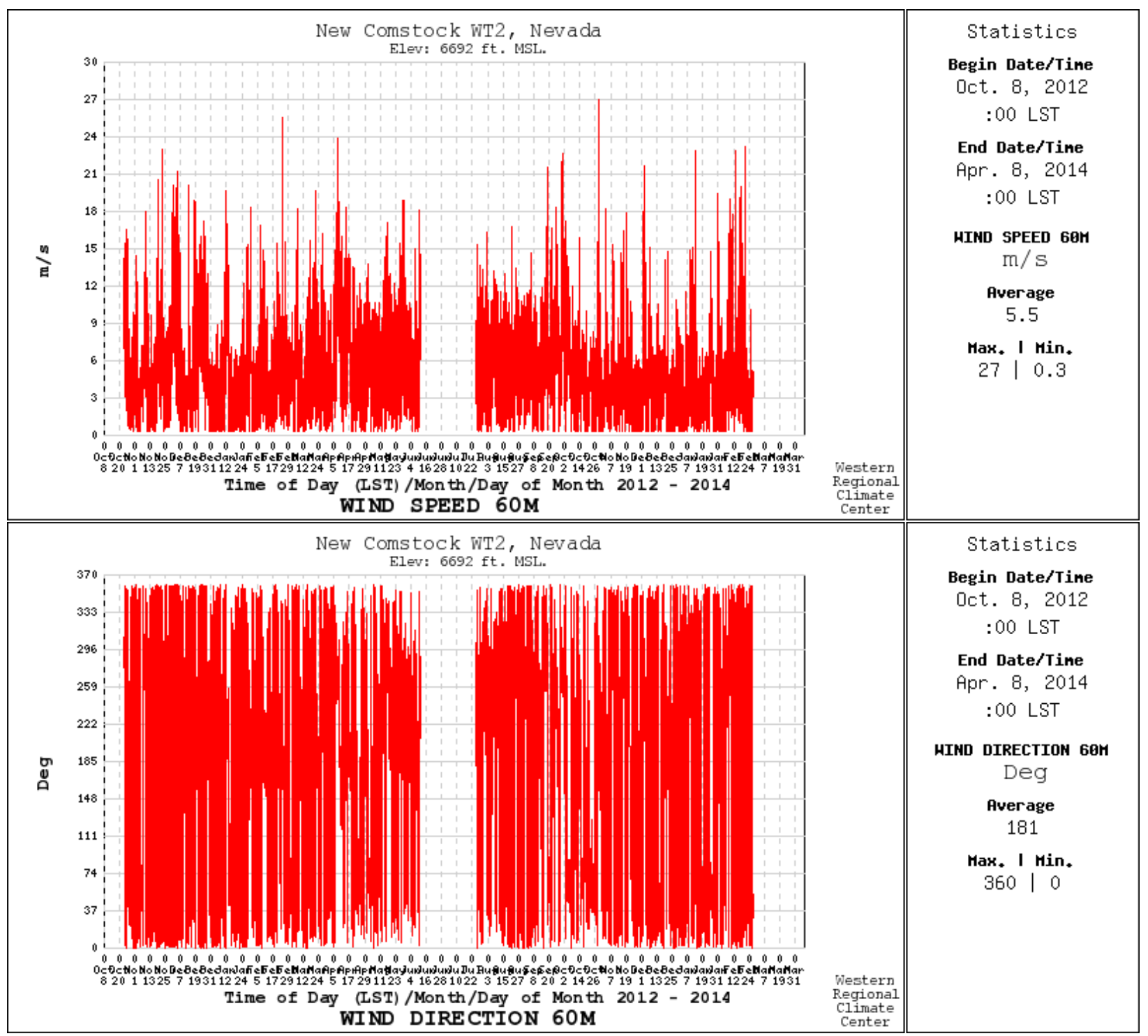

Figure 8. Time series (October 8, 2012-February 24, 2014) of the wind speed and wind direction measured by the cup anemometers at $20 \mathrm{~m}$ (top), $40 \mathrm{~m}$ (middle), and $60 \mathrm{~m}$ (bottom panel) at WT2

As in Figure 7, the gap at the end of the period is caused by plot program limits beyond 1 year when a user can choose either 1 year and 6 months or 2 years. In this case, we chose 1 year and 6 months to since the end of data on the X-axis is actually on February 24, 2014 when the tower field program ended.

The extended data collection beyond 1 year (October 22, 2012 to February 24, 2014) allows for compensation of the data gap on WT2.

The plots show an expected behavior of increasing mean wind speed with height. Most of the high wind periods are in fall and winter. See Section 4.2 for details. 


\subsubsection{Long-Term Series of Tower Data-Sonic Anemometers}

Figure 9 shows problems with the sonic at $20 \mathrm{~m}$, which were corrected as explained in the Task 3 report section. Some of the peaks at $20 \mathrm{~m}$ are also questionable, especially when the measurements at the upper level do not show peak values.

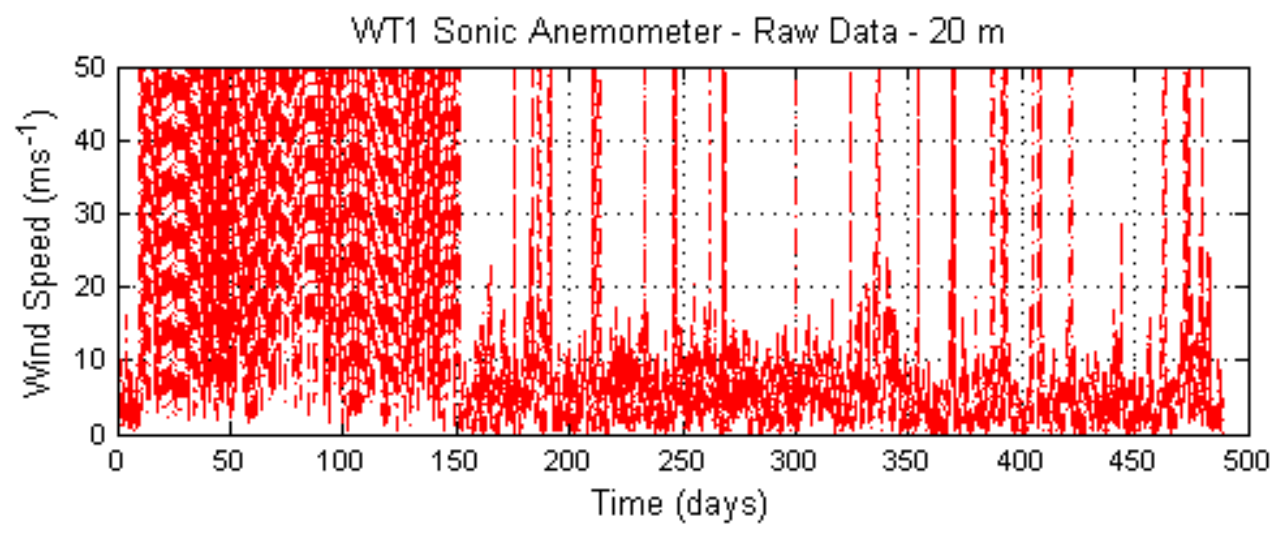

WT1 Sonic Anemometer - Raw Data - 60 m

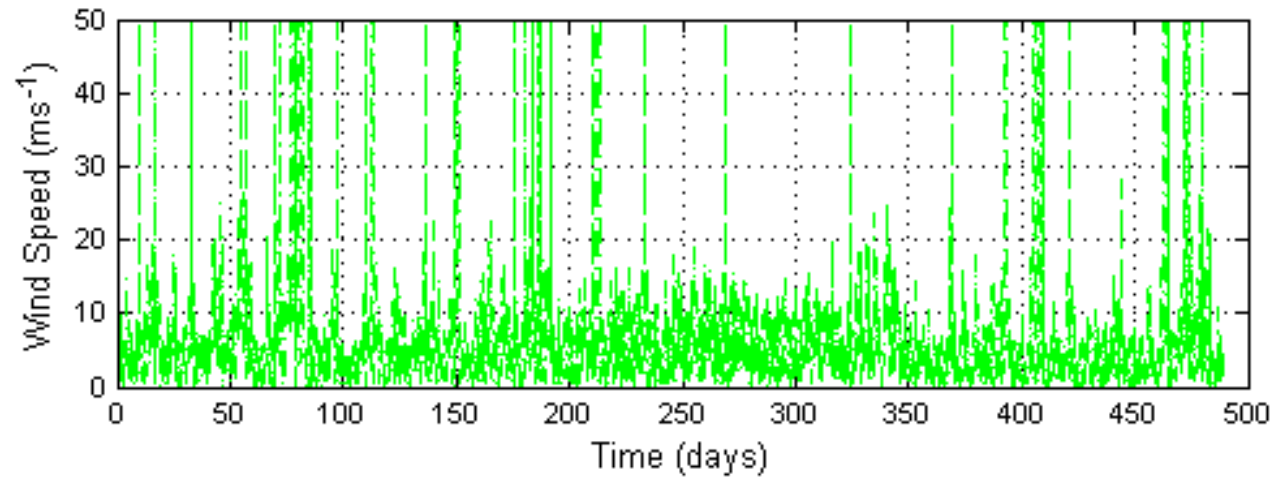

Figure 9. Time series (October 5, 2012-February 24, 2014) of the raw wind speed data measured by the sonic anemometers at $20 \mathrm{~m}$ (top), and $60 \mathrm{~m}$ (bottom panel) at WT1

Figure 10 and Figure 11 show edited sonic data at $20 \mathrm{~m}$ in which the outliers were removed based on the algorithm explained in the beginning of the data analysis section. The edited data at $20 \mathrm{~m}$ show similar wind patterns as data at $60 \mathrm{~m}$. 

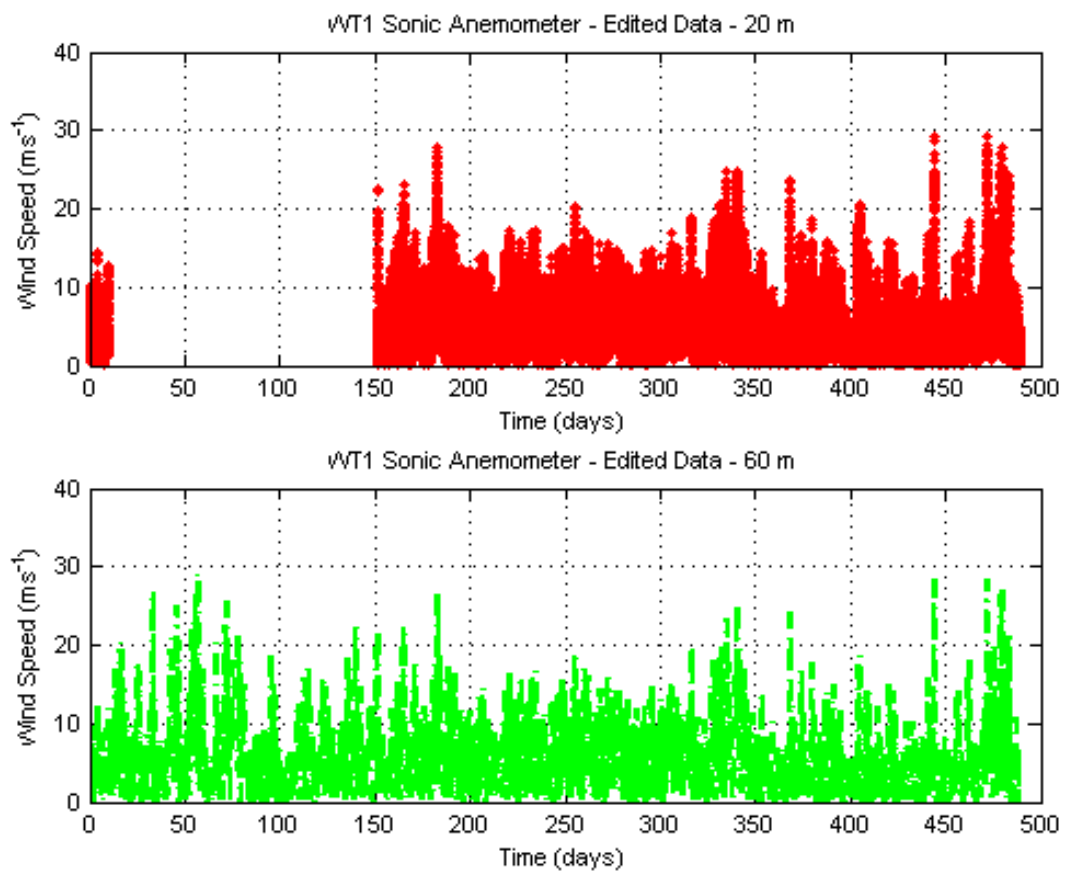

Figure 10. The same as Figure 9, but for the edited sonic wind speed time series
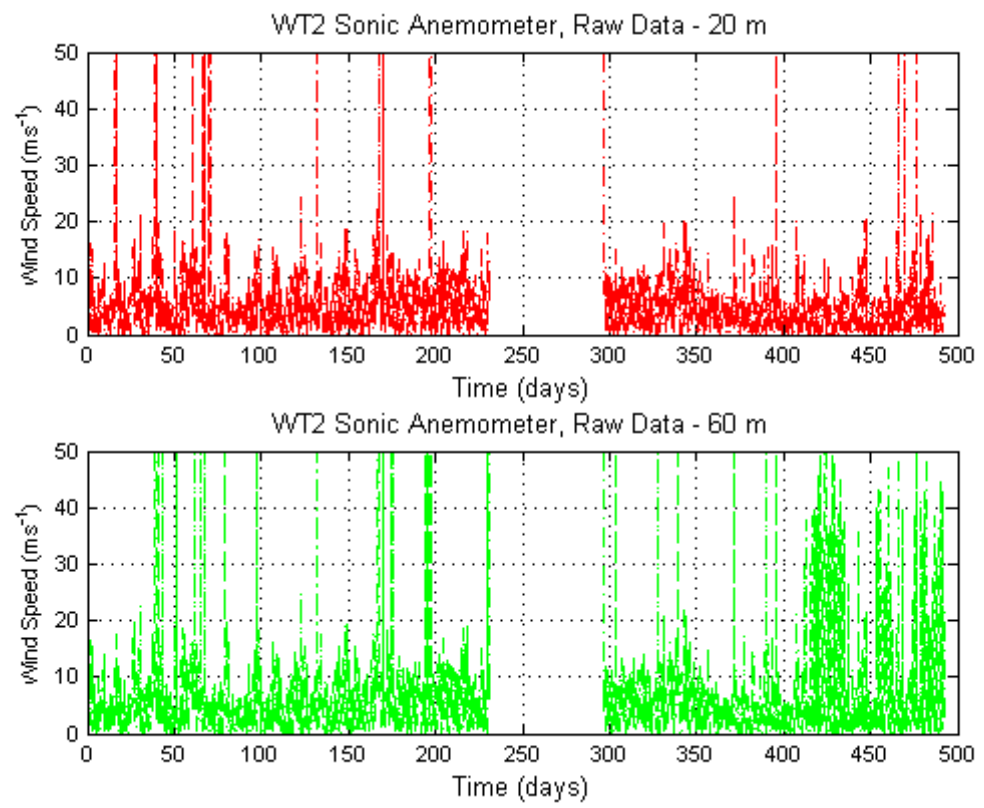

Figure 11. The same as Figure 9, but for WT2 tower (October 2, 2012-February 24, 2014)

Besides the gap in the middle of the period, the sonics at WT2 show similar behavior with some of the peaks occurring at both heights. However, the magnitudes of the peaks are considerably larger than measured by the cup anemometers (Figure 8). We also analyzed and removed outliers (Figure 12). The "cleaned" sonic data at WT2 look much more similar to the cup anemometer data and most peaks are removed. 

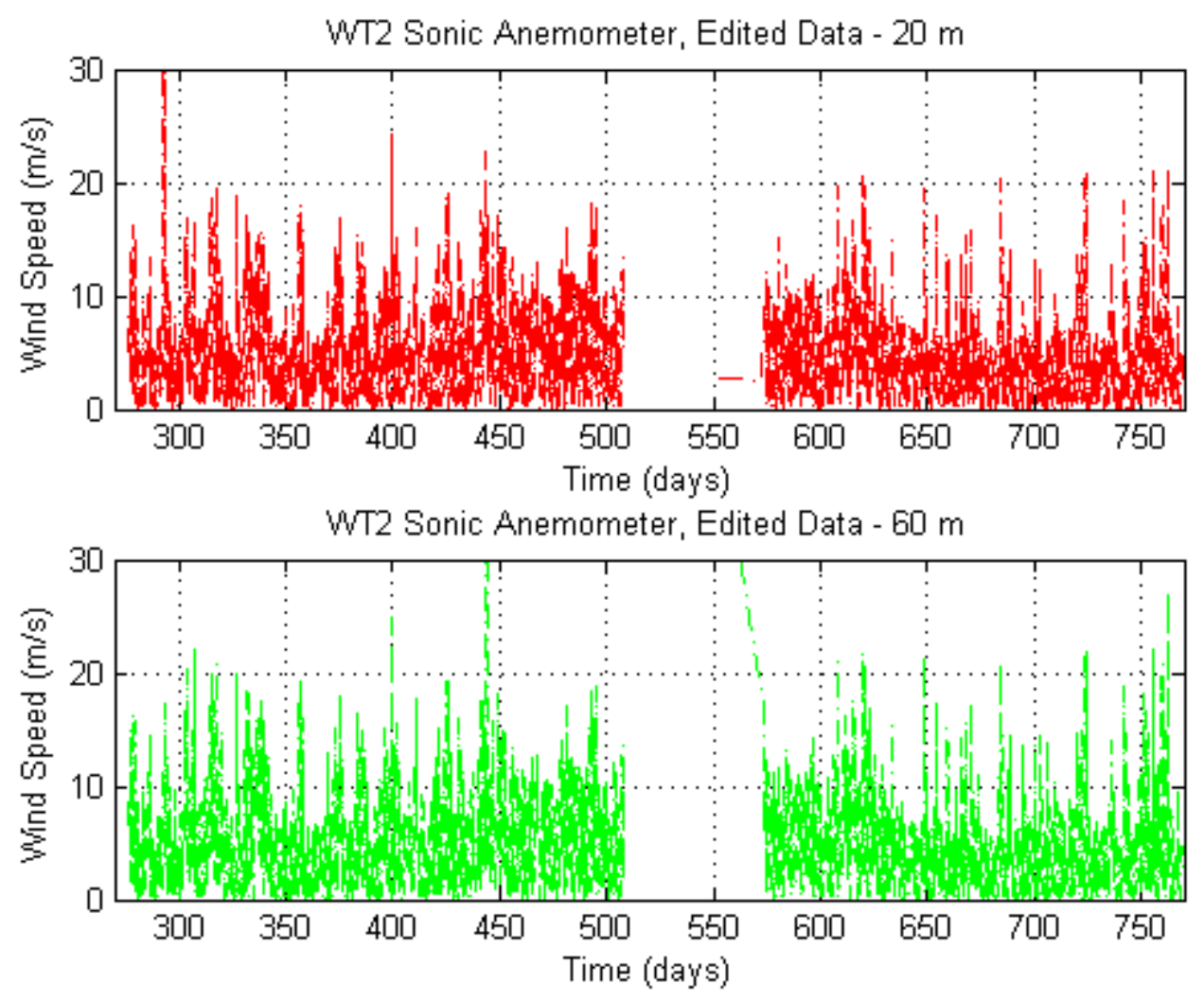

Figure 12. Same as Figure 11, but for the edited wind speed sonic data

\subsubsection{Long-Term Series of Sodar Data}

Sodar raw wind speed data at various heights are shown in Figures 13, 15, and 17. Corresponding edited data are shown in Figures 14, 16, and 18, respectively. The edited data have reduced wind speed range and have fewer isolated peaks. 

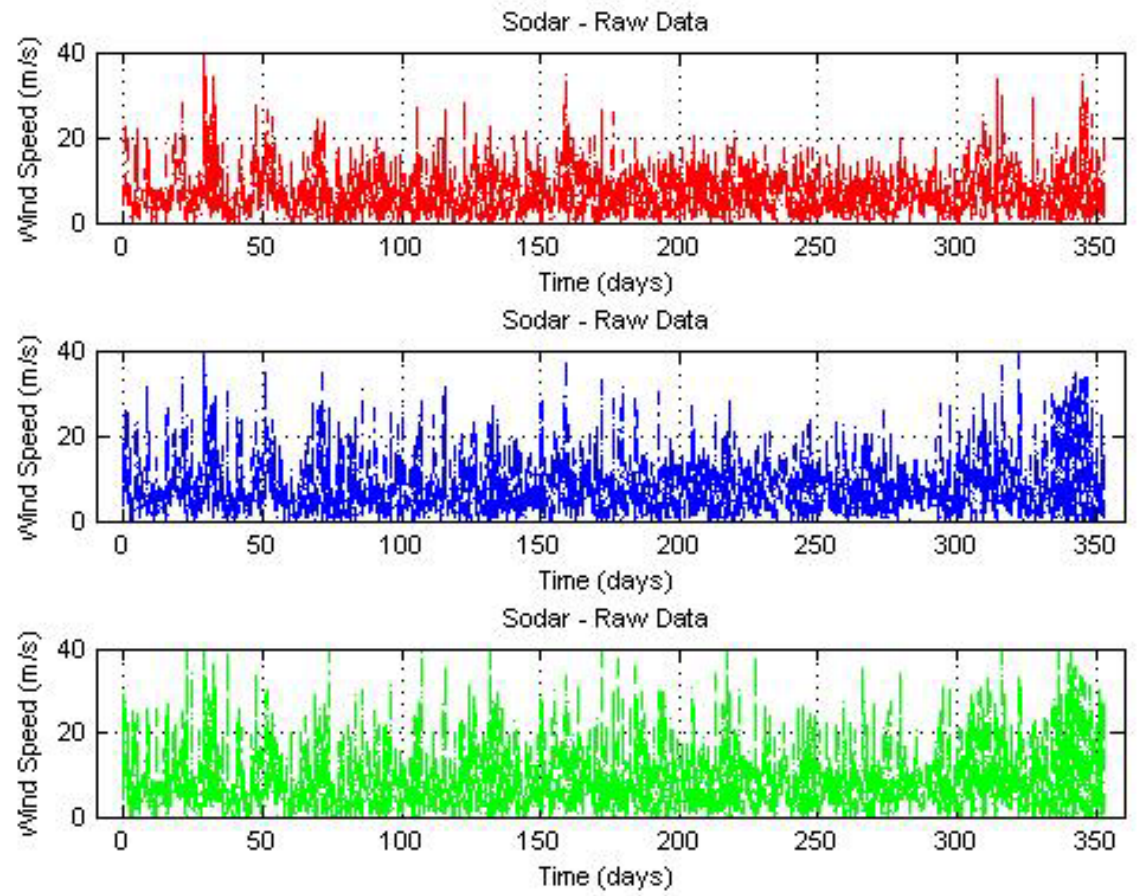

Figure 13. Sodar raw wind speed data at $40 \mathrm{~m}$ (red), $50 \mathrm{~m}$ (blue), and $60 \mathrm{~m}$ (green) Period: October 30, 2012-November 11, 2013
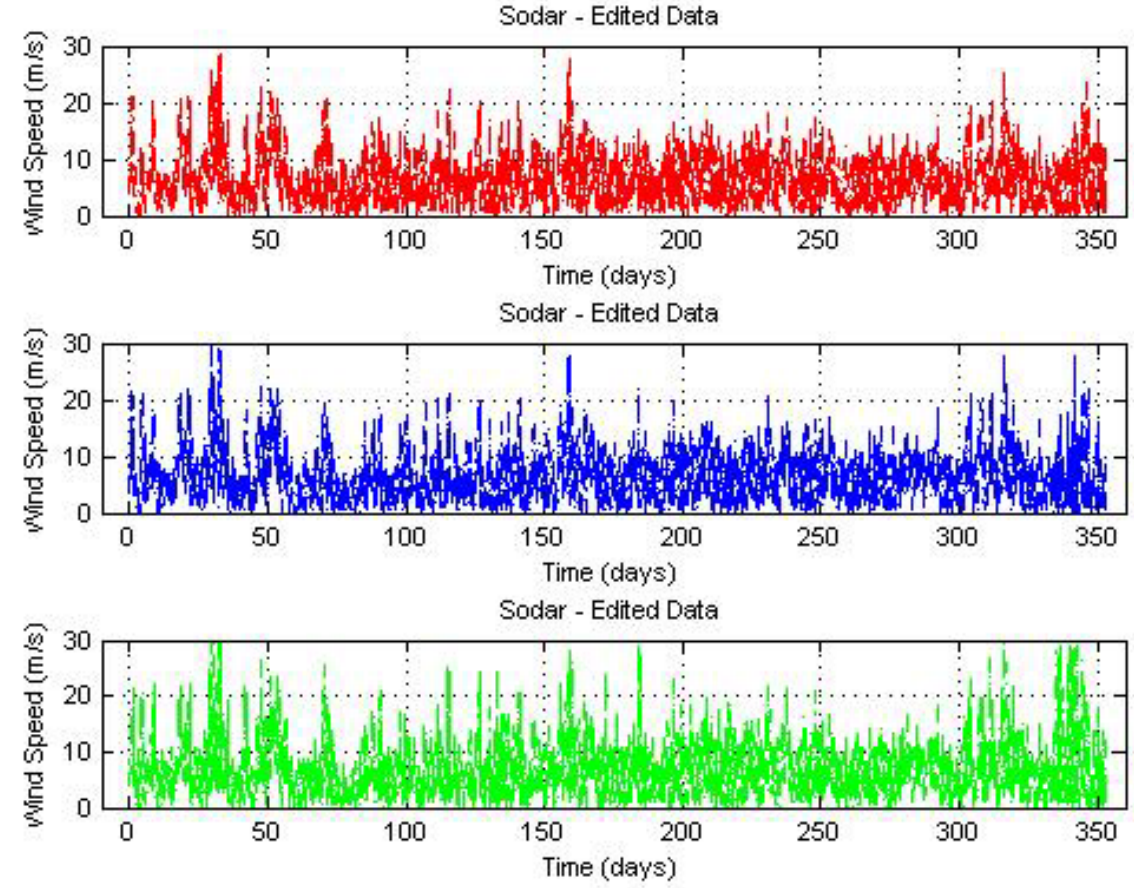

Figure 14. Same as Figure 13, but for sodar edited wind speed data, same levels and period 

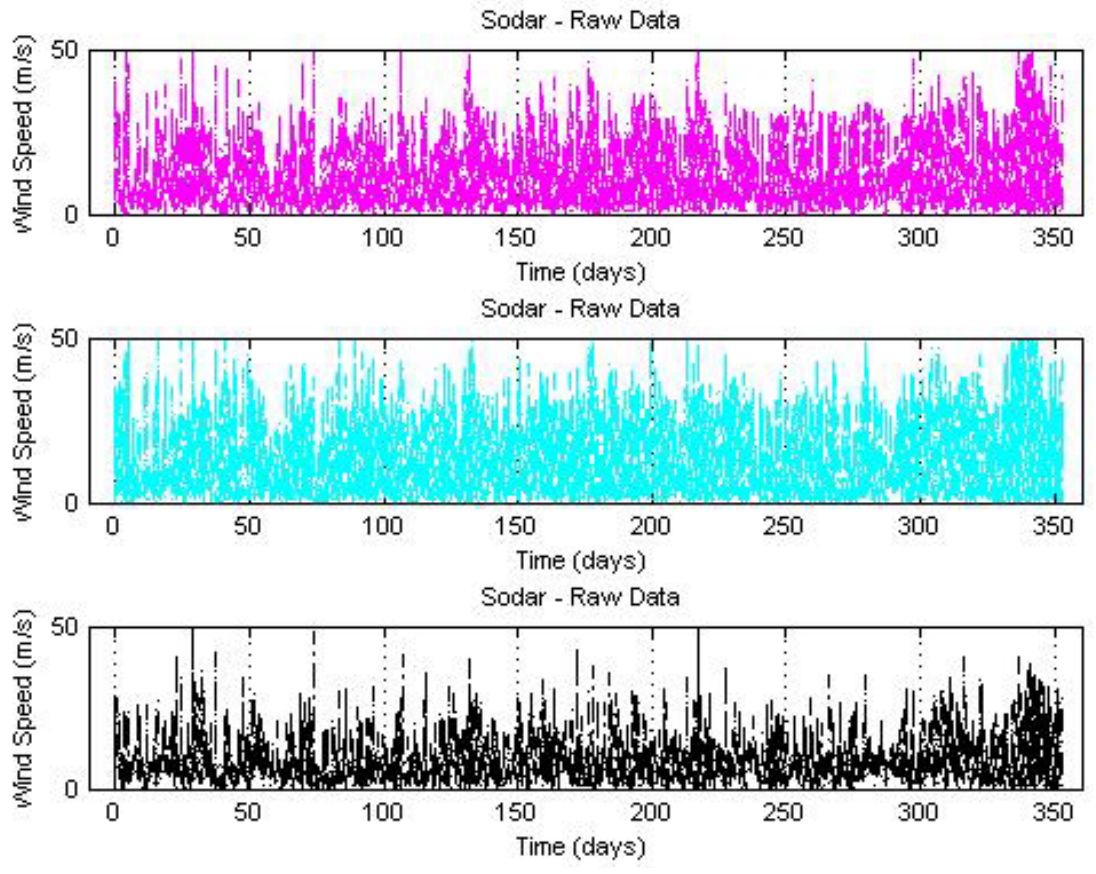

Figure 15. Sodar raw wind speed data at $80 \mathrm{~m}$ (purple), $100 \mathrm{~m}$ (cyan), and $120 \mathrm{~m}$ (black) Period: October 30, 2012-November 11, 2013
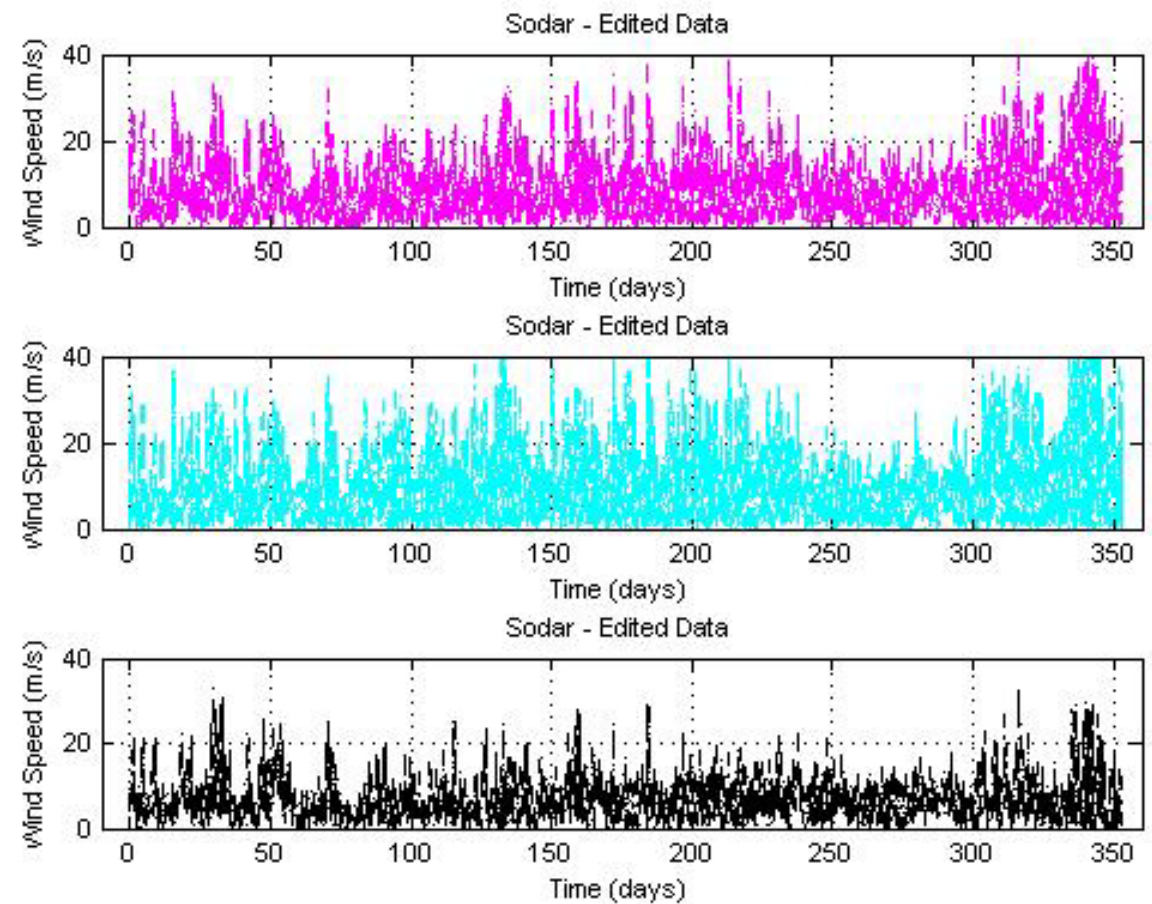

Figure 16. Same as Figure 15, but for sodar edited wind speed data, same levels and period

Sodar raw wind direction data are shown in Figures 17 and 19 and edited data are shown in Figures 18 and 20. Note that the edited data show more clearly a frequent southwesterly flow at all levels. 


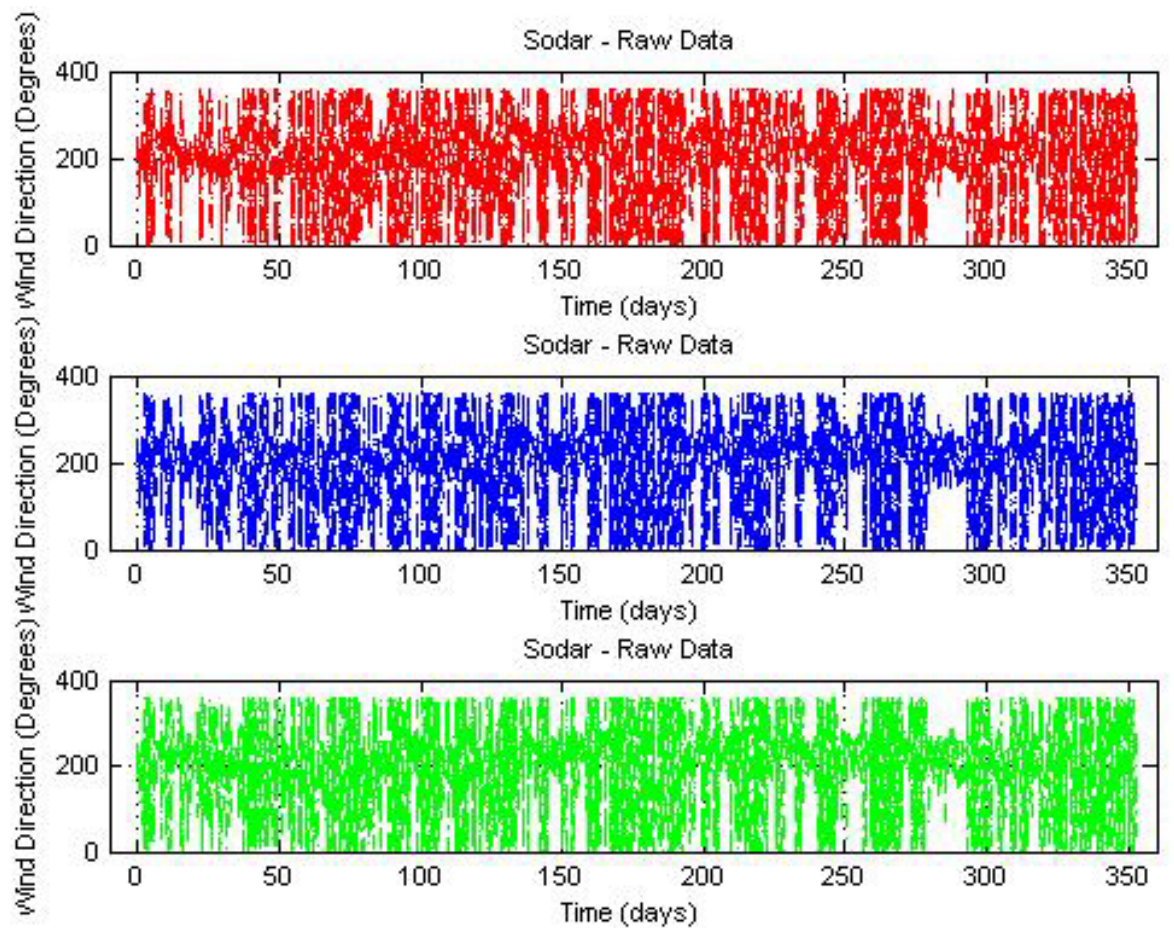

Figure 17. Sodar raw wind direction data at $40 \mathrm{~m}$ (purple), $50 \mathrm{~m}$ (blue), and $60 \mathrm{~m}$ (green) Period: October 30, 2012-November 11, 2013

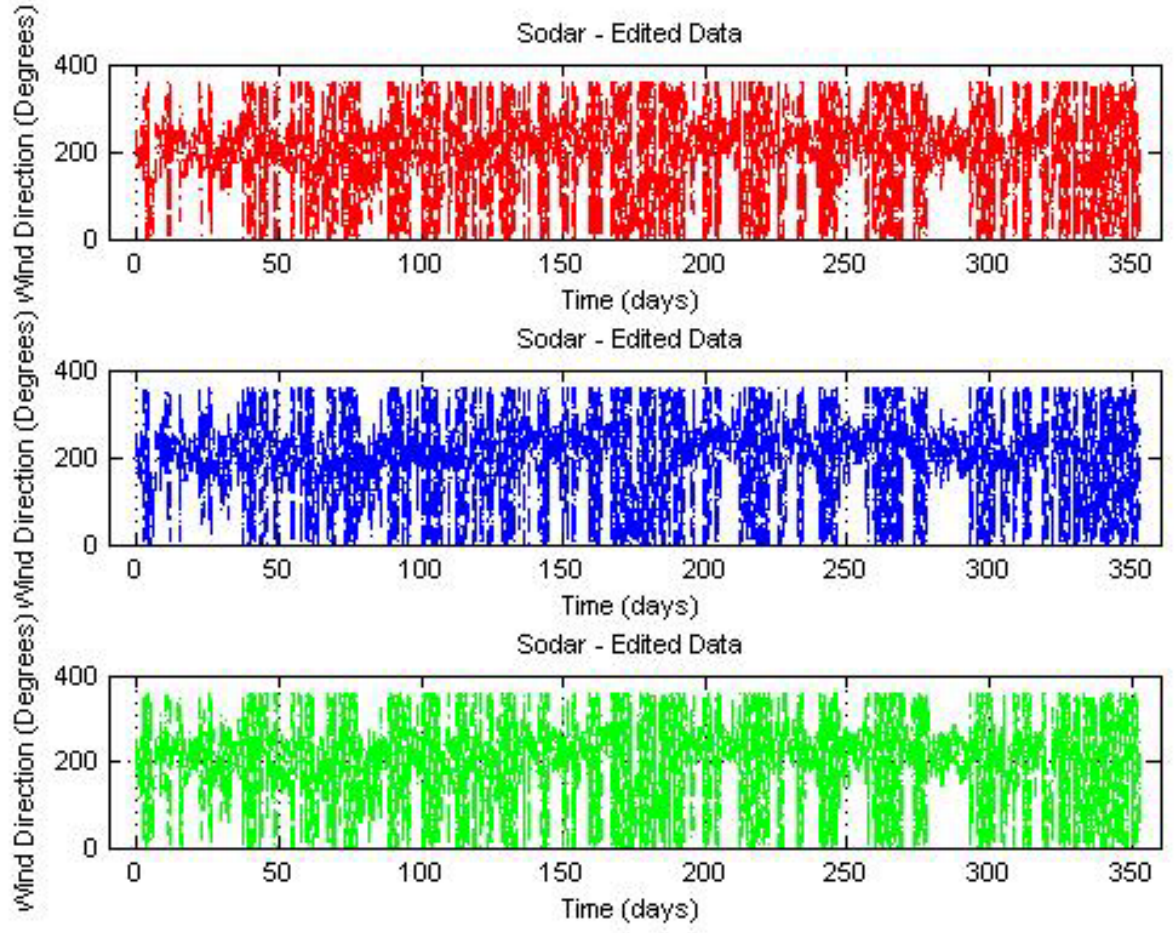

Figure 18. Same as Figure 17, but for sodar edited wind direction time series, same levels and period 


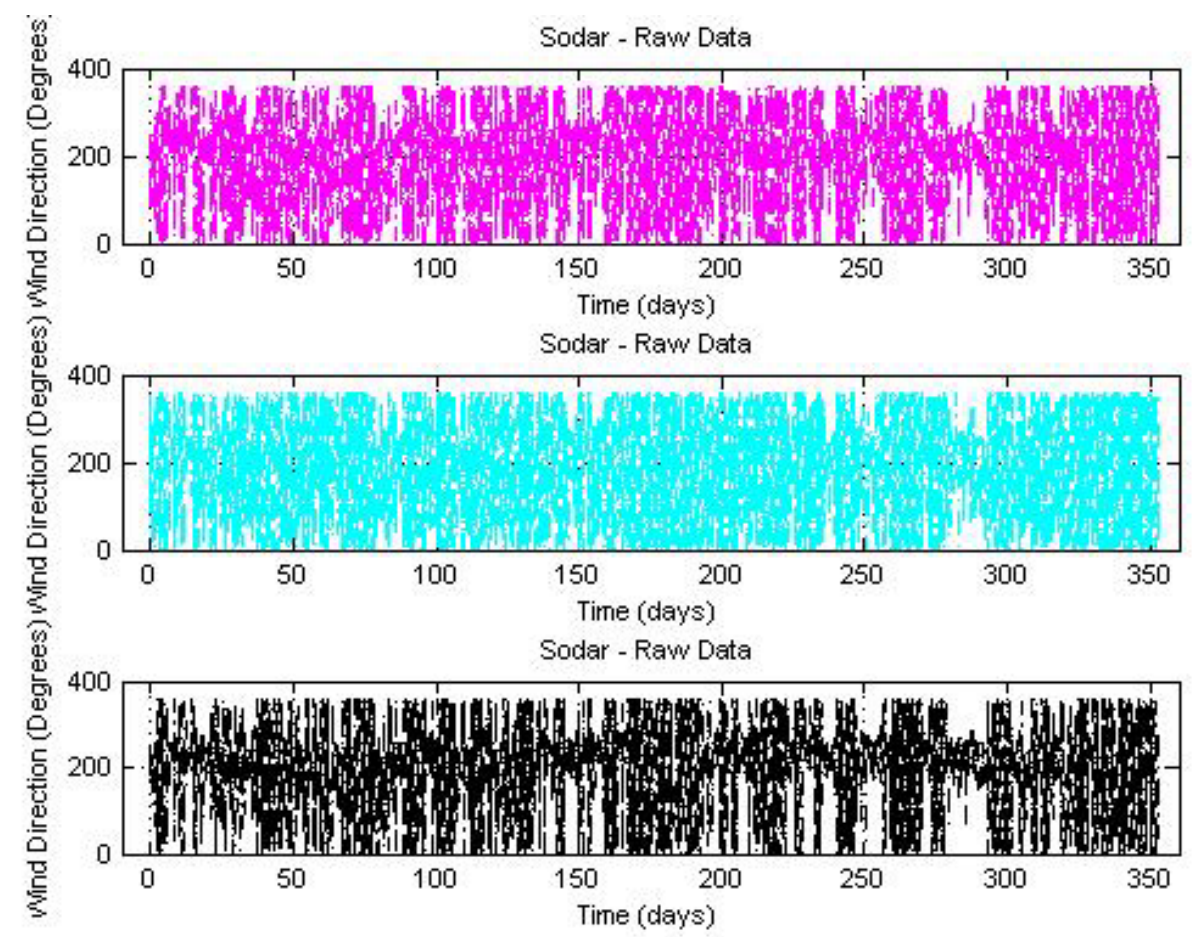

Figure 19. Sodar raw wind direction data at $80 \mathrm{~m}$ (purple), $100 \mathrm{~m}$ (cyan), and $120 \mathrm{~m}$ (black) Period: October 30, 2012-November 11, 2013

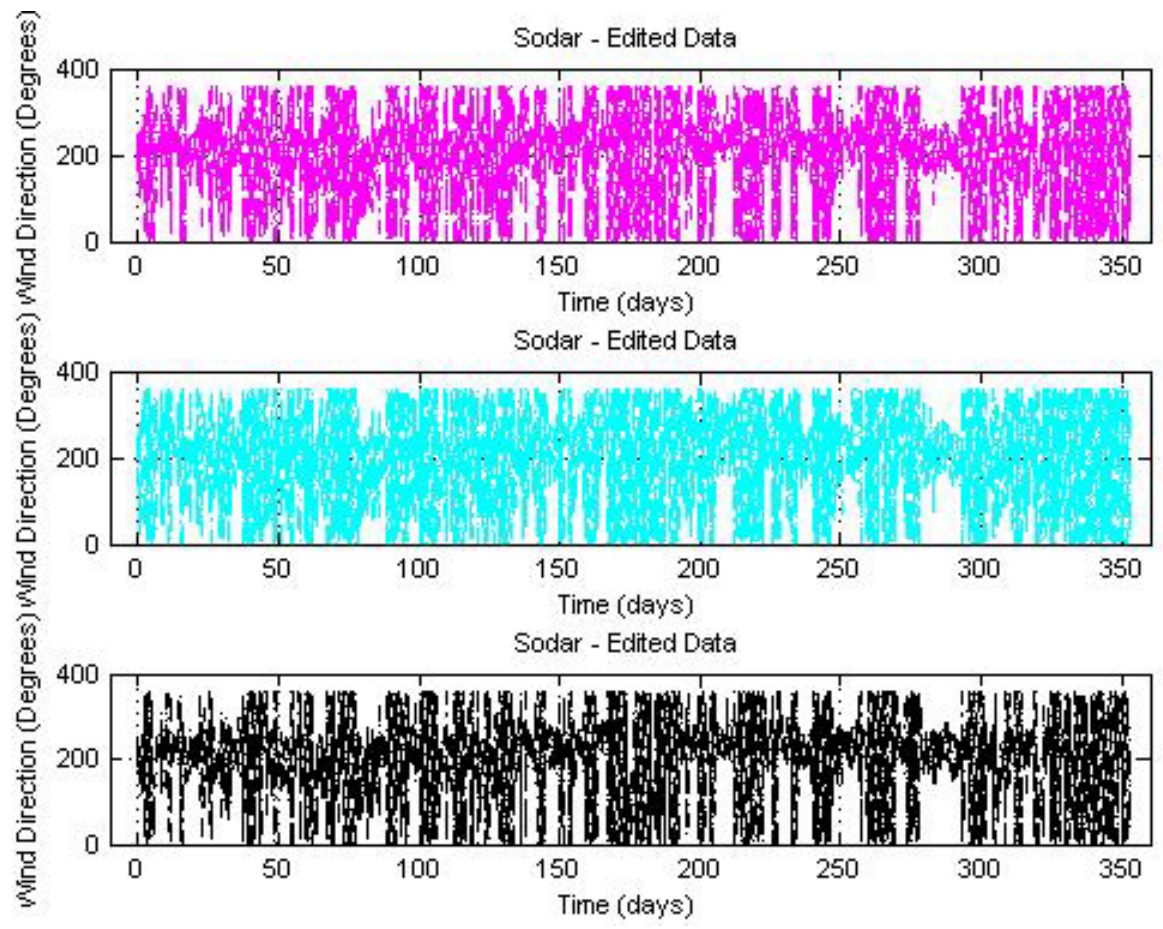

Figure 20. Same as Figure 19, but for sodar edited wind direction, same levels and period

\subsubsection{Sodar Data Versus Time of Day and Wind Speed Magnitude}

Figure 21 shows sodar data availability regarding the time of day and wind speed magnitude at $60 \mathrm{~m}$ height. 

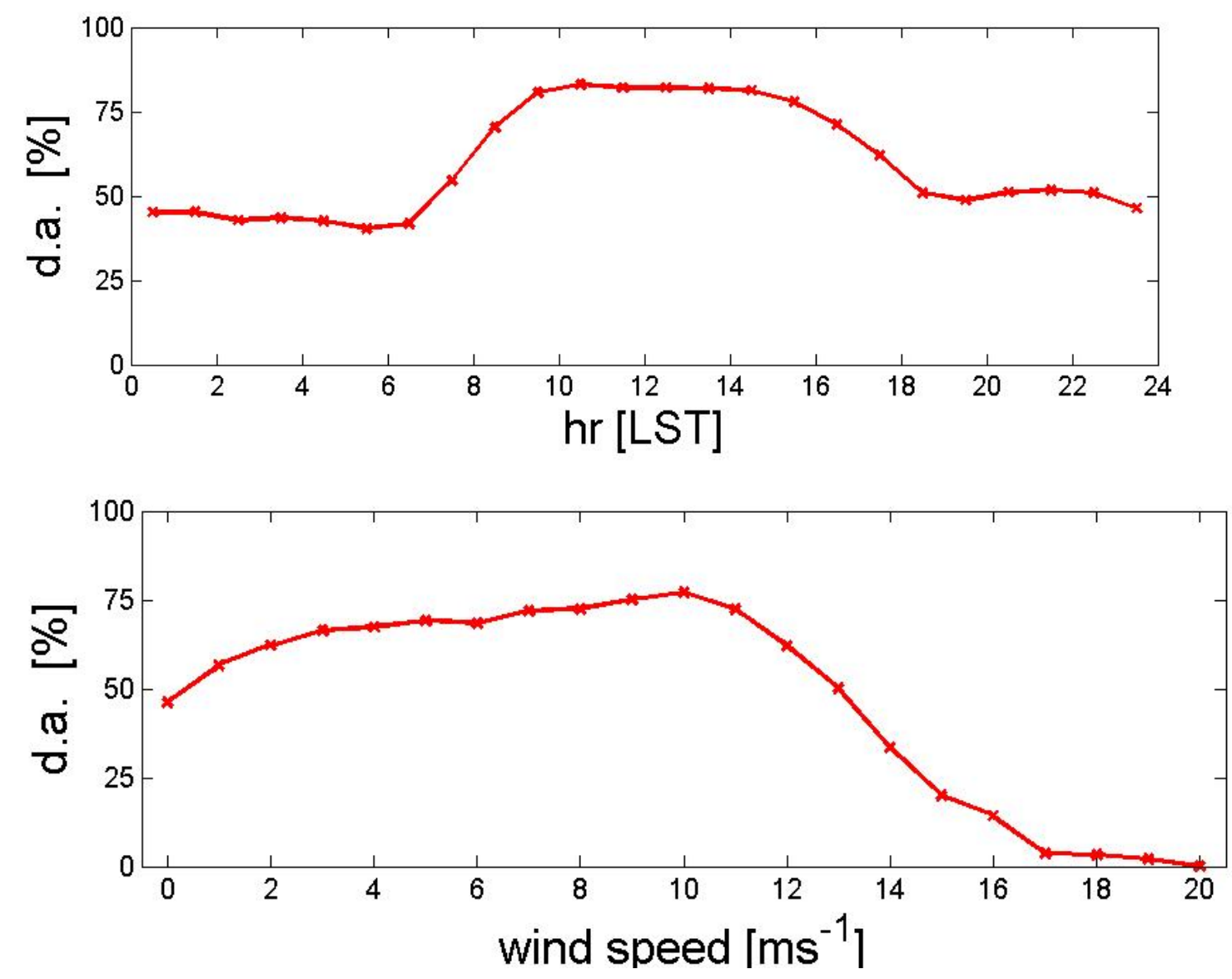

Figure 21. Percentage of data availability (d.a.: $100 \%$ means no data were excluded) from the Triton sodar (using the manufacturer-recommended QC minimum of $90 \%$ ) for the full duration of the deployment (October 31, 2012-November 1, 2013) binned as a function of time of day (top), and mean wind speed $\left(\mathrm{m} \mathrm{s}^{-1}\right)$ from the co-located sonic anemometer at $60 \mathrm{~m}$ (bottom)

Overall data recovery rates from the sodar (using the manufacturer-recommended QC minimum of $90 \%$ ) are low and biased with respect to mean wind speed from the sonic anemometer and time of day (Figure 21). According to Figure 21, the recovery rate is highest during winds up to $12 \mathrm{~m} / \mathrm{s}$ that occur during the daytime. One of the sodar's characteristics appears to be a rapid drop of the recovery rate for winds greater than $10 \mathrm{~m} \mathrm{~s}^{-1}$. This can have significant implications for the assessment of the wind power density.

\subsubsection{Comparison of Sodar Versus Cup Anemometer}

We performed a regression analysis of the sodar measurements at $60 \mathrm{~m}$ against the $60-\mathrm{m}$ cup anemometer on the co-located meteorological tower for various minimum QC values, an example of which is presented in Figure 22. Results for various minimum QC values are presented in Table 10. 

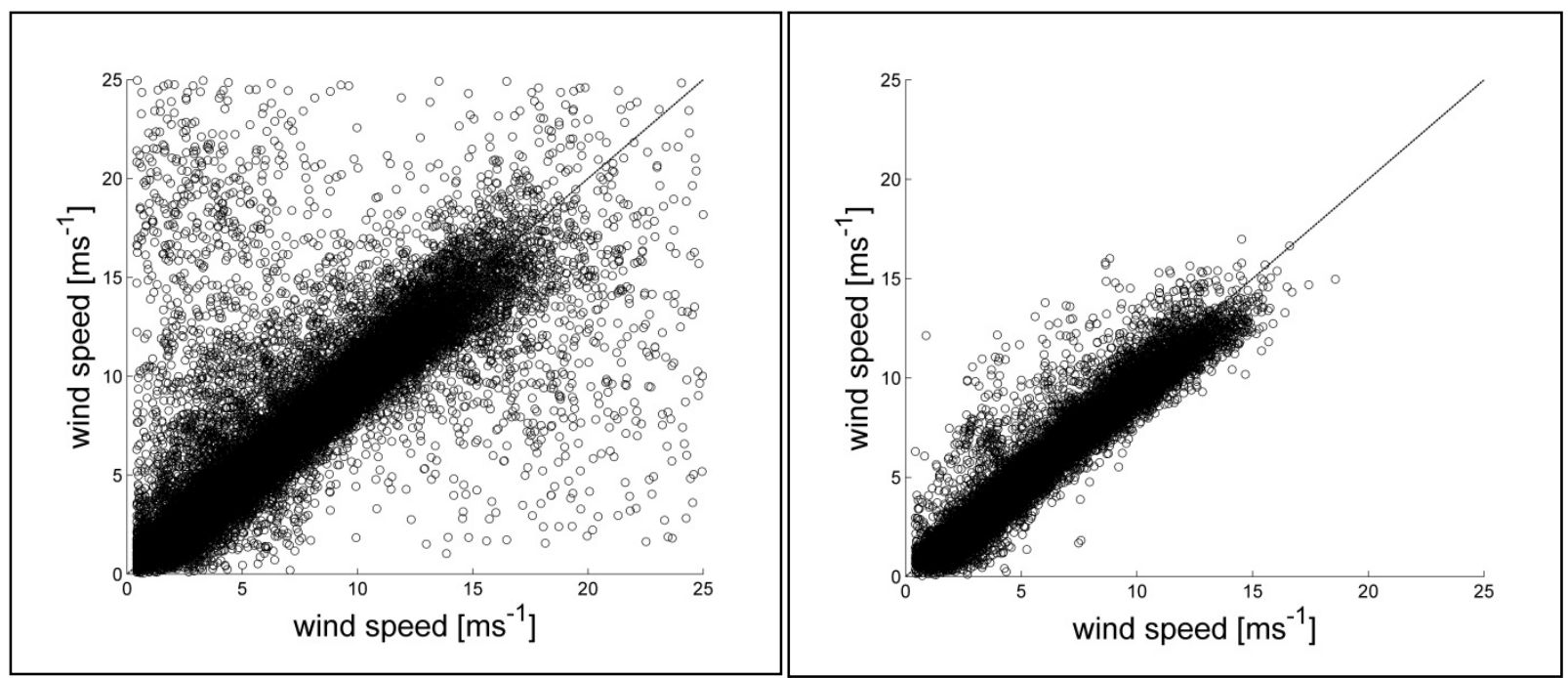

Figure 22. Scatter plots of cup (x-axis) versus sodar (y-axis) wind speed at $60 \mathrm{~m}$ (October 6, 2012November 1, 2013) at $60 \mathrm{~m}$ on tower WT1 for all sodar observations $(\mathrm{QC}=0$; slope $=0.82$; R2 = 0.63 ; number of observations $=42,540$ ) (left panel) and with QC > 95\% (slope $=0.93$; R2 = 0.91; number of observations $=18,032$ ) (right panel)

Table 10. Correlation Coefficient and Slope of Best-Fit Line Between Sodar and Cup Anemometer (October 6, 2012-November 1, 2013) at WT1 at 60 m Height for Various Filtering of Sodar Data Based on the Minimum QC Factor*

\begin{tabular}{cccc}
\hline $\begin{array}{c}\text { QC Factor } \\
(\mathbf{\%})\end{array}$ & Slope & $\mathbf{R}^{\mathbf{2}}$ & \# Observations \\
\hline 00 & 0.82 & 0.63 & 42540 \\
\hline 75 & 0.94 & 0.91 & 32002 \\
\hline 85 & 0.94 & 0.91 & 30455 \\
\hline 90 & 0.94 & 0.91 & 28522 \\
\hline 95 & 0.93 & 0.91 & 18032 \\
\hline 99 & 1.00 & 0.87 & 00483 \\
\hline
\end{tabular}

* All measurements with QC less than the value shown in the table are filtered out)

It is interesting to note that considering all observations the sodar overestimates wind speed during low wind speeds, but to some extent underestimates wind speeds during high winds (Figure 22; left panel). Although we chose the manufacturer-recommended value of QC $>90 \%$ in most of the analysis, it appears that even QC $>95 \%$ might be still too low for the wind power density calculations because of some sodar overestimation within the entire range (Figure 22; right panel).

Note that the correlation coefficient significantly increases from 0.63 for all data (irrespective of the QC factor) to 0.91 for data with a QC of $75 \%$ and then stays constant at that value till QC $=$ $99 \%$. The drop for the data with QC $=99 \%$ is possibly because it was a very small sample.

\subsubsection{Comparison of Cup Anemometer Measurements at 60 M-WT1 Versus WT2}

Figure 23 shows that both towers have very similar DI variation of the wind speed and the difference in topographic elevation results in almost uniform difference among the 
corresponding mean hourly values less than $1 \mathrm{~m} \mathrm{~s}^{-1}$. The difference is slightly larger in more stratified nocturnal flows and slightly smaller during daytime mixing. As expected, the greatest mean values are in the late afternoon hours during well-developed upslope flows.

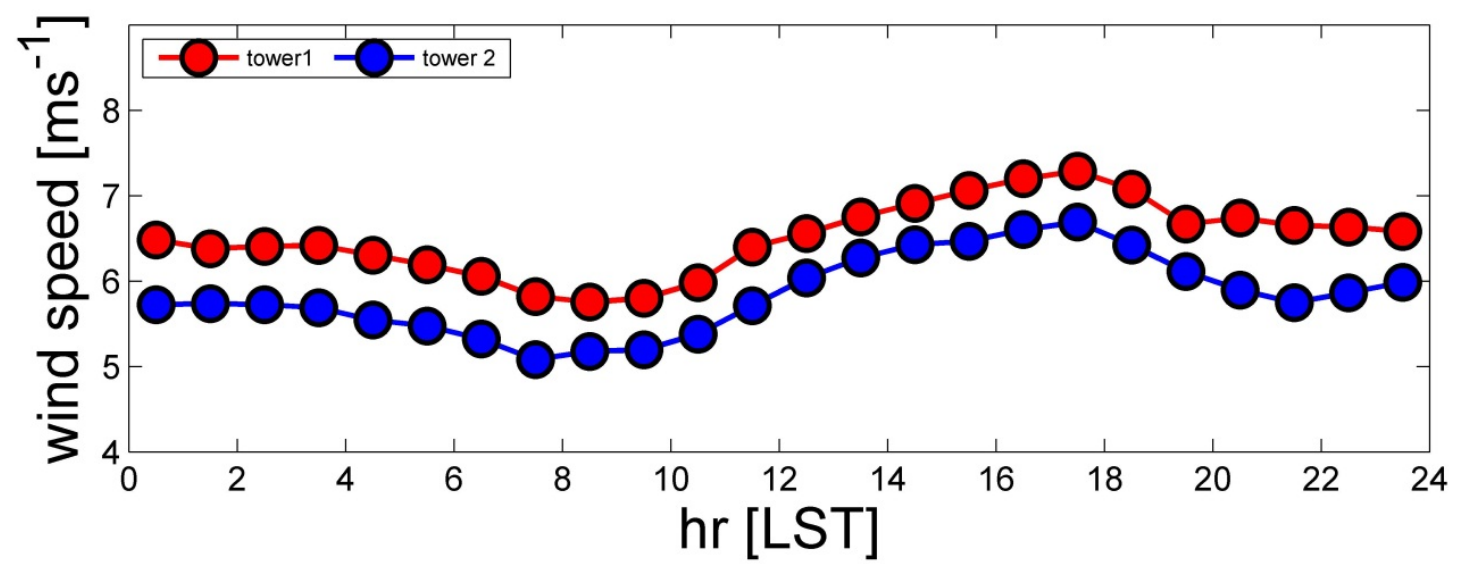

Figure 23. Mean wind speed versus time of day from the $60-\mathrm{m}$ cup anemometers at WT1 (red) and WT2 (blue) for the period November 1, 2012-June 1, 2013. Values are presented in such a way that the mean wind speed during any given hour is plotted at the center of that hour.

\subsubsection{Intercomparison Among Sodar, Cup Anemometers, and Sonics}

Figure 24 shows a comparison of wind speed measurements at $60 \mathrm{~m}$ among the sodar, cup anemometer, and sonic anemometer platforms.
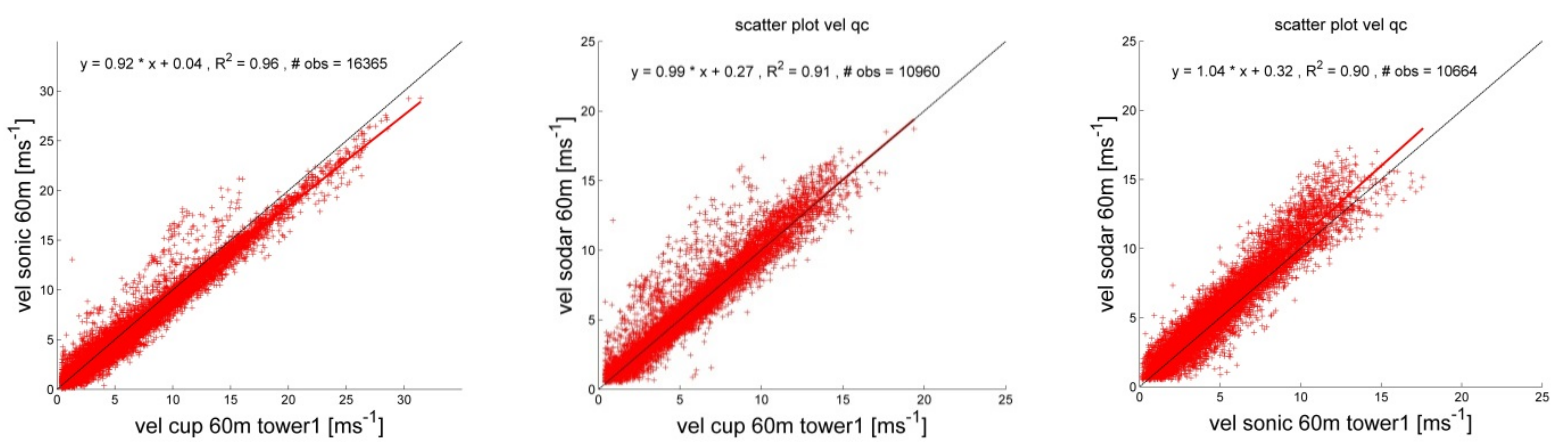

Figure 24. Scatter plot of wind speeds (October 6, 2012-March 14, 2013) at $60 \mathrm{~m}$ at WT1 for the sonic anemometer versus the cup anemometer (left), and filtered (QC minimum of $90 \%$ ) sodar velocity versus cup anemometer (middle) and versus sonic anemometer (right). The black line denotes a 1:1 correlation, and the best fit is denoted by the red line.

A comparison between sonic and cup anemometers shows the highest correlation. If we take the cup measurements as a reference, the sonic appears to overestimate wind speed for a lower range of speeds and underestimate the winds for a higher range of speeds. When applying the recommended $\mathrm{QC}=90 \%$, the correlation between the sodar and cup as well as sonic anemometers reaches 0.91 and 0.90 , respectively. Note that sodar shows some overestimation for almost the entire range. 


\subsubsection{Turbulence Intensity}

We also computed the turbulence intensity $(T I)$ :

$$
T I=\frac{\sigma_{u}}{\bar{U}_{10}}
$$

where $\sigma_{u}$ is the standard deviation of the wind speed over a 10 -minute interval, and $\bar{U}_{10}$ is the mean wind speed over the same interval. The highest values of the hourly average TI are found at wind speeds lower than $5.0 \mathrm{~m} \mathrm{~s}^{-1}$ (outside of the interest range concerning the wind turbine fatigue, 10 to $20 \mathrm{~m} \mathrm{~s}^{-1}$ ). The hourly averages of the TI are higher than 0.35 for the $10 \mathrm{~m} \mathrm{level,}$ whereas for levels above $20 \mathrm{~m}$ they are lower than 0.15 (see Figure 25). 


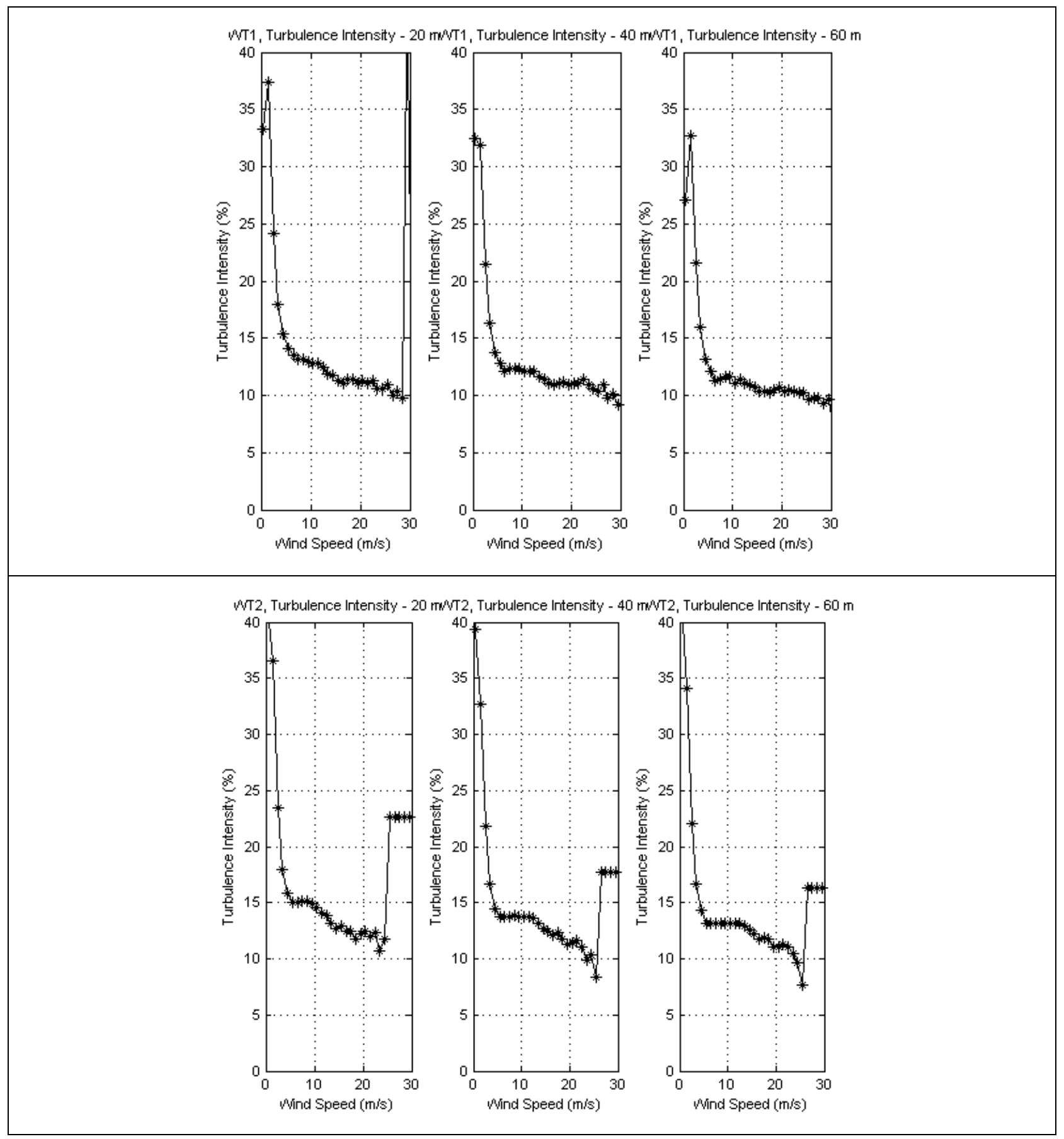

Figure 25. TI (\%) at WT1 (top) and WT2 (bottom panel) at 20 (left), 40 (middle), and $60 \mathrm{~m}$ (right column). Period for WT1: October 5, 2012-February 24, 2014 and for WT2: October 30, 2012November 11, 2013.

Note that high values of the TI are mainly, as expected, for low wind speeds when the wind direction is more variable with a large standard deviation. For wind speeds greater than about 5 $\mathrm{m} \mathrm{s}^{-1}$, the intensity is generally between $10 \%$ and $15 \%$. The intensity is somehow larger for WT2, which has lower speeds and is located in more complex terrain with surrounding ridges. For lower wind speeds, the intensity is greatest for the lowest level; however, for higher wind speeds the intensity is quite similar with height. 


\subsubsection{Calculation of the Weibull Distribution Parameters}

Parameters of the Weibull distribution for the WT1 cup anemometer data for seasonal and annual periods are presented in Table 11; for WT2 they are shown in Table 12. The Weibull probability distribution (equation 2) is the most frequently used technique to describe the distribution of wind speed (e.g., Stevens and Smulders 1979; Condrasen et al. 1984; Deaves and Lines 1997; and Seguro and Lambert 2000).

$$
f(v ; k ; c)=\left(\frac{k}{c}\right)\left(\frac{v}{c}\right)^{k-1} \exp \left[-\left(\frac{v}{c}\right)^{k}\right], v>0, k, c>0
$$

where $k$ and $c$ are the shape and scale parameters, respectively, and $v$ is the wind speed.

Essentially, the scale parameter $c$ indicates how "windy" a location under consideration is, whereas the shape parameter $k$ indicates how "peaked" the wind distribution is (i.e., if wind speeds are very close to a certain value, the distribution will have a high $k$ value and be very peaked). Once the Weibull distribution parameters are found, the cumulative frequencies or statistical descriptors can be computed (e.g., Basumatary et al. 2005; Monahan 2006). The Weibull distribution fails to describe the real situation when the wind speed is zero (calm). If there are no significant periods of calm in the data sets the Weibull distribution can be applied without any extra caution, as is the case with our data (10\% or less calm conditions).

There are several estimators of Weibull parameters (Basumatary et al. 2005) such as the Moment, Maximum Likelihood, Least-Square, and Percentile Estimators Methods. These estimators are unbiased, although some, such as the Method of Moments, may have large variances (Monahan 2006), so there is no reason to prefer any of them. We select three estimators of the Weibull parameters: the standard Least-Square, Maximum Likelihood, and a variation of the Maximum Likelihood methods (Christofferson and Gillete 1987). The shape and scale parameters are given by the averages of the estimates found by these methods. Table 11 through Table 13 give the annual and seasonal values of the shape $(k)$ and scale $(c)$ parameters of the wind speed distribution for both towers computed for the 2012-2014 composite datasets and for the 20-m, 40-m, and 60-m levels. As with the mean wind speed, the scale parameter values are higher during the peak season (spring) than for the rest of the year for both towers and all levels of observations.

Table 11. Coefficients $k$ and $c$ of the Weibull Distributions on Annual and Seasonal Scales From the Entire WT1 Cup Anemometer Datasets at All Levels (October 5, 2012-February 24, 2014). Available Wind Power Density Was Calculated by Using the Weibull Parameters.

a) Multiannual Values

\begin{tabular}{ccccc}
\hline $\begin{array}{c}\text { Measurement } \\
\text { Level }\end{array}$ & $\boldsymbol{k}$ & $\boldsymbol{c}\left(\mathbf{m s}^{-1}\right)$ & $\begin{array}{c}\text { Mean Wind } \\
\text { Speed }\left(\mathbf{m s}^{-1}\right)\end{array}$ & $\begin{array}{c}\text { Available Power } \\
\text { Density }\left(\mathbf{W m}^{-2}\right)\end{array}$ \\
\hline $20 \mathrm{~m}$ & 1.399 & 5.548 & 5.057 & 195.8 \\
\hline $40 \mathrm{~m}$ & 1.512 & 5.913 & 5.333 & 203.8 \\
\hline $60 \mathrm{~m}$ & 1.561 & 6.182 & 5.556 & 220.0 \\
\hline
\end{tabular}

Air Density $=0.986 \mathrm{kgm}^{-3}$ 
b) Winter Values

\begin{tabular}{ccccc}
\hline $\begin{array}{c}\text { Measurement } \\
\text { Level }\end{array}$ & $\boldsymbol{k}$ & $\boldsymbol{c}\left(\mathbf{m s}^{-1}\right)$ & $\begin{array}{c}\text { Mean Wind } \\
\text { Speed }\left(\mathbf{m s}^{-1}\right)\end{array}$ & $\begin{array}{c}\text { Available Power } \\
\text { Density }\left(\mathbf{W m}^{-2}\right)\end{array}$ \\
\hline $20 \mathrm{~m}$ & 1.174 & 5.053 & 4.782 & 171.4 \\
\hline $40 \mathrm{~m}$ & 1.253 & 5.498 & 5.117 & 173.9 \\
\hline $60 \mathrm{~m}$ & 1.125 & 5.362 & 5.137 & 201.4 \\
\hline
\end{tabular}

Air Density $=0.994 \mathrm{kgm}^{-3}$

c) Spring Values

\begin{tabular}{ccccc}
\hline $\begin{array}{c}\text { Measurement } \\
\text { Level }\end{array}$ & $\boldsymbol{k}$ & $\boldsymbol{c}\left(\mathbf{m s}^{-1}\right)$ & $\begin{array}{c}\text { Mean Wind } \\
\text { Speed }\left(\mathbf{m s}^{-1}\right)\end{array}$ & $\begin{array}{c}\text { Available Power } \\
\text { Density }\left(\mathbf{W m}^{-2}\right)\end{array}$ \\
\hline $20 \mathrm{~m}$ & 1.625 & 5.815 & 5.207 & 228.3 \\
\hline $40 \mathrm{~m}$ & 1.771 & 6.093 & 5.423 & 246.0 \\
\hline $60 \mathrm{~m}$ & 1.448 & 6.172 & 5.597 & 309.4 \\
\hline
\end{tabular}

Air Density $=0.971 \mathrm{kgm}^{-3}$

d) Summer Values

\begin{tabular}{ccccc}
\hline $\begin{array}{c}\text { Measurement } \\
\text { Level }\end{array}$ & $\boldsymbol{k}$ & $\boldsymbol{c}\left(\mathbf{m s}^{-1}\right)$ & $\begin{array}{c}\text { Mean Wind } \\
\text { Speed }\left(\mathbf{m s}^{-1}\right)\end{array}$ & $\begin{array}{c}\text { Available Power } \\
\text { Density }\left(\mathbf{W m} \mathbf{m}^{-2}\right)\end{array}$ \\
\hline $20 \mathrm{~m}$ & 1.758 & 5.319 & 4.736 & 116.9 \\
\hline $40 \mathrm{~m}$ & 2.131 & 5.614 & 4.972 & 118.5 \\
\hline $60 \mathrm{~m}$ & 1.704 & 6.012 & 5.364 & 176.3 \\
\hline
\end{tabular}

Air Density $=0.934 \mathrm{kgm}^{-3}$

e) Fall Values

\begin{tabular}{ccccc}
\hline $\begin{array}{c}\text { Measurement } \\
\text { Level }\end{array}$ & $\boldsymbol{k}$ & $\boldsymbol{c}\left(\mathbf{m s}^{-1}\right)$ & $\begin{array}{c}\text { Mean Wind } \\
\text { Speed }\left(\mathbf{m s}^{-1}\right)\end{array}$ & $\begin{array}{c}\text { Available Power } \\
\text { Density }\left(\mathbf{W m} \mathbf{~}^{-2}\right)\end{array}$ \\
\hline $20 \mathrm{~m}$ & 1.443 & 5.894 & 5.347 & 220.4 \\
\hline $40 \mathrm{~m}$ & 1.549 & 6.258 & 5.629 & 231.3 \\
\hline $60 \mathrm{~m}$ & 1.334. & 6.242 & 5.736 & 309.7 \\
\hline
\end{tabular}

Air Density $=0.934 \mathrm{kgm}^{-3}$ 
Table 12. Coefficients $k$ and $c$ of the Weibull Distributions on Annual and Seasonal Scales From the Entire WT2 Cup Anemometer Datasets at All Levels (October 22, 2012-February 24, 2014)

a) Multiannual Values

\begin{tabular}{ccccc}
\hline $\begin{array}{c}\text { Measurement } \\
\text { Level }\end{array}$ & $\boldsymbol{k}$ & $\boldsymbol{c}\left(\mathbf{m s}^{-1}\right)$ & $\begin{array}{c}\text { Mean Wind } \\
\text { Speed }\left(\mathbf{m s}^{-1}\right)\end{array}$ & $\begin{array}{c}\text { Available Power } \\
\text { Density }\left(\mathbf{W m} \mathbf{m}^{-2}\right)\end{array}$ \\
\hline $20 \mathrm{~m}$ & 1.589 & 5.019 & 4.503 & 114.4 \\
\hline $40 \mathrm{~m}$ & 1.681 & 5.295 & 4.728 & 122.9 \\
\hline $60 \mathrm{~m}$ & 1.642 & 5.347 & 4.783 & 131.1 \\
\hline
\end{tabular}

Air Density $=0.994 \mathrm{kgm}^{-3}$

b) Winter Values

\begin{tabular}{ccccc}
\hline $\begin{array}{c}\text { Measurement } \\
\text { Level }\end{array}$ & $\boldsymbol{k}$ & $\boldsymbol{c}\left(\mathbf{m s}^{-1}\right)$ & $\begin{array}{c}\text { Mean Wind } \\
\text { Speed }\left(\mathbf{m s}^{-1}\right)\end{array}$ & $\begin{array}{c}\text { Available Power } \\
\text { Density }\left(\mathbf{W m}^{-2}\right)\end{array}$ \\
\hline $20 \mathrm{~m}$ & 1.509 & 4.779 & 4.311 & 108.0 \\
\hline $40 \mathrm{~m}$ & 1.545 & 5.034 & 4.529 & 121.0 \\
\hline $60 \mathrm{~m}$ & 1.224 & 5.347 & 4.360 & 159.0 \\
\hline
\end{tabular}

Air Density $=1.014 \mathrm{kgm}^{-3}$

c) Spring Values

\begin{tabular}{ccccc}
\hline $\begin{array}{c}\text { Measurement } \\
\text { Level }\end{array}$ & $\boldsymbol{k}$ & $\boldsymbol{c}\left(\mathbf{m s}^{-1}\right)$ & $\begin{array}{c}\text { Mean Wind } \\
\text { Speed }\left(\mathbf{m s}^{-1}\right)\end{array}$ & $\begin{array}{c}\text { Available Power } \\
\text { Density }\left(\mathbf{W m}^{-2}\right)\end{array}$ \\
\hline $20 \mathrm{~m}$ & 1.754 & 5.565 & 4.955 & 134.2 \\
\hline $40 \mathrm{~m}$ & 1.868 & 5.777 & 5.129 & 178.5 \\
\hline $60 \mathrm{~m}$ & 1.470 & 5.752 & 5.206 & 197.6 \\
\hline
\end{tabular}

Air Density $=0.988 \mathrm{kgm}^{-3}$

d) Summer Values

\begin{tabular}{ccccc}
\hline $\begin{array}{c}\text { Measurement } \\
\text { Level }\end{array}$ & $\boldsymbol{k}$ & $\boldsymbol{c}\left(\mathbf{m s}^{-1}\right)$ & $\begin{array}{c}\text { Mean Wind } \\
\text { Speed }\left(\mathbf{m s}^{-1}\right)\end{array}$ & $\begin{array}{c}\text { Available Power } \\
\text { Density }\left(\mathbf{W m} \mathbf{m}^{-2}\right)\end{array}$ \\
\hline $20 \mathrm{~m}$ & 1.814 & 4.846 & 4.308 & 85.0 \\
\hline $40 \mathrm{~m}$ & 2.046 & 5.045 & 4.469 & 94.0. \\
\hline $60 \mathrm{~m}$ & 1.559 & 4.774 & 4.291 & 101.6 \\
\hline
\end{tabular}

Air Density $=0.949 \mathrm{kgm}^{-3}$ 
e) Fall Values

\begin{tabular}{ccccc}
\hline $\begin{array}{c}\text { Measurement } \\
\text { Level }\end{array}$ & $\boldsymbol{k}$ & $\boldsymbol{c}\left(\mathbf{m s}^{-1}\right)$ & $\begin{array}{c}\text { Mean Wind } \\
\text { Speed }\left(\mathbf{m s}^{-1}\right)\end{array}$ & $\begin{array}{c}\text { Available Power } \\
\text { Density }\left(\mathbf{W m} \mathbf{m}^{-2}\right)\end{array}$ \\
\hline $20 \mathrm{~m}$ & 1.544 & 4.936 & 4.441 & 114.2 \\
\hline $40 \mathrm{~m}$ & 1.679 & 5.288 & 4.722 & 122.6 \\
\hline $60 \mathrm{~m}$ & 1.325 & 5.047 & 4.944 & 166.3 \\
\hline
\end{tabular}

Air Density $=0.986 \mathrm{kgm}^{-3}$

The parameters of the Weibull distributions were also calculated for the sodar data (Table 13). 
Table 13. Coefficients $k$ and $c$ of the Weibull Distributions on Annual and Seasonal Scales From the Entire Sodar Dataset At All Levels (October 30, 2012-November 11, 2013)

Multiannual Values

\begin{tabular}{ccccc}
\hline $\begin{array}{c}\text { Measurement } \\
\text { Level }\end{array}$ & $\boldsymbol{k}$ & $\boldsymbol{c}\left(\mathbf{m s}^{-1}\right)$ & $\begin{array}{c}\text { Mean Wind } \\
\text { Speed }\left(\mathbf{m s}^{-1}\right)\end{array}$ & $\begin{array}{c}\text { Available Power } \\
\left.\text { Density }(\mathbf{W m})^{-2}\right)\end{array}$ \\
\hline $40 \mathrm{~m}$ & 1.770 & 6.061 & 5.395 & 171.2 \\
\hline $50 \mathrm{~m}$ & 1.734 & 6.096 & 5.432 & 179.2 \\
\hline $60 \mathrm{~m}$ & 1.701 & 6.284 & 5.607 & 201.9 \\
\hline $80 \mathrm{~m}$ & 1.568 & 7.274 & 6.534 & 355.9 \\
\hline $100 \mathrm{~m}$ & 1.429 & 8.046 & 7.310 & 571.9 \\
\hline $120 \mathrm{~m}$ & 1.319 & 9.060 & 8.344 & 971.7 \\
\hline $140 \mathrm{~m}$ & 1.273 & 10.859 & 10.073 & $1,822.2$ \\
\hline $160 \mathrm{~m}$ & 1.270 & 12.161 & 11.287 & $2,576.2$ \\
\hline $180 \mathrm{~m}$ & 1.311 & 13.792 & 12.716 & $3,475.5$ \\
\hline
\end{tabular}

a) Winter Values

\begin{tabular}{ccccc}
\hline $\begin{array}{c}\text { Measurement } \\
\text { Level }\end{array}$ & $\boldsymbol{k}$ & $\boldsymbol{c}\left(\mathbf{m s}^{-1}\right)$ & $\begin{array}{c}\text { Mean Wind } \\
\text { Speed }\left(\mathbf{m s}^{-1}\right)\end{array}$ & $\begin{array}{c}\text { Available Power } \\
\text { Density }\left(\mathbf{W m}^{-2}\right)\end{array}$ \\
\hline $40 \mathrm{~m}$ & 1.465 & 6.116 & 5.538 & 239.1 \\
\hline $50 \mathrm{~m}$ & 1.444 & 6.049 & 5.487 & 237.9 \\
\hline $60 \mathrm{~m}$ & 1.449 & 6.075 & 5.509 & 239.7 \\
\hline $80 \mathrm{~m}$ & 1.428 & 6.500 & 5.907 & 301.9 \\
\hline $100 \mathrm{~m}$ & 1.343 & 7.012 & 6.436 & 432.1 \\
\hline $120 \mathrm{~m}$ & 1.261 & 7.940 & 7.381 & 730.2 \\
\hline $140 \mathrm{~m}$ & 1.216 & 9.605 & 9.005 & $1,420.4$ \\
\hline $160 \mathrm{~m}$ & 1.194 & 11.124 & 10.478 & $2,320.5$ \\
\hline $180 \mathrm{~m}$ & 1.222 & 13.053 & 12.223 & $3,519.5$ \\
\hline
\end{tabular}


b) Spring Values

\begin{tabular}{ccccc}
\hline $\begin{array}{c}\text { Measurement } \\
\text { Level }\end{array}$ & $\boldsymbol{k}$ & $\boldsymbol{c}\left(\mathbf{m s}^{-1}\right)$ & $\begin{array}{c}\text { Mean Wind } \\
\text { Speed }\left(\mathbf{m s}^{-1}\right)\end{array}$ & $\begin{array}{c}\text { Available Power } \\
\text { Density }\left(\mathbf{W m}^{-2}\right)\end{array}$ \\
\hline $40 \mathrm{~m}$ & 1.899 & 5.819 & 5.163 & 138.7 \\
\hline $50 \mathrm{~m}$ & 1.835 & 5.895 & 5.238 & 150.4 \\
\hline $60 \mathrm{~m}$ & 1.813 & 6.054 & 5.382 & 165.3 \\
\hline $80 \mathrm{~m}$ & 1.620 & 7.120 & 6.377 & 316.4 \\
\hline $100 \mathrm{~m}$ & 1.432 & 8.135 & 7.389 & 588.7 \\
\hline $120 \mathrm{~m}$ & 1.308 & 9.284 & 8.565 & $1,967.3$ \\
\hline $140 \mathrm{~m}$ & 1.270 & 11.310 & 10.497 & $2,071.6$ \\
\hline $160 \mathrm{~m}$ & 1.271 & 12.656 & 11.744 & $2,896.4$ \\
\hline $180 \mathrm{~m}$ & 1.320 & 14.628 & 13.137 & $3,785.9$ \\
\hline & & & &
\end{tabular}

c) Summer Values

\begin{tabular}{ccccc}
\hline $\begin{array}{c}\text { Measurement } \\
\text { Level }\end{array}$ & $\boldsymbol{k}$ & $\boldsymbol{c}\left(\mathbf{m s}^{-1}\right)$ & $\begin{array}{c}\text { Mean Wind } \\
\text { Speed }\left(\mathbf{m s}^{-1}\right)\end{array}$ & $\begin{array}{c}\text { Available Power } \\
\text { Density }\left(\mathbf{W m}^{-2}\right)\end{array}$ \\
\hline $40 \mathrm{~m}$ & 1.732 & 5.768 & 5.140 & 152.0 \\
\hline $50 \mathrm{~m}$ & 1.700 & 5.793 & 5.168 & 158.2 \\
\hline $60 \mathrm{~m}$ & 1.681 & 5.931 & 5.296 & 172.7 \\
\hline $80 \mathrm{~m}$ & 1.545 & 6.632 & 5.967 & 276.7 \\
\hline $100 \mathrm{~m}$ & 1.412 & 6.981 & 6.355 & 383.2 \\
\hline $120 \mathrm{~m}$ & 1.260 & 7.808 & 7.259 & 695.0 \\
\hline $140 \mathrm{~m}$ & 1.156 & 9.523 & 9.048 & $1,594.3$ \\
\hline $160 \mathrm{~m}$ & 1.146 & 10.625 & 10.121 & $2,272.5$ \\
\hline $180 \mathrm{~m}$ & 1.172 & 12.443 & 11.778 & $3,419.3$ \\
\hline
\end{tabular}


d) Fall Values

\begin{tabular}{ccccc}
\hline $\begin{array}{c}\text { Measurement } \\
\text { Level }\end{array}$ & $\boldsymbol{k}$ & $\boldsymbol{c}\left(\mathbf{m s}^{-1}\right)$ & $\begin{array}{c}\text { Mean Wind } \\
\text { Speed }\left(\mathbf{m s}^{-1}\right)\end{array}$ & $\begin{array}{c}\text { Available Power } \\
\text { Density }\left(\mathbf{W m}^{-2}\right)\end{array}$ \\
\hline $40 \mathrm{~m}$ & 1.684 & 6.354 & 5.673 & 211.7 \\
\hline $50 \mathrm{~m}$ & 1.627 & 6.378 & 5.710 & 225.7 \\
\hline $60 \mathrm{~m}$ & 1.570 & 6.704 & 6.022 & 278.1 \\
\hline $80 \mathrm{~m}$ & 1.446 & 8.090 & 7.338 & 568.1 \\
\hline $100 \mathrm{~m}$ & 1.331 & 8.915 & 8.196 & 906.9 \\
\hline $120 \mathrm{~m}$ & 1.251 & 9.912 & 9.230 & $1,447.3$ \\
\hline $140 \mathrm{~m}$ & 1.241 & 11.666 & 10.883 & $2,410.3$ \\
\hline $160 \mathrm{~m}$ & 1.247 & 13.068 & 12.177 & $3,343.9$ \\
\hline $180 \mathrm{~m}$ & 1.290 & 14.794 & 13.685 & $4,461.2$ \\
\hline
\end{tabular}

The $k$ coefficient for the sodar drops with height more uniformly than in the case of the cup anemometer, while the $c$ coefficient increases with height (wind speed generally increases with height). Winter season is characterized by low wind speeds and by the lowest $k$ and highest $c$ coefficients. An opposite effect is for high wind spring cases - the $k$ coefficient is the largest and the $c$ coefficient is the smallest. Consequently, there are seasonal effects in the $k$ and $c$ Weibull parameters.

\subsubsection{Wind Speed Diurnal Variability}

For a statistical analysis of wind data, we computed auto-correlation and cross-correlation functions of the wind speed and wind direction (with the longest lag of 28 days), for all towers and for all levels of measurements. Using the relationship in Equation (3), where the $y$ is replaced by $x$, the auto-correlation coefficients $\mathrm{R}_{\mathrm{xy}}(\tau)$ can be computed.

$$
R_{x y}(\tau)=\left\{\begin{array}{l}
\sum_{k=0}^{N-\tau-1} \frac{x_{k+\tau} y_{k}}{\sigma_{x} \sigma_{y}} \tau>0 \\
R_{x y}(\tau), \quad \tau<0
\end{array}\right.
$$

Figures 26 and 27 show the auto-correlation functions of the wind speed, at $20 \mathrm{~m}, 40 \mathrm{~m}$, and 60 $\mathrm{m}$ for both towers, respectively, while Figures 28 and 29 show the auto-correlations of wind directions. Figure 30 shows the autocorrelations sodar wind speeds for $40 \mathrm{~m}, 60 \mathrm{~m} 80 \mathrm{~m}$ and 100 $\mathrm{m}$ measurement levels. All these functions are coincidental and show similar periodicity. A similar pattern in the auto-correlation functions was found for the sodar, even for the shorter dataset. Regular oscillations occur, indicating that a quite well-defined periodicity characterizes the wind speed in western Nevada. A very slow decrease in the amplitude of the oscillation as the lag time $\tau$ increases indicates that the wind speed is not strictly periodic but is randomly modulated in frequency and phase. The maintained oscillatory character of these functions indicates that the dominant frequencies associated with the wind speeds and directions are roughly coincidental. 


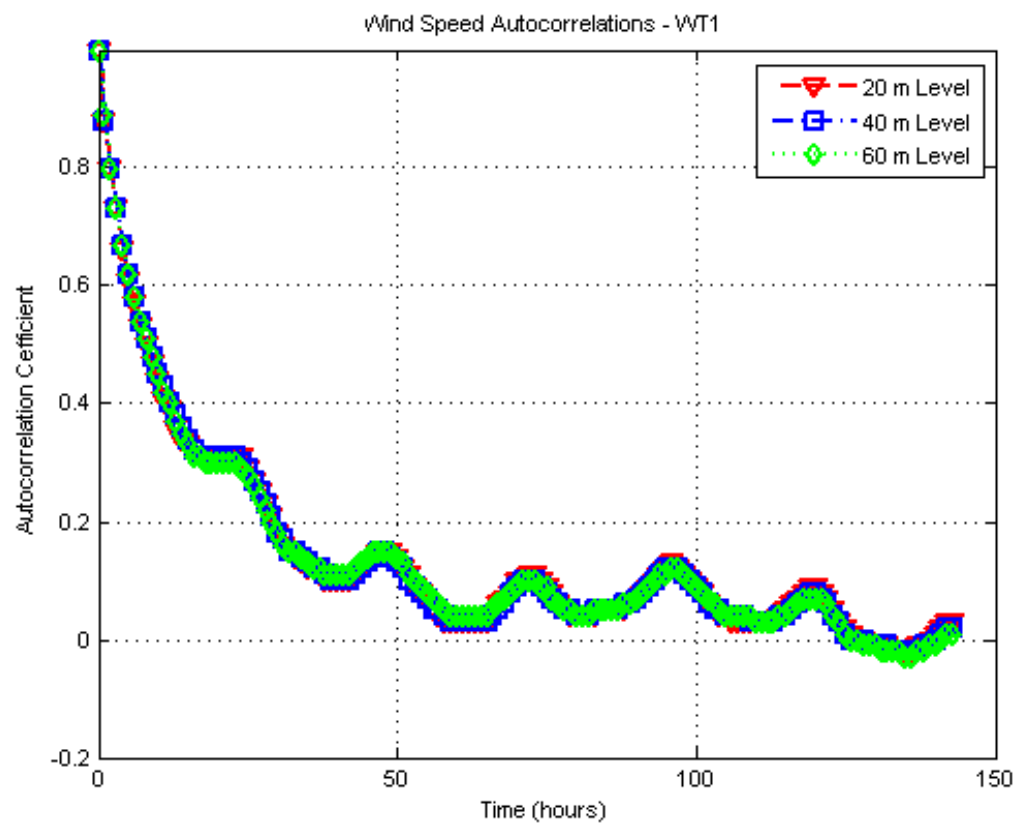

Figure 26. Autocorrelation functions for 10-min wind speed at all levels $(20,40$, and $60 \mathrm{~m})$ for WT1; the 2012-2014 composite dataset

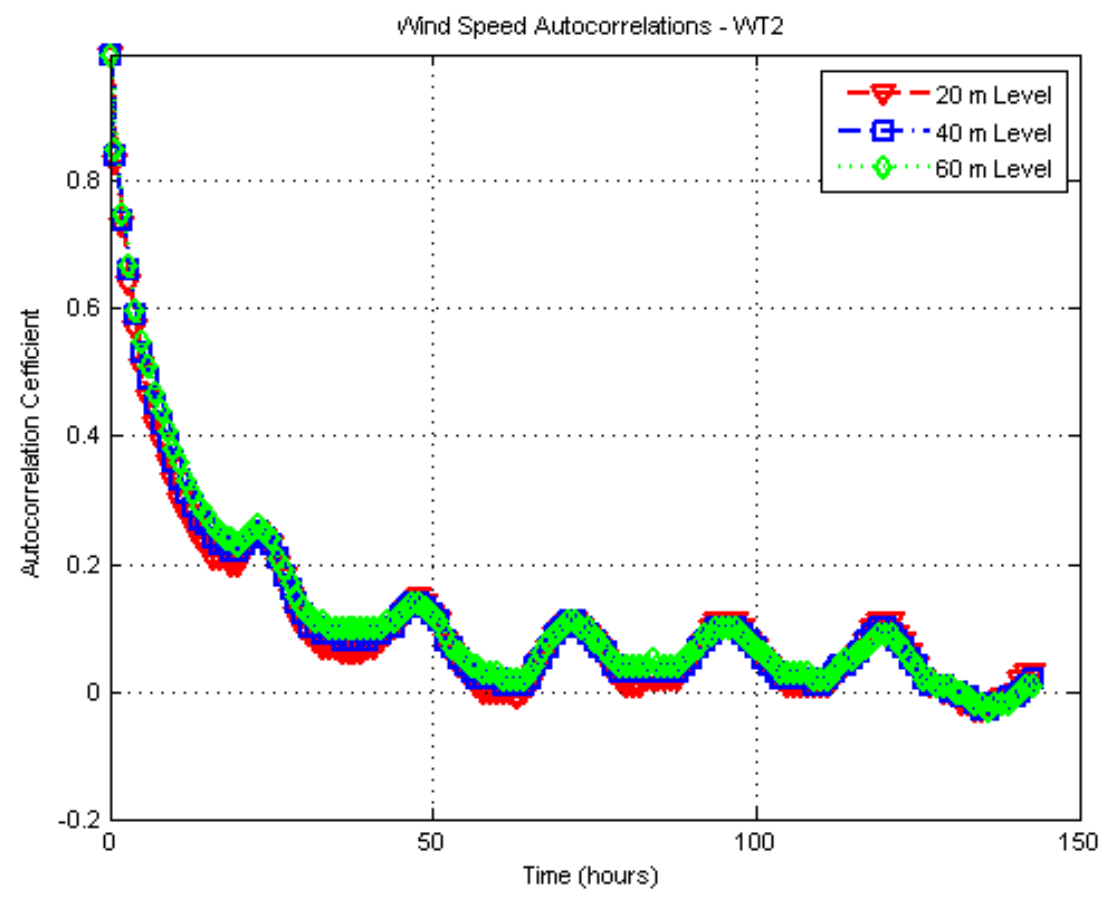

Figure 27. Same as Figure 26, but for WT2 


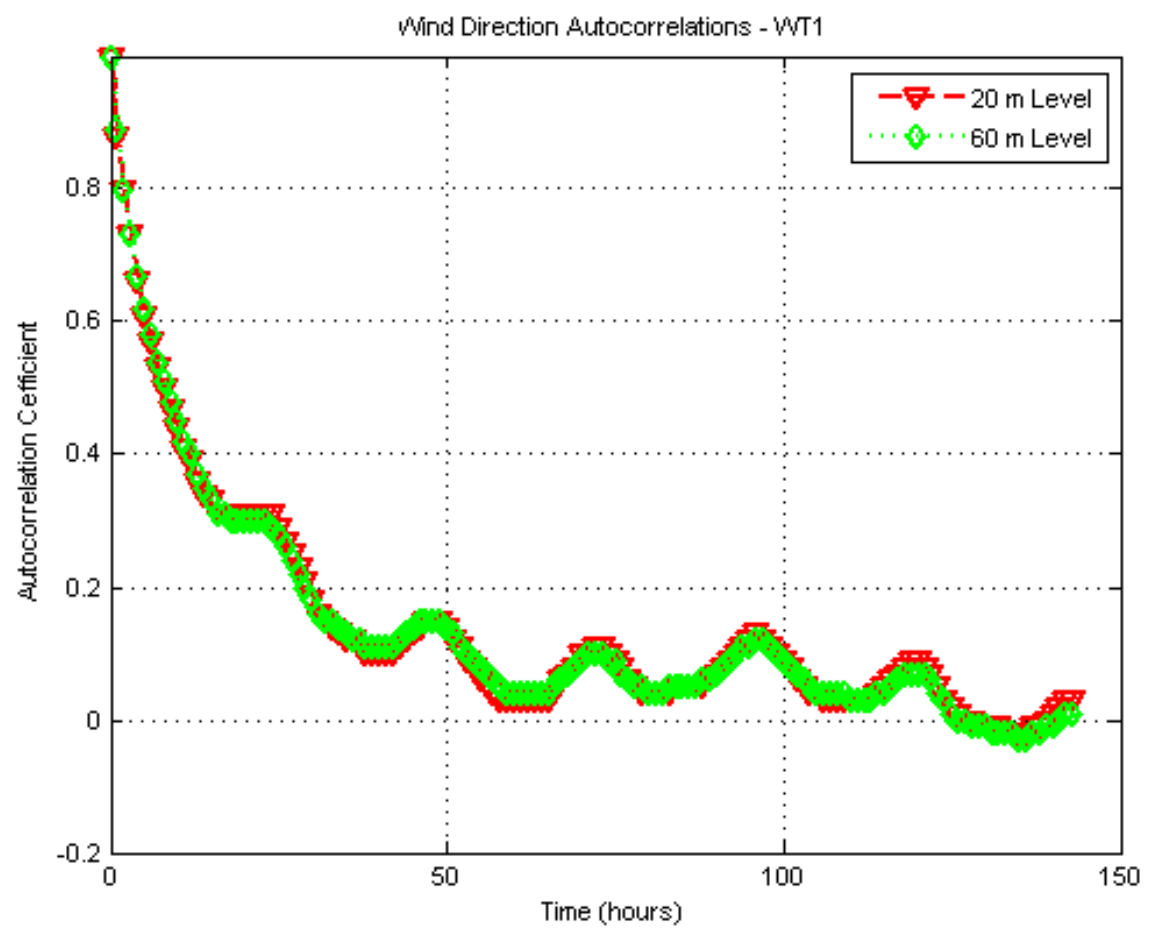

Figure 28. Autocorrelation functions for 10-min wind direction at 20 and $60 \mathrm{~m}$ levels for WT1; the 2012-2014 composite dataset

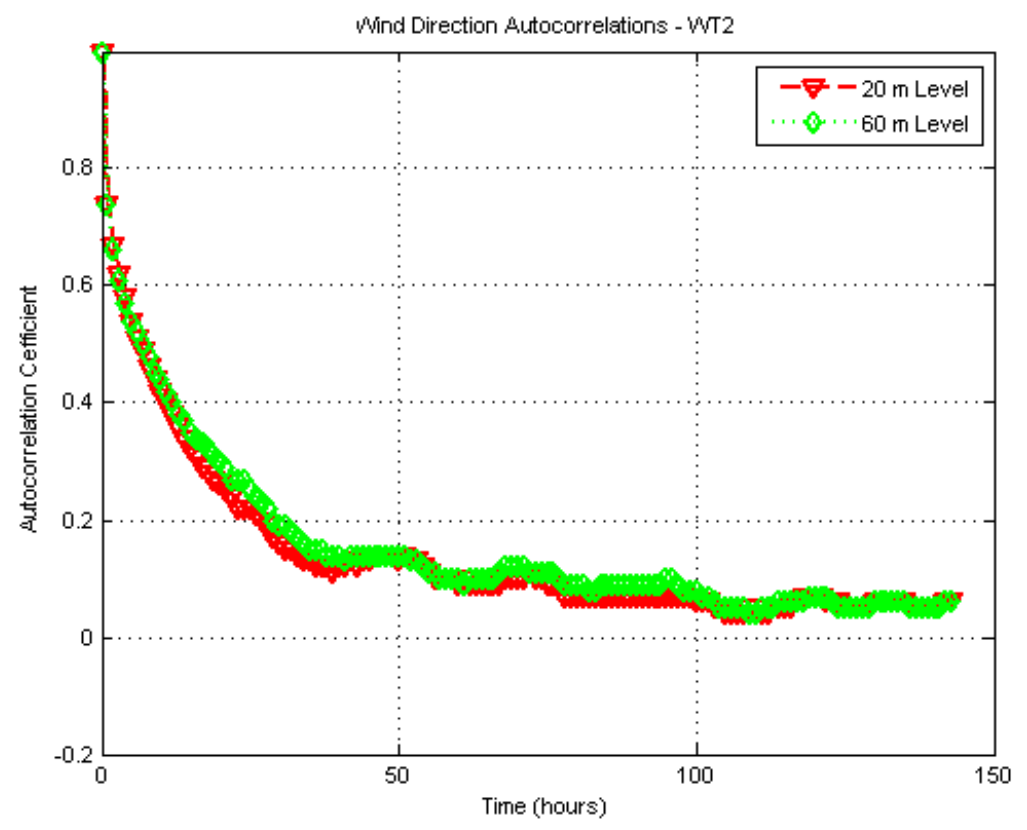

Figure 29. Autocorrelation functions for 10-min wind direction at 20 and 60 m levels for WT2; the 2012-2014 composite dataset 


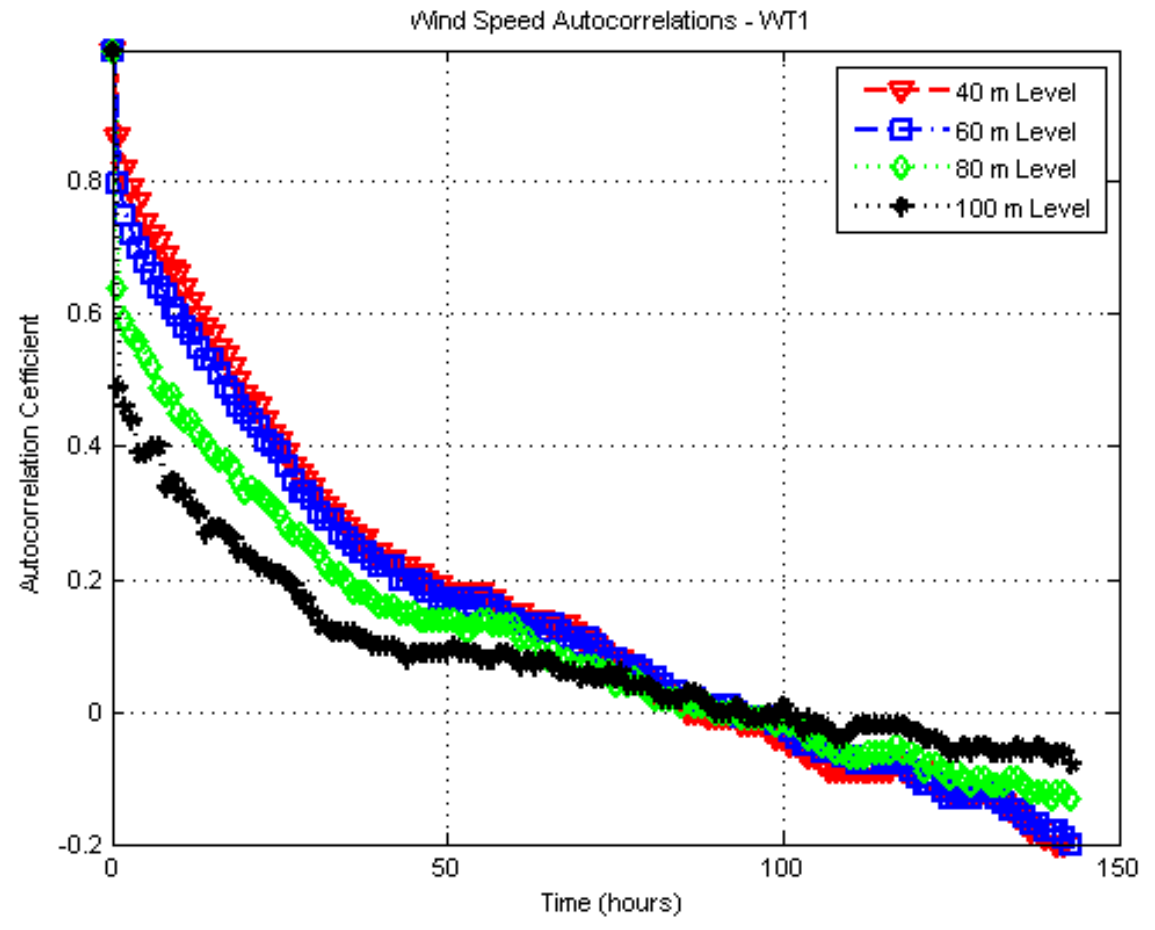

Figure 30. Same as Figure 26, but for sodar wind speed time series

Note that the wind direction shows similar autocorrelation coefficients as the wind speed, but fewer oscillations, which indicated more variability in the tower wind speed data. 


\section{Report on Task 5: Evaluation of the OMEGA Numerical Model}

Unlike other operational atmospheric models, OMEGA incorporates an unstructured triangular horizontal grid that allows for increased flexibility and accuracy in characterizing areas of complex terrain (Bacon et al. 2000). OMEGA is the first operational atmospheric model to use an unstructured, adaptive triangular grid in the horizontal dimensions. OMEGA's triangular grid incorporates technology employed for engineering computational fluid dynamics which was developed to create grids over irregular surfaces such as urban landscapes (Bacon et al. 2000). This project utilizes the OMEGA model to simulate flows in the complex terrain of Nevada to determine the effectiveness of using OMEGA and unstructured grids for wind potential studies. The advantages for wind prediction are the result of resolving terrain-induced circulations that can mechanically and/or thermodynamically create localized wind maxima and/or minima. Because the variation in terrain height is so irregular, OMEGA can enhance the efficiency of resolving circulations caused by local and complex terrain.

The present study evaluates OMEGA's ability to reproduce winds at certain grid points compared to data from the two observational towers at hub height, $60 \mathrm{~m}$ above ground level.

The OMEGA simulations were designed based on the WRF simulations used in Task 6. The horizontal grid resolutions used in the OMEGA simulations employed nested triangular grids with minimum horizontal edge lengths of $18 \mathrm{~km}, 6 \mathrm{~km}, 2 \mathrm{~km}$, and $667 \mathrm{~m}$ (Figure 31). The simulations were performed over 40 total vertical levels with the first level at approximately 12 $\mathrm{m}$ above the Earth's surface. The model was initialized at 00 Coordinated Universal Time (UTC) and ran for 48 hours for each simulation of which the last 24 hours was used in the statistical analysis. The model was initialized using the Global Forecast System data as initial and boundary condition values. Each 30-day group of model simulations was then analyzed using statistical techniques to determine how the model-generated winds compared with the observed winds. The statistical results were then compared with the results from the WRF simulations.

The OMEGA model simulated the months of December 2012 and June 2013 in the Virginia Hills region of Nevada. Post-simulation, the wind speed and direction were extracted from the simulation data at the $60 \mathrm{~m}$ height for the closest OMEGA grid points to WT1 $\left(39.2628^{\circ} \mathrm{N}\right.$, $\left.119.7169^{\circ} \mathrm{W}\right)$ and WT2 $\left(39.28360^{\circ} \mathrm{N}, 119.6997^{\circ} \mathrm{W}\right)$. This model-generated wind speed and direction were used to compare with both the observations at the towers and the WRF model simulations at the same time. Table 9 contains the statistical analysis of the December 2012 and June 2013 wind simulations at $60 \mathrm{~m}$ above ground including: average wind speed (AVG), standard deviation of the wind speed (STD), the coefficient of determination $\left(\mathrm{R}^{2}\right)$, and root mean square error (RMSE). From these numbers, it is clear that the OMEGA simulations are consistently underpredicting wind speed. Furthermore, OMEGA appears to perform better, by these criteria, in December 2012 than in June 2013. It is unclear from this analysis whether increasing the resolution of the model provides a more accurate simulation.

Table 14 contains the statistical analysis of the December 2012 and June 2013 wind simulations at $60 \mathrm{~m}$ above ground including: AVG, STD, $\mathrm{R}^{2}$, and RMSE. 


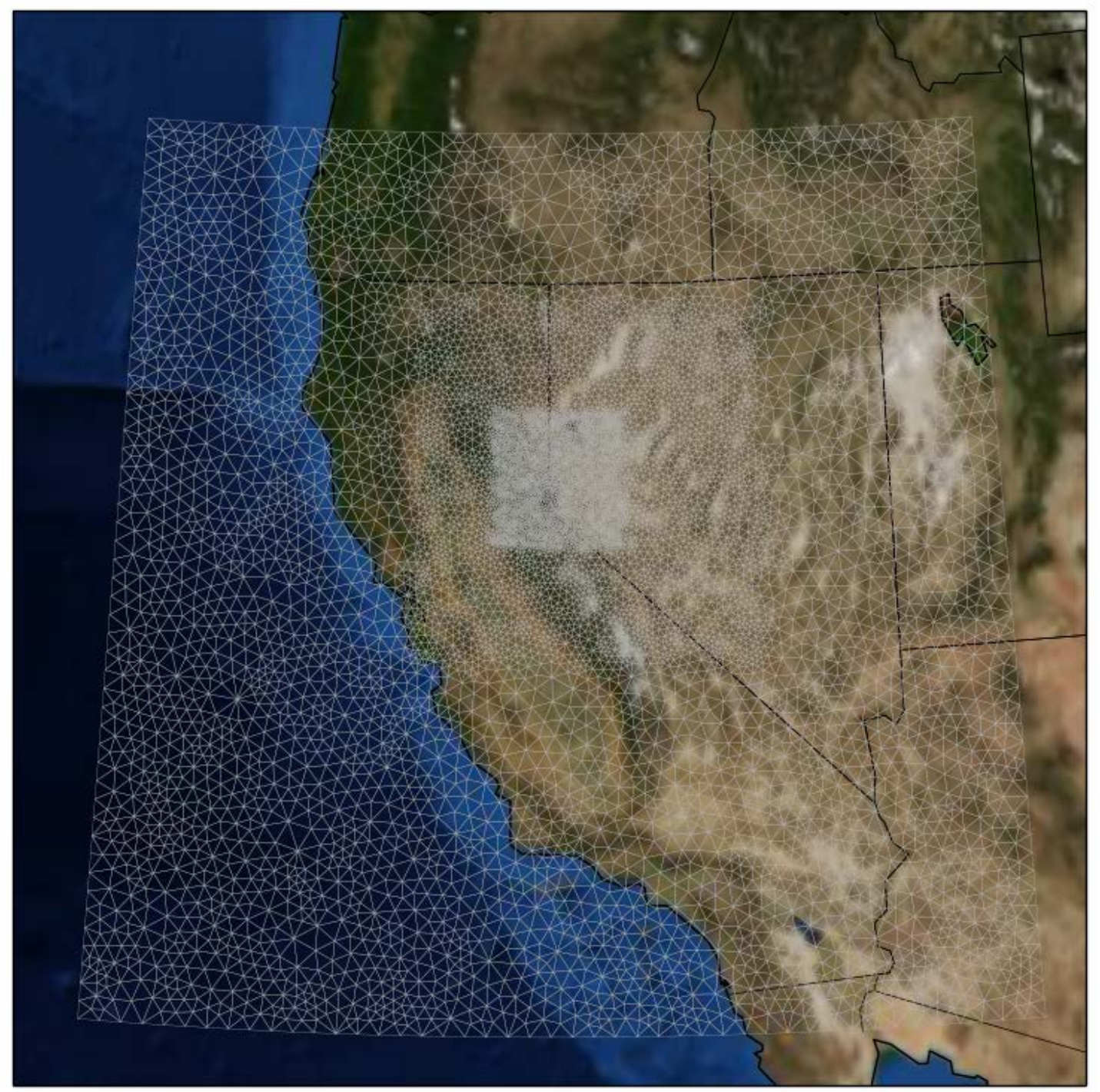

Figure 31. OMEGA grid for simulations for December 2012 and June 2013

Table 14. Statistical Analysis of OMEGA Simulations at Grid Points Nearest to WT1 for December 2012 and June 2013

\begin{tabular}{lcccccccccc}
\hline & $\begin{array}{l}\text { Obs. } \\
\text { cup }\end{array}$ & \multicolumn{3}{c}{} & \multicolumn{3}{c}{ OMEGA } & $\mathbf{2 ~ k m}$ & \multicolumn{4}{c}{ OMEGA } & $\mathbf{6 6 7} \mathbf{~ m}$ \\
\hline $\begin{array}{c}\text { AVG } \\
\left(\mathbf{m s}^{-1}\right)\end{array}$ & $\begin{array}{c}\text { STD } \\
\left(\mathbf{m s}^{-1}\right)\end{array}$ & $\begin{array}{c}\text { AVG } \\
\left(\mathbf{m s}^{-1}\right)\end{array}$ & $\begin{array}{c}\text { STD } \\
\left(\mathbf{m s}^{-1}\right)\end{array}$ & $\mathbf{R}^{2}$ & $\begin{array}{c}\text { RMSE } \\
\left(\mathbf{m s}^{-1}\right)\end{array}$ & $\begin{array}{c}\text { AVG } \\
\left(\mathbf{m s}^{-1}\right)\end{array}$ & $\begin{array}{c}\text { STD } \\
\left(\mathbf{m s}^{-1}\right)\end{array}$ & $\mathbf{R}^{2}$ & $\begin{array}{c}\text { RMSE } \\
\left(\mathbf{m s}^{-1}\right)\end{array}$ \\
\hline $\begin{array}{l}\text { December } \\
2012\end{array}$ & 7.175 & 5.120 & 4.587 & 4.338 & 0.440 & 4.716 & 4.191 & 3.644 & 0.601 & 4.648 \\
\hline $\begin{array}{l}\text { June } \\
2012\end{array}$ & 6.096 & 3.377 & 6.691 & 6.119 & 0.044 & 6.361 & 4.138 & 2.546 & 0.156 & 3.863 \\
\hline
\end{tabular}


To compare the OMEGA simulation results with both the observations from the towers and the WRF simulations, we plotted both the wind speed and wind direction in weekly charts. The OMEGA 2 km December 2012 run is shown in Figure 32, the OMEGA 667 m December 2012 run is shown in Figure 33, OMEGA $2 \mathrm{~km}$ June 2013 run is shown in Figure 34, and the OMEGA $667 \mathrm{~m}$ June 2013 run is shown in Figure 35. By visual inspection of the December 2012 figures, it is clear that the OMEGA wind speeds from both the $2 \mathrm{~km}$ and $667 \mathrm{~m}$ resolution simulations are generally too weak compared with both WRF and the observations. The wind direction values tend to cluster similarly to both the observations and WRF simulations; however, there is more spread in the OMEGA simulated wind direction. The June 2013 simulations show similar results. The OMEGA simulations of wind speed tend to be too weak and the wind direction is relatively consistent with the observations, except on June 13 and 14.

\subsection{Ongoing Investigation of Errors}

The poor performance of the OMEGA model in the simulations for this project led us to investigate where the errors were coming from and how to fix them. From our testing, it appears that the planetary boundary layer (PBL) portion of the code is not being activated or is not running correctly. This led to problems with mixing and the energy budget near the surface, resulting in incorrect mass and temperature profiles in the lowest portion of the atmosphere. The wind speed time series shown here are affected by the incorrect PBL profile and do not correspond well with the observations. We are in the process of obtaining an updated version of OMEGA from the developers to fix this issue and continue to investigate the model simulations to determine why the boundary layer code failed. 


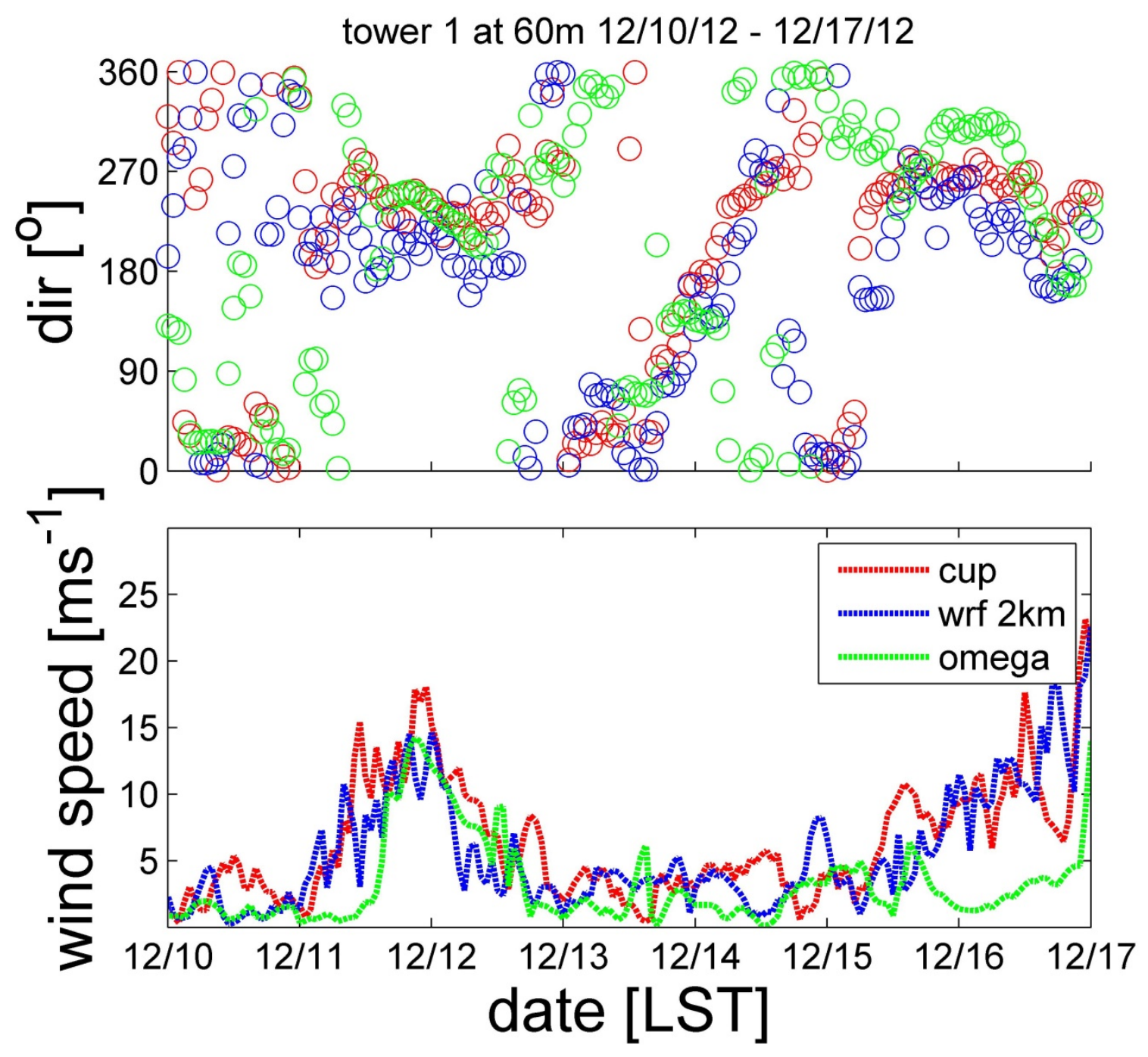

Figure 32. Wind direction (degrees) and wind speed $\left(\mathrm{m} \mathrm{s}^{-1}\right)$ at $60 \mathrm{~m}$ from WT1 observations (cup anemometer), WRF $2 \mathrm{~km}$ resolution simulations, and OMEGA $2 \mathrm{~km}$ resolution simulations over the period from December 10, 2012-December 17, 2012 


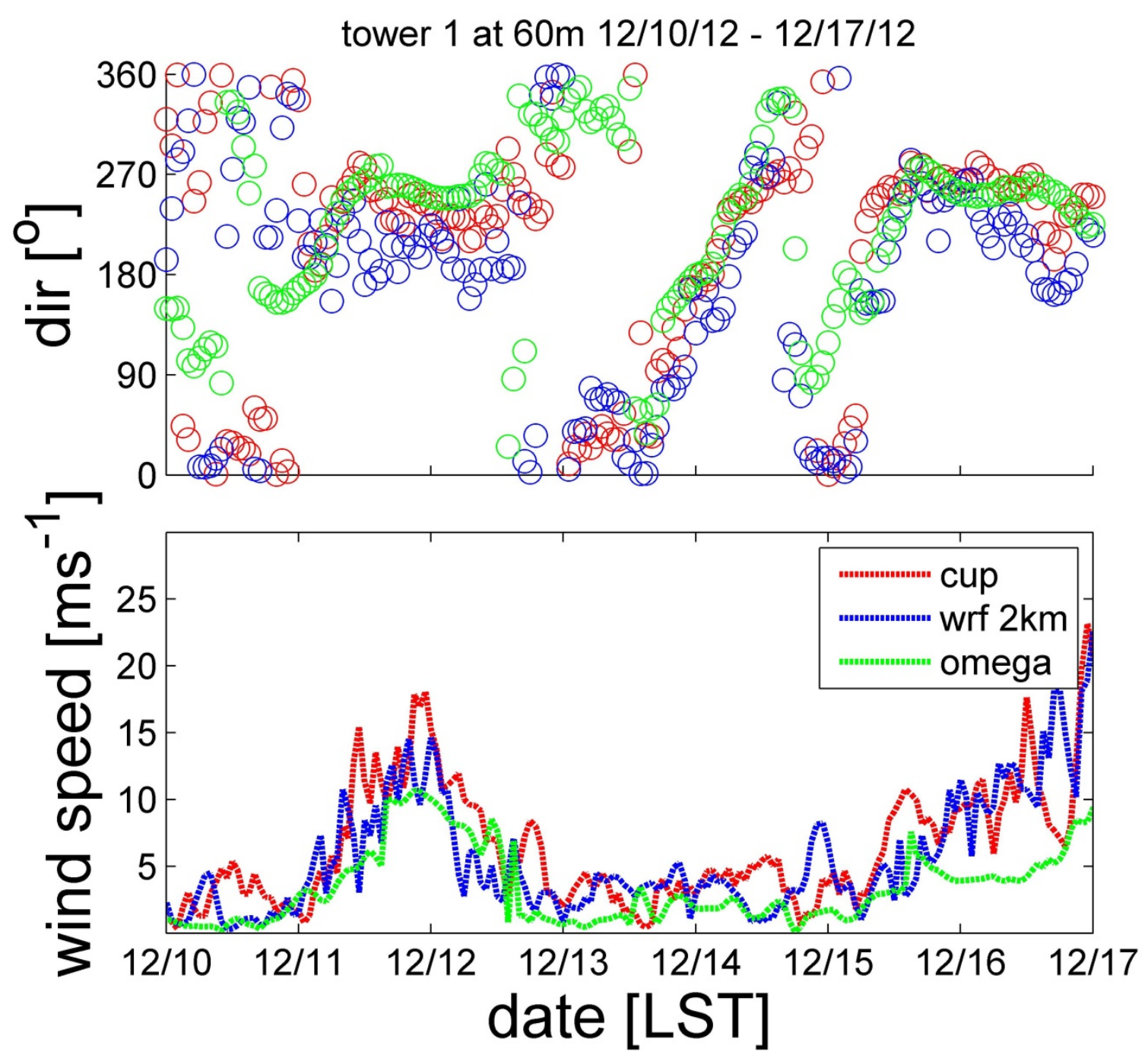

Figure 33. Wind direction (degrees) and wind speed ( $\mathrm{m} \mathrm{s}^{-1}$ ) at $60 \mathrm{~m}$ from WT1 observations (cup), WRF $2 \mathrm{~km}$ resolution simulations, and OMEGA $667 \mathrm{~m}$ resolution simulations over the period from December 10, 2012-December 17, 2012 


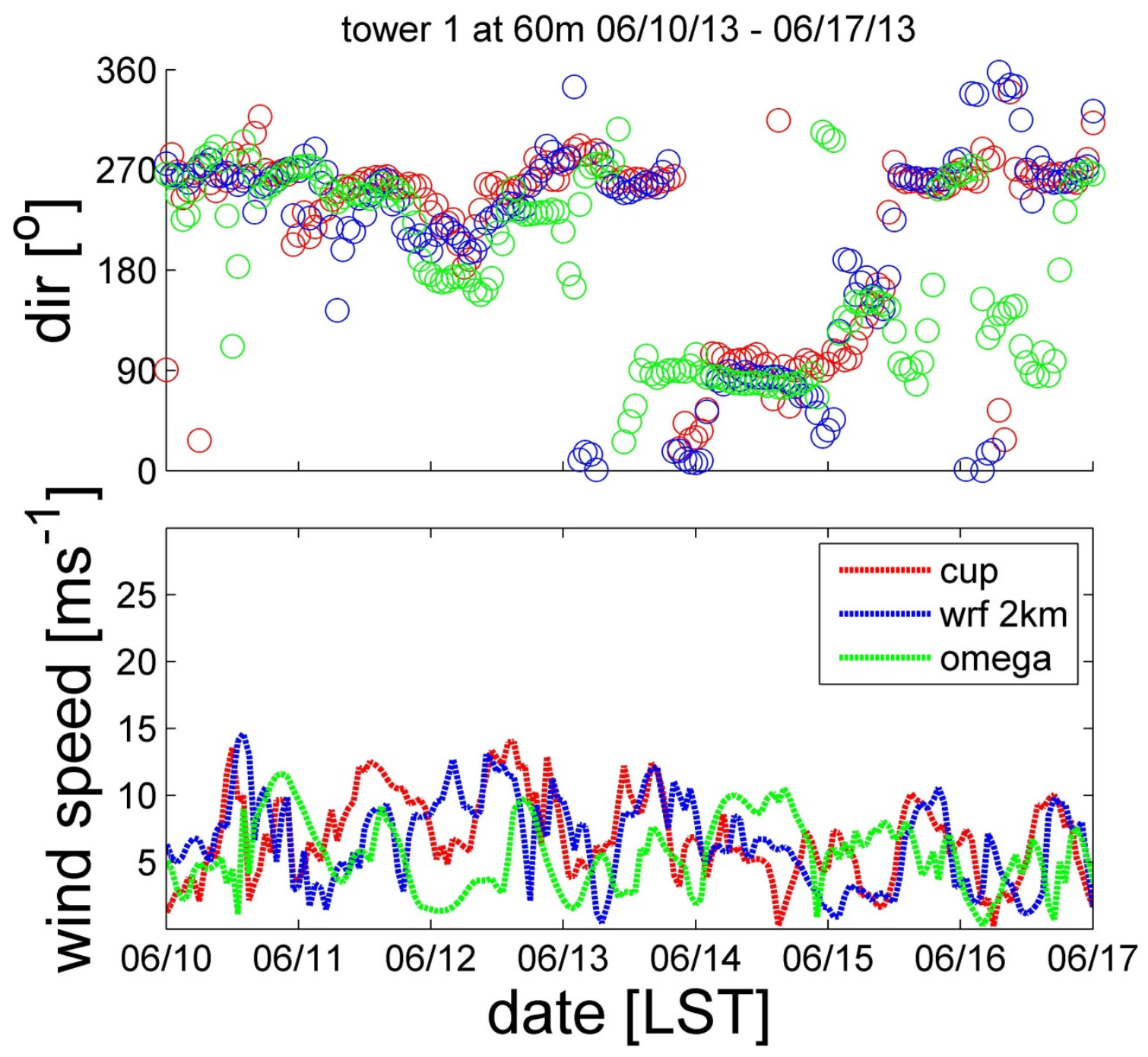

Figure 34. Wind direction (degrees) and wind speed ( $\mathrm{m} \mathrm{s}^{-1}$ ) at $60 \mathrm{~m}$ from WT1 observations (cup), WRF $2 \mathrm{~km}$ resolution simulations, and OMEGA $2 \mathrm{~km}$ resolution simulations over the period from June 10, 2013-June 17, 2013 


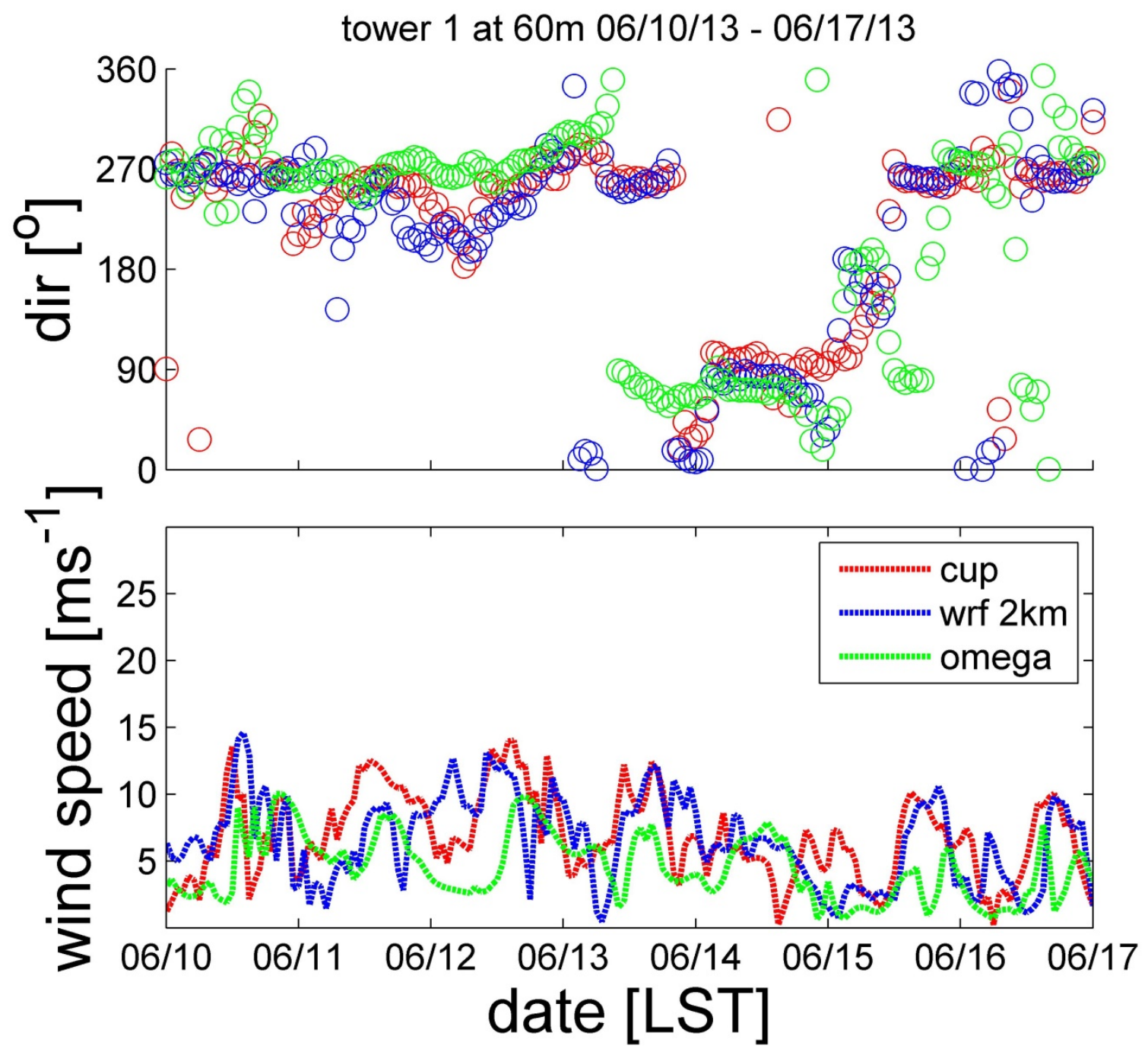

Figure 35. Wind direction (degrees) and wind speed ( $\mathrm{m} \mathrm{s}^{-1}$ ) at $60 \mathrm{~m}$ from WT1 observations (cup), WRF $2 \mathrm{~km}$ resolution simulations, and OMEGA $667 \mathrm{~m}$ resolution simulations over the period from June 10, 2013-June 16, 2013 


\section{Report on Task 6: Evaluation of the Weather Research and Forecasting Numerical Model}

The major modeling efforts were directed toward investigation of capabilities of two regional/mesoscale models to simulate wind field characteristics in complex terrain: Weather and Research Forecasting (WRF; Skamarock et al. 2008) and OMEGA (Bacon et al. 2000). The WRF model utilizes a standard structured X-Y-Z domain mesh, while OMEGA (see a report on the previous Task 5) has an unstructured grid whose resolution can be adapted to take into account topographic and flow gradient complexities. During the first part of the study, additional analysis and modeling using Mesoscale Model 5 (MM5) and WRF were conducted using data from the prior NREL-supported tower field program in western Nevada.

\subsection{Weather Research and Forecasting Deterministic Forecasting}

WRF was set up with multiple nested grids for a large span of horizontal resolutions to capture various scales of atmospheric processes from synoptic to microscale. Table 15 shows the specifics of all WRF model domains, including resolutions, number of grid points, size of the domains, and coordinates of the domains. More details on the model setup and results can be found in Smith et al. (2014).

Table 15. Specifics of the WRF Model Domains

\begin{tabular}{|c|c|c|c|c|c|c|}
\hline $\begin{array}{l}\text { Domain (Grid } \\
\text { Resolution) }\end{array}$ & $n x \times n y$ & $\begin{array}{l}\text { Domain } \\
\text { Size }(\mathbf{k m})\end{array}$ & sW Corner & SE Corner & NE Corner & NW Corner \\
\hline $1(27$ km) & $\begin{array}{l}100 \times \\
100\end{array}$ & $2700 \times 2700$ & $\begin{array}{c}26^{\circ} 57^{\prime} 34.93 \mathrm{~N} \\
136^{\circ} 1{ }^{\prime} 7.79 \mathrm{~W}\end{array}$ & $\begin{array}{c}26^{\circ} 35^{\prime} 46.65 \mathrm{~N} \\
103^{\circ} 47^{\prime} 10.79 \mathrm{~W}\end{array}$ & $\begin{array}{c}50^{\circ} 42^{\prime} 22.61 \mathrm{~N} \\
103^{\circ} 16^{\prime} 50.27 \mathrm{~W}\end{array}$ & $\begin{array}{l}51^{\circ} 21^{\prime} 31.43 \mathrm{~N} \\
142^{\circ} 2^{\prime} 58.57 \mathrm{~W}\end{array}$ \\
\hline $2(9 \mathrm{~km})$ & $\begin{array}{l}200 \times \\
200\end{array}$ & $1800 \times 1800$ & $\begin{array}{c}31^{\circ} 59^{\prime} 7.92 \mathrm{~N} \\
130^{\circ} 44^{\prime} 21.25 \mathrm{~W}\end{array}$ & $\begin{array}{c}32^{\circ} 17^{\prime} 20.25 \mathrm{~N} \\
110^{\circ} 43^{\prime} 41.72 \mathrm{~W}\end{array}$ & $\begin{array}{l}47^{\circ} 46^{\prime} 16.31 \mathrm{~N} \\
109^{\circ} 2^{\prime} 32.46 \mathrm{~W}\end{array}$ & $\begin{array}{c}48^{\circ} 21^{\prime} 6.71 \mathrm{~N} \\
133^{\circ} 44^{\prime} 31.00 \mathrm{~W}\end{array}$ \\
\hline $3(3 \mathrm{~km})$ & $\begin{array}{l}150 \times \\
150\end{array}$ & $450 \times 450$ & $\begin{array}{c}36^{\circ} 56^{\prime} 49.00 \mathrm{~N} \\
117^{\circ} 21^{\prime} 12.97 \mathrm{~W}\end{array}$ & $\begin{array}{r}26^{\circ} 57^{\prime} 34.93 \mathrm{~N} \\
136^{\circ} 1{ }^{\prime} 7.79 \mathrm{~W}\end{array}$ & $\begin{array}{l}40^{\circ} 58^{\prime} 7.06 \mathrm{~N} \\
117^{\circ} 77^{\prime} 8.04 \mathrm{~W}\end{array}$ & $\begin{array}{c}41^{\circ} 2^{\prime} 2.77 \mathrm{~N} \\
122^{\circ} 30^{\prime} 16.40 \mathrm{~W}\end{array}$ \\
\hline $4(1 \mathrm{~km})$ & $\begin{array}{l}100 \times \\
100\end{array}$ & $100 \times 100$ & $\begin{array}{c}38^{\circ} 50^{\prime} 39.47 \mathrm{~N} \\
120^{\circ} 23^{\prime} 23.55 \mathrm{~W}\end{array}$ & $\begin{array}{l}38^{\circ} 49^{\prime} 41.87 \mathrm{~N} \\
119^{\circ} 4^{\prime} 9.74 \mathrm{~W}\end{array}$ & $\begin{array}{l}39^{\circ} 44^{\prime} 11.67 \mathrm{~N} \\
119^{\circ} 2^{\prime} 43.41 \mathrm{~W}\end{array}$ & $\begin{array}{r}39^{\circ} 44^{\prime} 35.06 \mathrm{~N} \\
120^{\circ} 12^{\prime} 45.69 \mathrm{~W}\end{array}$ \\
\hline $5(1 / 3 \mathrm{~km})$ & $\begin{array}{l}100 \times \\
100\end{array}$ & $33.3 \times 33.3$ & $\begin{array}{c}39^{\circ} 24^{\prime} 28.97 \mathrm{~N} \\
119^{\circ} 50^{\prime} 35.87 \mathrm{~W}\end{array}$ & $\begin{array}{r}39^{\circ} 13^{\prime} 16.07 \mathrm{~N} \\
119^{\circ} 25^{\prime} 35.54 \mathrm{~W}\end{array}$ & $\begin{array}{c}39^{\circ} 31^{\prime} 7.03 \mathrm{~N} \\
119^{\circ} 27^{\prime} 3.54 \mathrm{~W}\end{array}$ & $\begin{array}{r}39^{\circ} 31^{\prime} 23.76 \mathrm{~N} \\
119^{\circ} 50^{\prime} 20.25 \mathrm{~W}\end{array}$ \\
\hline
\end{tabular}

Geographical setup of the WRF model domains is shown in Figure 36. 


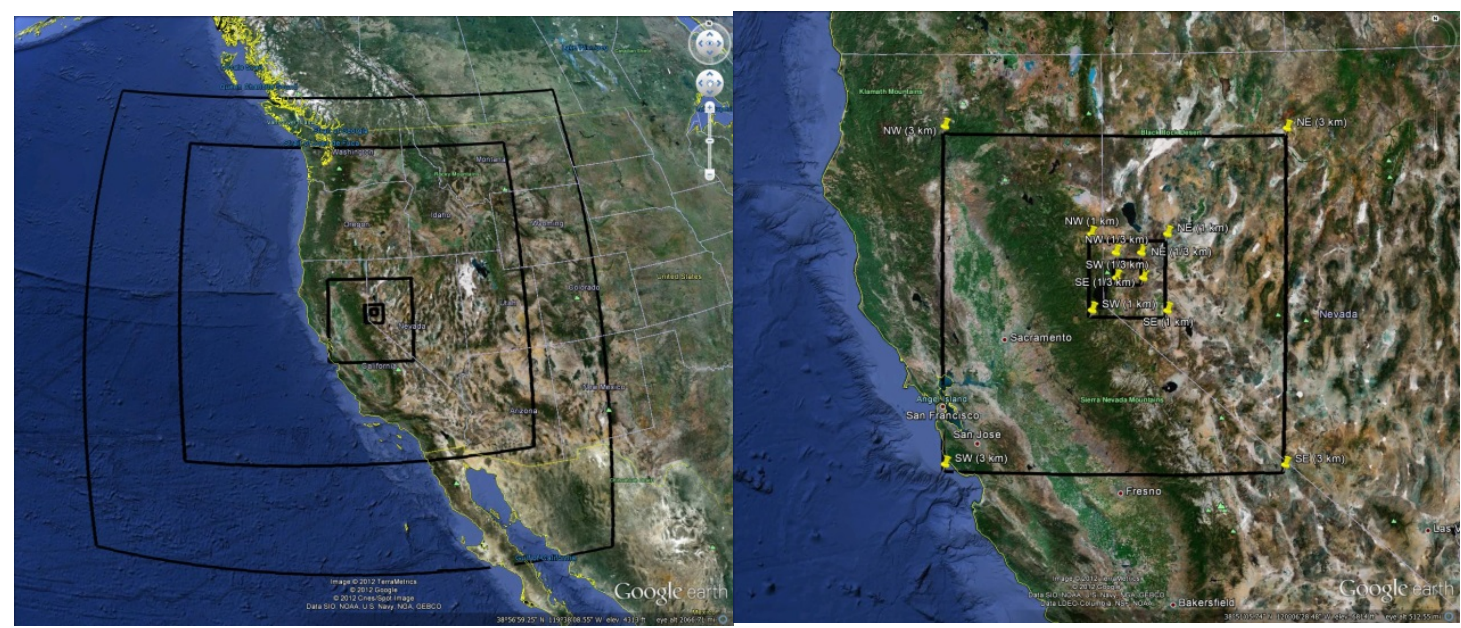

Figure 36. Full (left) and zoomed in (right) view of the WRF multiple-domain setup

Topographic details of the Virginia Peak area where the field program took place as well as microscale topography of the ridge where the towers were located are shown in Figure 37.
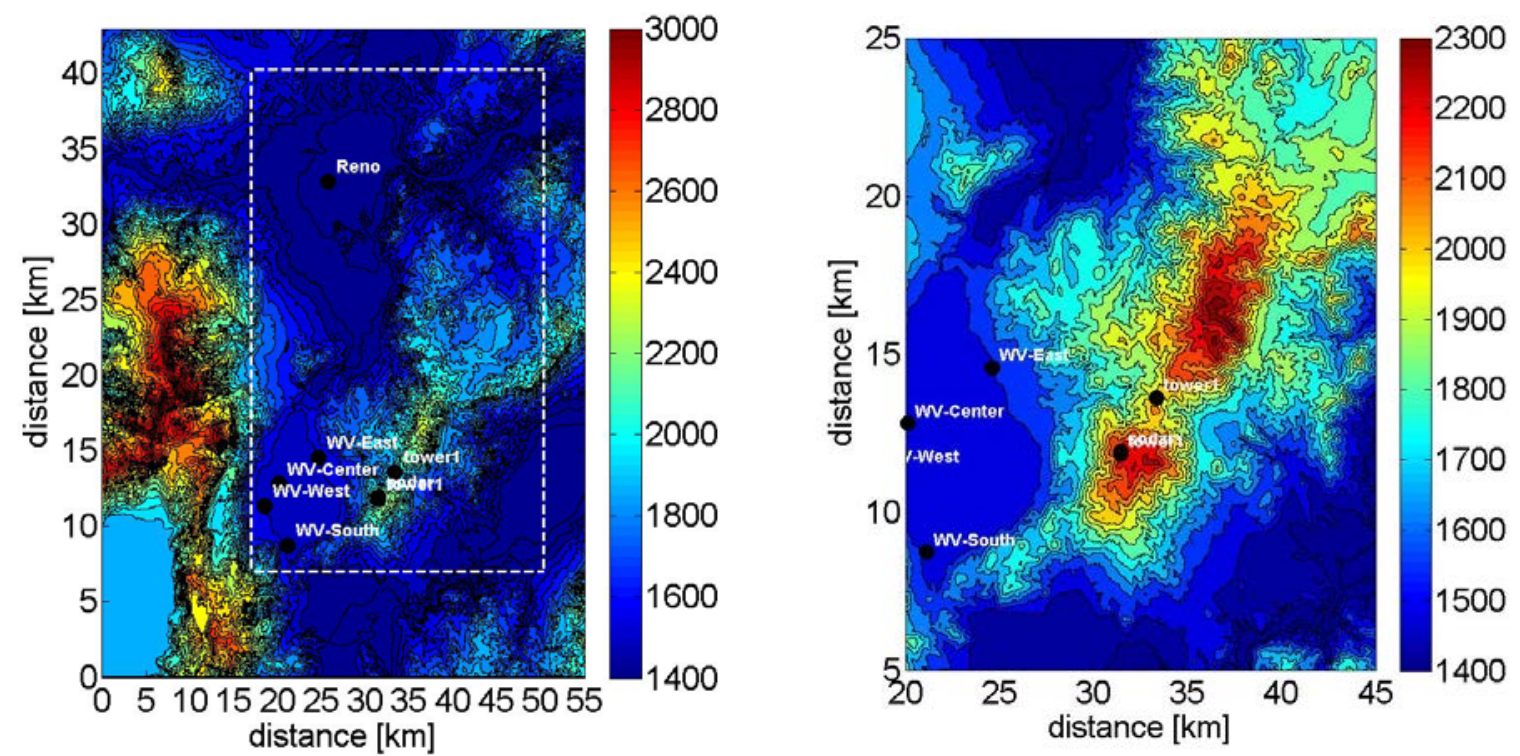

Figure 37. Topography [m] of the innermost WRF domain (left) and close-up of the Virginia Hills, Nevada. Also shown are the locations of nearby surface stations, and the 60-m towers and the sodar.

Google-view maps for the area with indicated tower and sodar locations are shown in Figure 38. 


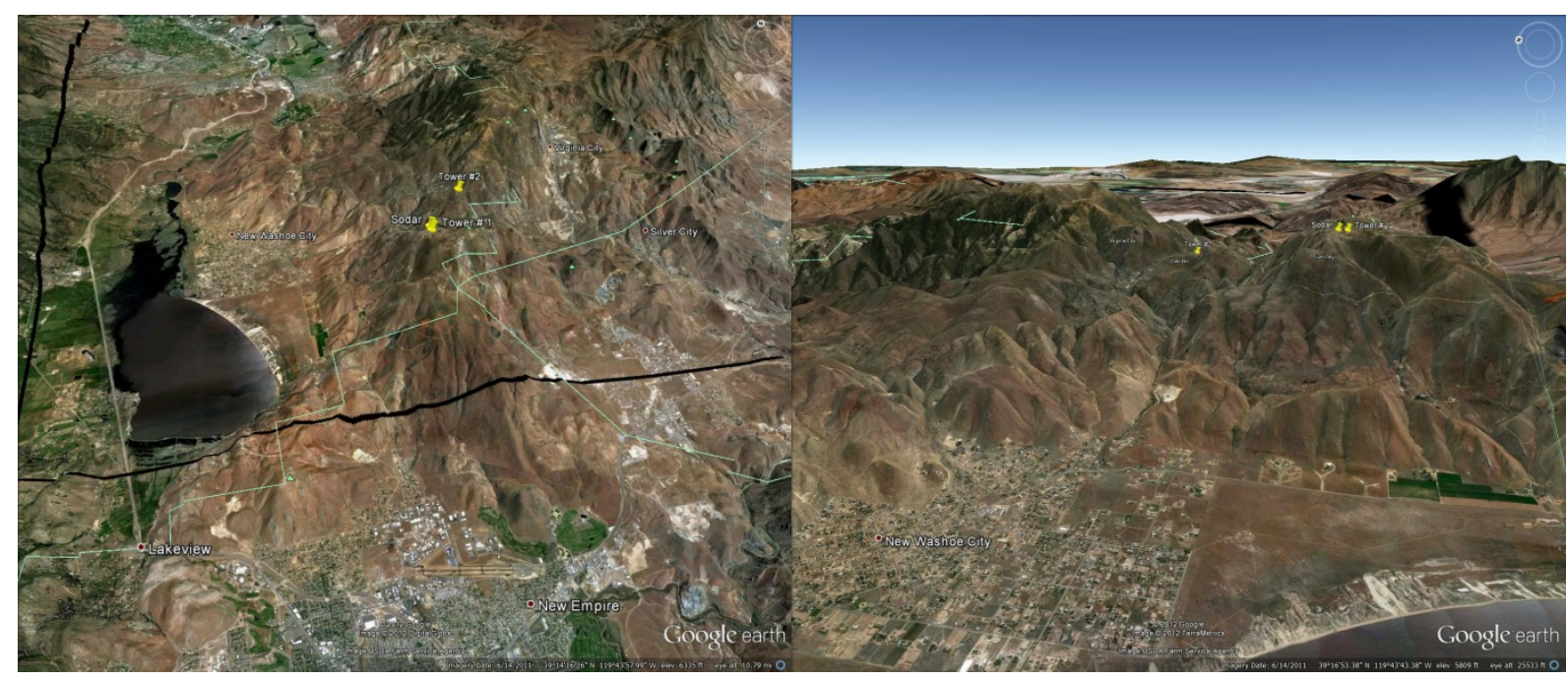

Figure 38. Google view of the Virginia Hills looking north (left) and looking east (right), approximately toward the dominant wind direction. Also shown are the locations of the 60-m towers and the sodar.

WRF was originally run in a hindcast mode and comparisons were made with the towers and the sodar at the Virginia Hills site. The WRF setup was for a 48-hour forecast initialized with the National Centers for Environmental Prediction FiNaL Analysis (FNL) data (available from the Computational and Information Systems Laboratory research data archive at http://rda.ucar.edu/datasets/ds0832.2). Forecasts have been run also in another setup applicable to ensemble forecasting to reduce computational requirements with five and six domains, with horizontal grid resolutions of $\Delta_{\mathrm{h}}=108,36,12,4,1.3$, and $0.444 \mathrm{~km}$ (Figures 39 and 40). The model ran a 48-hour forecast in 3.5 hours (14 hours) of wall clock time with 48 processors for a five (six) domain run. Also, to achieve a feasible ensemble forecast, the members were run without domain 6.
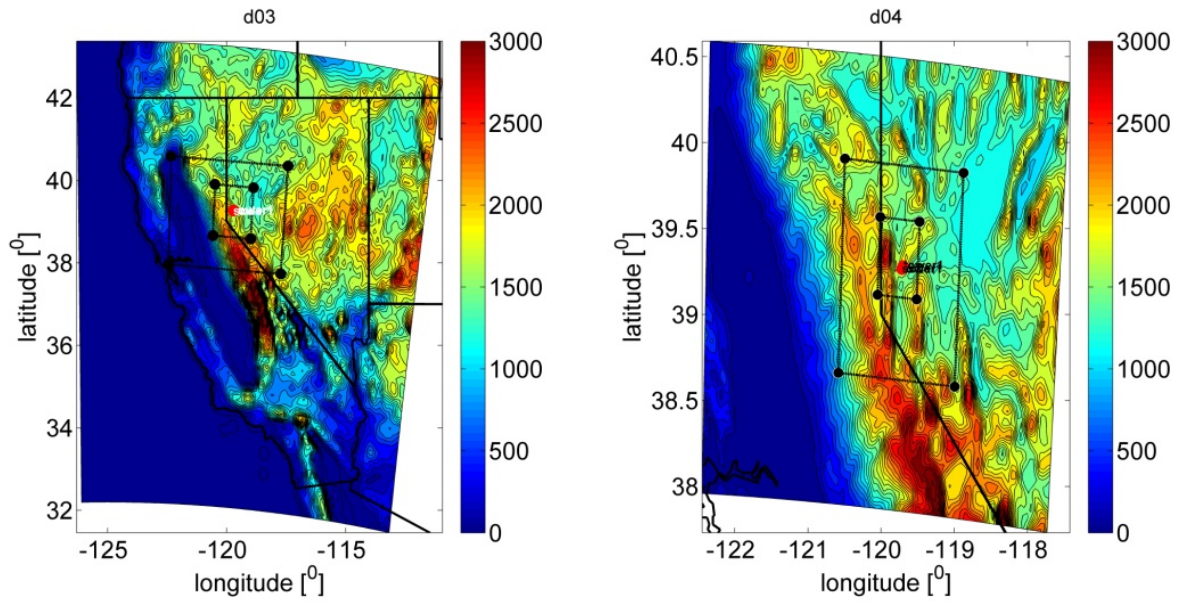

Figure 39. View of the WRF domains \#3 (left, $\Delta_{h}=12 \mathrm{~km}$ ), and \#4 (right, $\Delta_{h}=4 \mathrm{~km}$ ). Topography $(\mathrm{m})$ is color contoured; and solid lines indicate the positions of the inner domains 

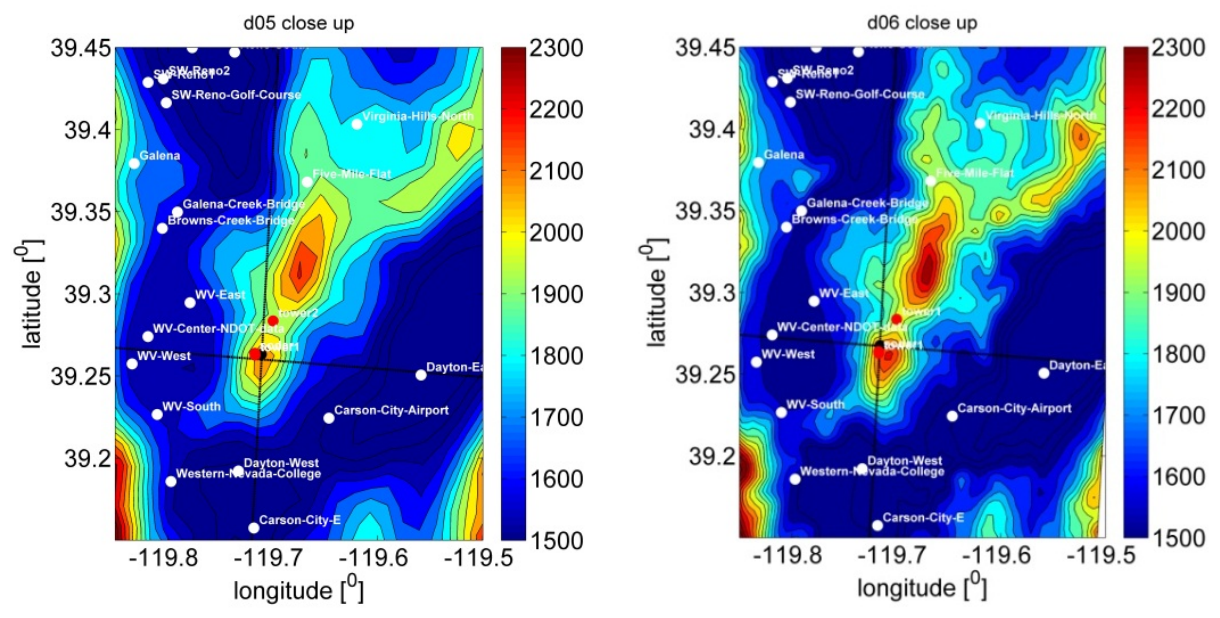

Figure 40. Close-up (partial) view of the Virginia Hills site in the WRF domains \#5 (left, $\Delta_{h}=1.33$ $\mathrm{km}$ ) and \#6 (right, $\Delta_{\mathrm{h}}=\mathbf{4 4 4} \mathrm{m}$ ). Topography [m] is color contoured. Also shown are the locations of nearby surface stations (white dots), the 60-m towers, the sodar (red dots), and the closest grid points in the WRF domains \#5 and \#6 for comparison (black circle and black dashed lines).

An example forecast for the high-resolution domain 6 is shown in Figure 41. WRF was initialized on February 9, 2013 at 1600 LST (February 10, 2013, 0000 UTC) and ran for 48 hours. Output from the nearest grid point in the WRF domain 6 (444 m resolution, see Figure 40, right panel) is compared to the meteorological tower and the sodar data. Figure 41 shows the wind direction at $60 \mathrm{~m}$ (top), wind speed at $60 \mathrm{~m}$ (center) and near surface temperature (bottom) for the WRF forecast (blue), the sodar (red), and the towers' measurements (sonic-green, cup anemometer-cyan). 


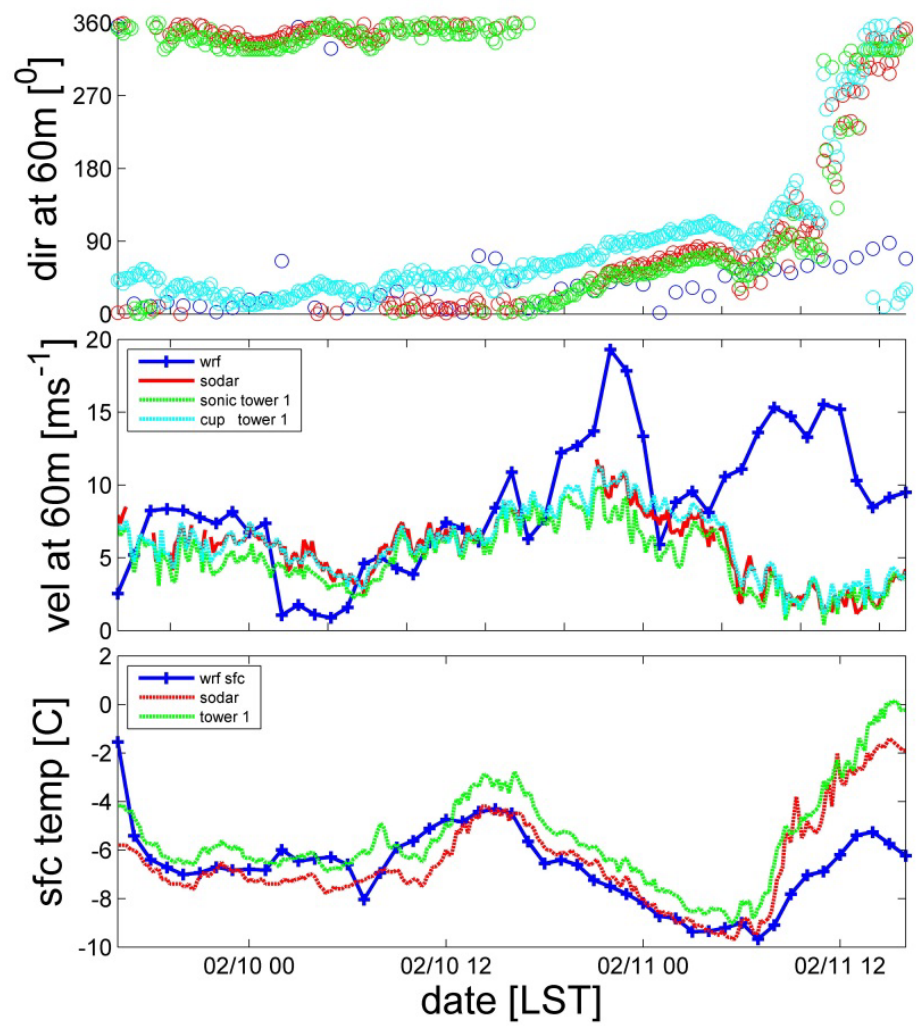

Figure 41. Wind direction at $60 \mathrm{~m}$ (top), wind speed at $60 \mathrm{~m}$ (middle), and the near-surface temperature (bottom) from February 9, 2012 16:00 to February 11, 2012 16:00 (LST) from the WRF forecast (blue-48-hour forecast, initialized with FNL at February 9, 2012 16:00), the sodar (red), cup, vane and temperature sensors (green) and sonic anemometer (cyan). WRF output is at hourly intervals, all other measurements are presented as 10-minute averages.

General agreement can be seen between the sodar and cup and vane measurements. WRF shows fairly good results of capturing the wind speed up-event during the afternoon of February 10, 2013, but does not capture the decrease of wind speed and changing wind direction on the subsequent morning of February 11, 2013. Although WRF follows closely a cold front on February 10, 2012, it significantly overestimates the peak wind speed, overestimates the peak on February 9, 2012, and during warm advection on February 11, 2012.

WRF was also run for a longer period in a hindcast mode without domain 6 . Runs were initialized every 24 hours, then run for 48 hours, and the final 24 hours of each run were aggregated into a forecast for the duration of the entire field campaign. An example of the aggregated forecast is shown in Figure 42 for the period February 6-13, 2013. 


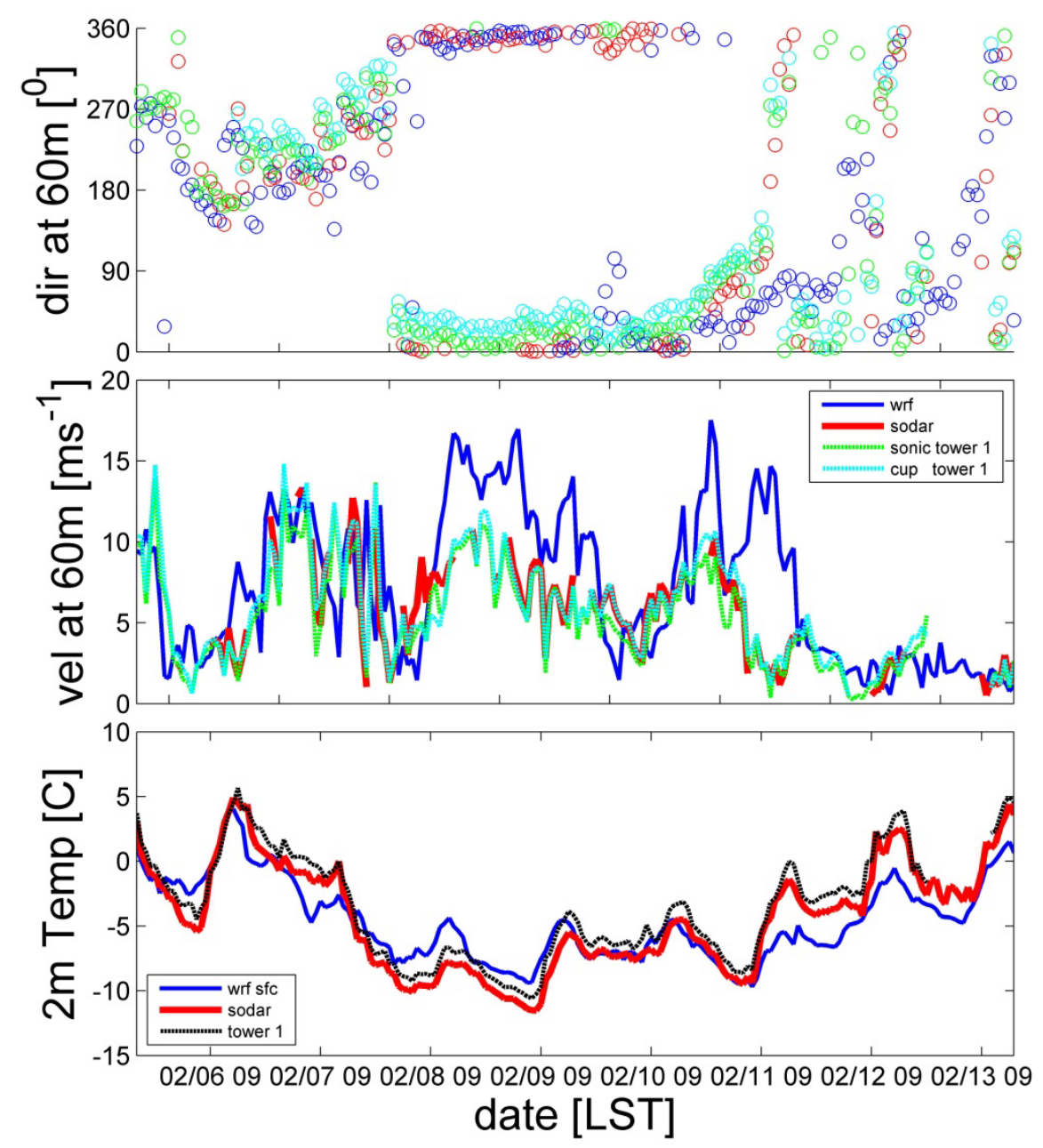

Figure 42. Wind direction at $60 \mathrm{~m}$ (top), wind speed at $60 \mathrm{~m}$ (middle), and the near-surface temperature (bottom) for February 6, 2013-February 13, 2013 from the final 24 hours of the daily initialized (FNL) 48-hour WRF forecasts (blue), sodar (red), cup, vane and temperature sensors (green), and the sonic anemometer (cyan). WRF output is at hourly intervals, and all other measurements are presented as 10 -minute averages.

Except on February 11, 2013, WRF follows wind variations closely, but with a certain overestimation of the wind speed. A general WRF overestimation of the wind speed has been shown also in other studies (e.g., Horvath et al. 2012).

\subsection{WRF Ensemble Forecasting}

Besides conducting single deterministic forecasts, we also set up an initial system for WRF probabilistic forecasting using ensemble techniques. Because of computer limitations, this effort with a small number of ensembles represents a so-called a poor-man ensemble, we believe that it can be a basis for future ensemble forecasting. Many studies demonstrated that the forecasting accuracy is improved by using ensemble techniques (e.g., Stensrud 2000; Koračin et al. 2014). WRF forecasting for high wind events and the selection of ensemble members for an ensemble forecast are shown in Table 16. The ensemble members were based upon variation of boundary layer and surface layer physics options in the WRF namelist file. Each member was initialized every 24 hours and was run for 48 hours of forecast time. The first 24 hours were discarded as a 
spin-up and the final 24 hours were aggregated and scored against the meteorological tower stations and a few local surface stations (KRNO - Reno airport, a Citizen Weather Observer Program station on the eastern edge of Washoe Lake, and multiple Nevada Department of Transportation stations). Each 48-hour forecast member takes 3 hours of wall clock time on 128 processors with three domains at 12-, 6-, and 2-km resolution, respectively. The resolution of the finest domain was based on available computational resources and sensitivity tests (described below). The DRI cluster size allows three members to be run concurrently, such that each full complement of each ensemble forecast takes 6 hours, and thus 4 days of model time can be run in 1 day of wall clock time. Thus, the full year of the campaign of ensemble forecasts basically takes 3 months of wall clock time.

Table 16. Characteristics of the Ensemble Members*

\begin{tabular}{cccccc}
\hline $\begin{array}{c}\text { Ensemble } \\
\text { Number }\end{array}$ & $\begin{array}{c}\text { Surface } \\
\text { Layer } \\
\text { Physics }\end{array}$ & $\begin{array}{c}\text { Surface } \\
\text { Physics }\end{array}$ & $\begin{array}{c}\text { Boundary } \\
\text { Layer Physics }\end{array}$ & $\begin{array}{c}\text { Maximum Length } \\
\text { Formulation }\end{array}$ & $\begin{array}{c}\text { Topographic } \\
\text { Correction }\end{array}$ \\
\hline 1 & 1 & 2 & 1 & 1 & 0 \\
\hline 2 & 1 & 2 & 1 & 1 & 1 \\
\hline 3 & 2 & 2 & 2 & 1 & 0 \\
\hline 4 & 4 & 2 & 4 & 2 & 0 \\
\hline 5 & 2 & 2 & 0 & 3 & 0 \\
\hline 6 & 2 & 2 & 0 & 1 & 0 \\
\hline
\end{tabular}

* The options correspond to the WRF namelist file. Surface layer physics (sf_sfclay_physics) 1, MM5 Monin-Obukov (MO), YonSei University (YSU); 2 - MO Janjic Eta; 4 - Quasi-Normal Scale Elimination (QNSE). Surface physics (sf surface physics) - 2, Noah land surface model. Boundary layer physics (bl_pbl_physics) - 1, YSU scheme; 2 - MO Janjic Eta; 4 - QNSE; 0 large eddy simulation. Mixing length formulation (km_opt) - 1, constant k, $2-1.5$ order TKE formulation, 3 - Smagorinsky. Topographic correction as per Jiménez and Dudhia (2012), available only for YSU PBL formulation. See WRF User's Guide for details (http://www2.mmm.ucar.edu/wrf/users/docs/user_guide_V3/ARWUsersGuideV3.pdf).

High-resolution modeling using WRF was also undertaken. These forecasts, with the finest domain 6 at 1/3 km, are quite expensive computationally, and a run on 128 processors has a ratio of 4:1 wall clock time to forecast time. Once production runs of the ensemble members are fully up and running, this high-resolution modeling work with a significant number of ensemble members will most likely have to be conducted at a supercomputing center. Work on this task, in no small portion, included implementation of high-resolution (1-s, $\sim 30-\mathrm{m})$ topography into WRF, which normally uses the U.S. Geological Survey 30-s ( 1-km) dataset (Figure 43). The high-resolution forecasts were done for particular case studies, primarily of high wind events in the Washoe Valley necessitating the closure of U.S. 395 and gap flow events through the Virginia Hills (see Figures 44 and 45). 

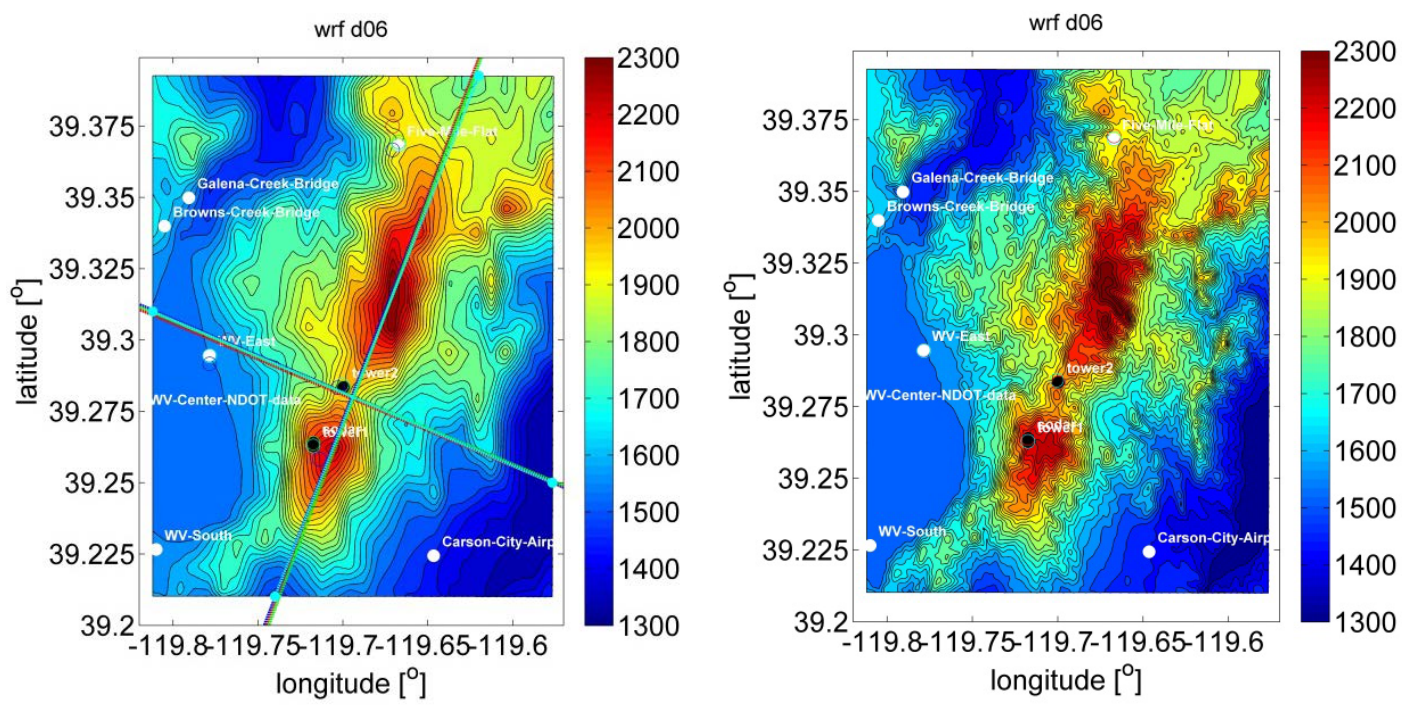

Figure 43. Topography contours [m] of the Virginia Hills in the finest domain (\#6) of the high resolution $\left(\Delta_{h}=100 \mathrm{~m}\right)$ WRF runs using the standard $30 \mathrm{~s}$ topography (left) and $1 \mathrm{~s}$ topography (right). Solid lines indicate axes generally parallel and perpendicular to the ridge line.

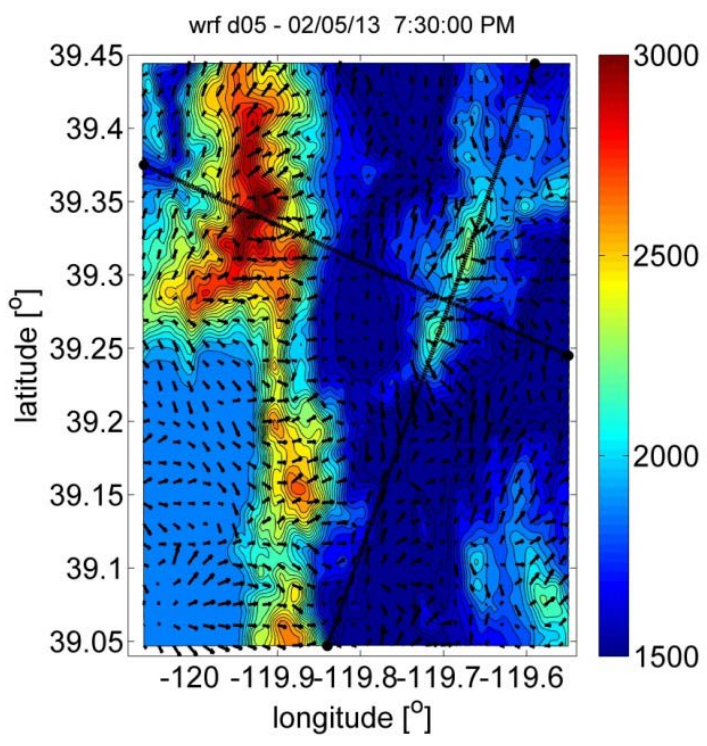

Figure 44. Ten-m velocity quivers on February 5, 2013 at 19:30 LST and topography [m] from the WRF domain \#5 $\left(\Delta_{h}=200 \mathrm{~m}\right)$

Note: Lake Tahoe is in the lower left of the plot, and during this event a downslope windstorm was occurring in the lee of the Carson Range, which runs north-south through the middle-left of the domain. Cross sections parallel to and perpendicular to the Virginia Hills range are noted by the black lines. Note the gap flow through the Virginia Hills (intersection of black lines) and the localized properties of the high surface wind in the Washoe Valley, which is typical for this location. 


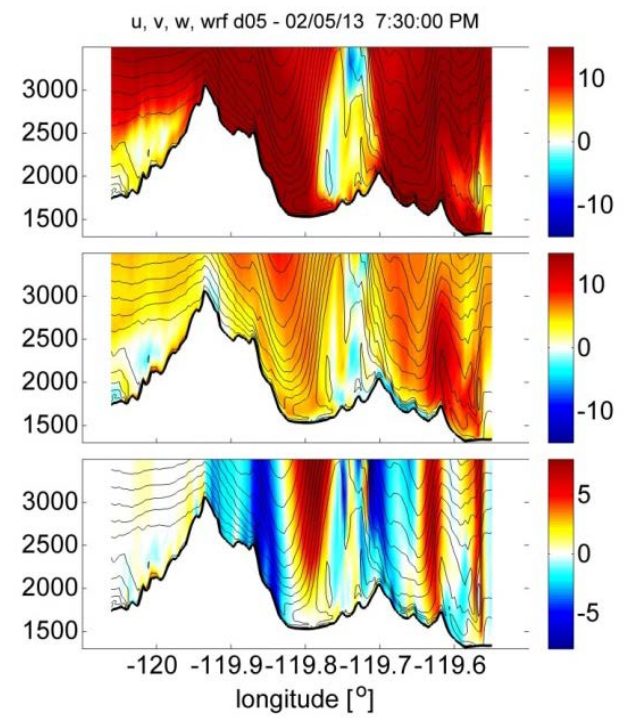

Figure 45. Cross-section velocity contours on February 5, 2013 at 19:30 LST. The near-longitudinal cross section is shown in Figure 37 (left to right).

Note: The high topography on the left is the Northern Carson Range, and the lower secondary ridge on the right is the Virginia Hills. Plotted are the zonal (top), meridional (middle), and vertical (bottom) velocity as a function of longitude. Note the high vertical velocities associated with the downslope windstorm and rotor. Typical of high wind (downslope windstorm) events for this area, the spatial extent of the high wind event in the Washoe Valley is limited by the presence of the rotor, which can be clearly seen in the top plot by the near-zero and negative $u$ velocities.

One of the typical wind events is shown in Figure 46. Preliminary analysis for a single 30-hr forecast shows that higher resolution forecasts did not show a much greater skill score than forecasts with moderate grid resolution. 

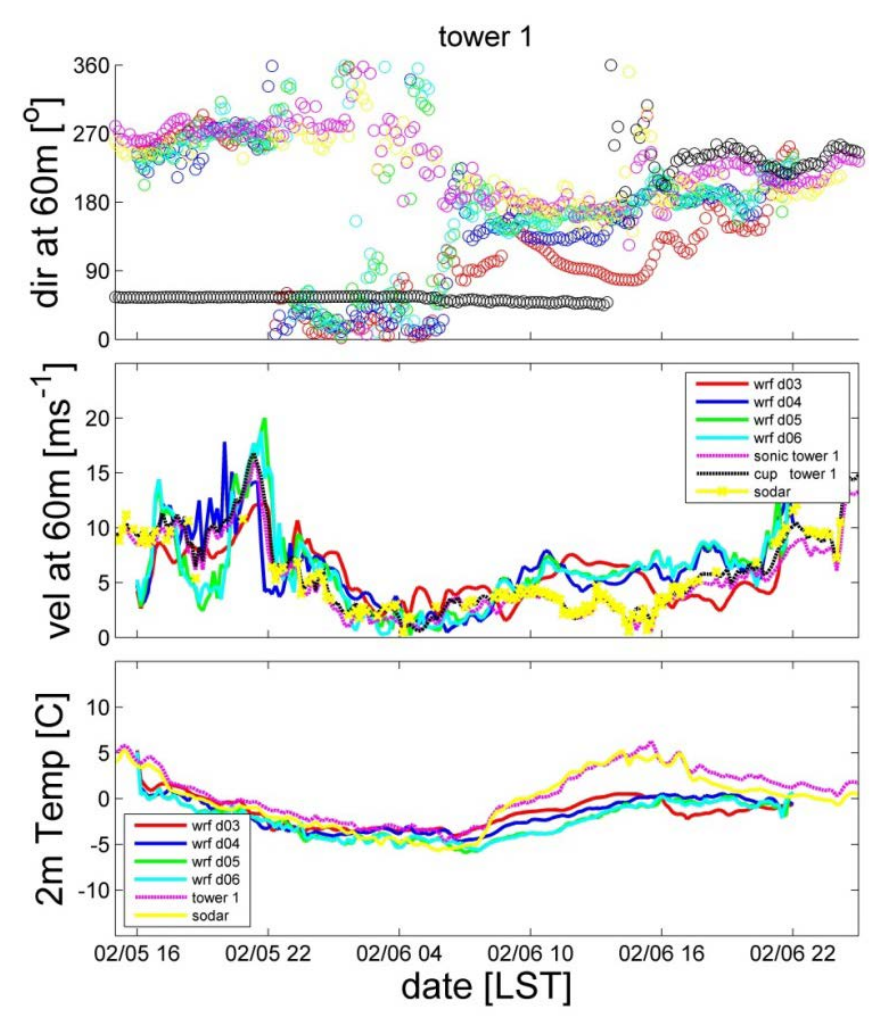

Figure 46. WRF forecast for all domains, data from the collocated sodar, and WT1 data for February 5, 2013 at 16:00 UTC to February 6, 2013 at 22:00 UTC. Plotted are the wind direction (top), wind speed (middle), and the surface temperature (bottom) from WT1 and the co-located sodar.

\subsection{WRF Evaluation}

As mentioned in the foregoing text, modeling experiments were performed with the WRF model version 3.4.1 (Skamarock et al. 2008). Experiments were initialized with the Global Forecast System boundary conditions at 6-hour intervals and grid spacing of $0.5^{\circ} \times 0.5^{\circ}$. Because our interest was in a day-ahead forecast (24- to 48-hour window), we allow development of a full DI cycle and discard the first 24 hours of each forecast as spin-up. Each second day forecast is accumulated for calculation and analysis of the model skill. We use the following parameterizations in the WRF model: Morrison 2 moment microphysics, Rapid Radiative Transfer Model longwave radiation, Dudhia shortwave scheme, MM5 MO similarity, and unified Noah land surface model. The dimensions of the $2 \mathrm{~km}$ domain, roughly $100 \times 100 \mathrm{~km}$, were prescribed to avoid spurious numerical noise originating from the Davis relaxation coupling zone near the boundary of the nested domains. The one-way interaction option was used among the model's domains. All results are presented in local standard time (LST $=\mathrm{UTC}-08)$, using standard American dating nomenclature $(\mathrm{MM} / \mathrm{DD} / \mathrm{YY})$, and unless otherwise stated results are presented for the innermost domain only (grid spacing of $2 \mathrm{~km}$ ).

A statistical analysis was conducted for four members of WRF, at nested horizontal grid spacings of 12, 6, and $2 \mathrm{~km}$, from January 1, 2013 to August 1, 2013. The four members herein used to test sensitivity to boundary layer parameterizations include two local and two nonlocal PBL schemes. We have discarded the Jiménez and Dudhia topographic correction parameterization for a new member due to poor performance at coarse grid resolution. The four 
PBL schemes were the YSU (bl_pbl_physics = 1), Asymmetric Convective Model version 2 (bl_pbl_physics = 7), MO/Janjic ETA (bl_pbl_physics = 2), and the QNSE eddy diffusivity mass flux (bl_pbl_physics = 4). Hereafter, these are referred to as members 1, 2, 3, and 4, respectively. See WRF's User Guide for details and Table 16. The model skill was evaluated for consecutive forecasts from 24 to 48 hours. An example forecast for each domain $(\# 1=18 \mathrm{~km}$ resolution; $\# 2=6 \mathrm{~km}$; $\# 3=2 \mathrm{~km}$ ) for member 3 is presented in Figure 47.

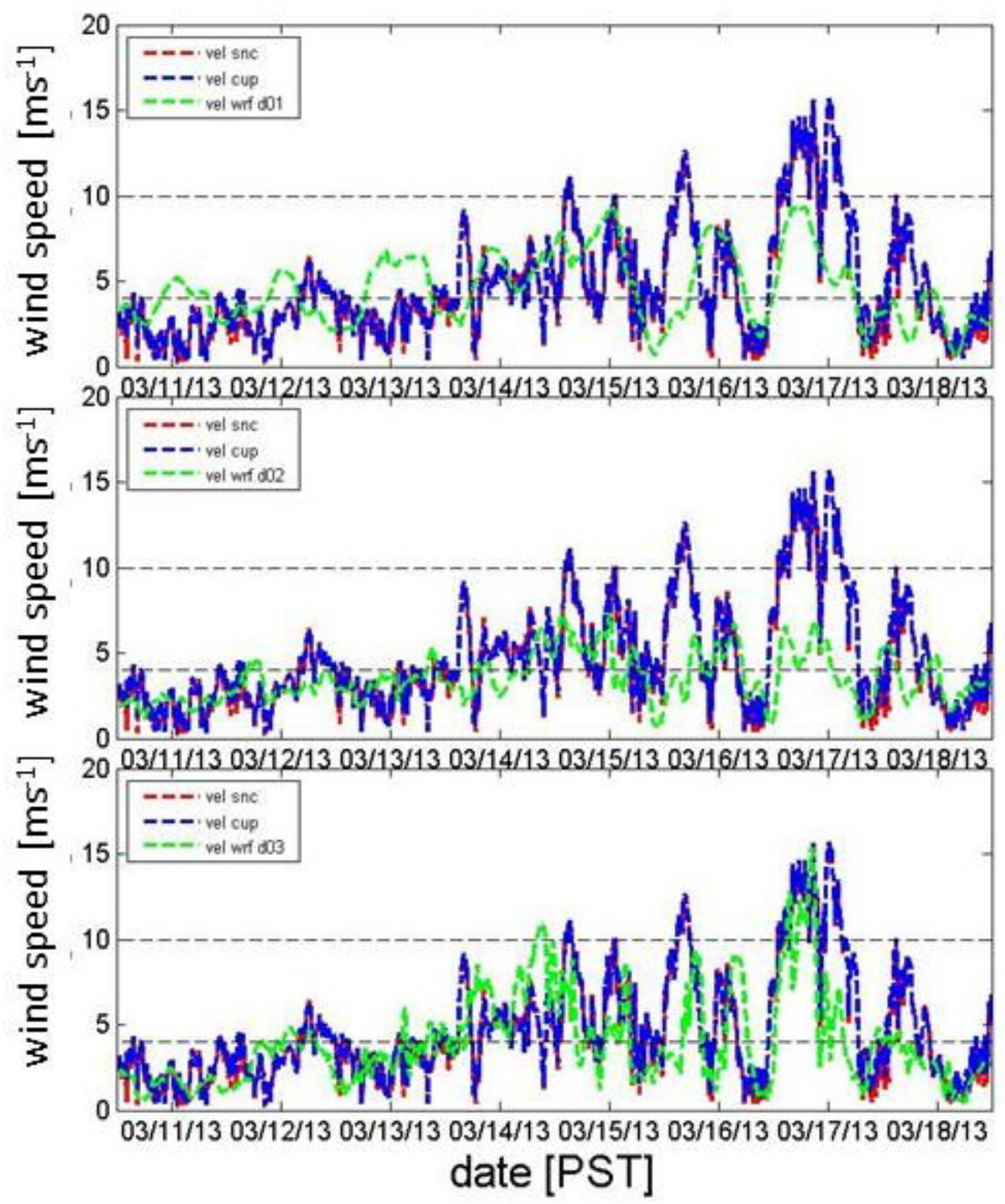

Figure 47. WT2 wind speed from the cup (blue) and sonic anemometers (red) at $60 \mathrm{~m}$ versus date for the WRF member 3 (MO Janjić Eta PBL option). Also plotted is the WRF 24-48 hour forecast wind speed (green) for the domain \#1 (top, $\Delta h=18 \mathrm{~km}$ ), domain \#2 (middle, $\Delta \mathrm{h}=6 \mathrm{~km}$ ), and the finest domain (bottom, $\Delta \mathrm{h}=2 \mathrm{~km}$ ).

For the time period January 1-July 31, 2013, we have calculated the RMSE (Figures 48 and 49), bias (Figures 48 and 49), and the correlation coefficient (Figure 50) for each member and for each domain. 
The formulas for the RMSE and bias are:

$$
\begin{aligned}
\text { RMSE } & =\sqrt{\frac{1}{n} \sum_{i=1}^{n}\left(v_{i, f}-v_{i, o}\right)^{2}} \\
\text { bias } & =\frac{1}{n} \sum_{i=1}^{n}\left(v_{i, f}-v_{i, o}\right)
\end{aligned}
$$

where $v$ is the wind speed, $f$ denotes the forecasts, and $o$ denotes the observations.

We use the closest grid point in the WRF domain and interpolate to $60 \mathrm{~m}$ between the model grid levels. An example of the correlation coefficient calculation is shown in Figure 51. The linear correlation coefficient monotonically increases with respect to increased horizontal grid resolution, while the behavior of RMSE and bias is not so clear. However, the smallest RMSE and close to the smallest bias are generally seen in the innermost domain $(2 \mathrm{~km})$. This effect is likely related to the finer domain's ability to capture topographically forced motions on DI and sub-diurnal (SD) scales (Figure 52). The correlation coefficient is also a very important indicator of the model's ability to capture wind ramps; however, wind ramps in this area are very difficult to forecast because the flow is topographically forced. In particular, many wind ramps on the ridge of the Virginia Hills are related to downslope windstorms in the lee of the Sierra Nevada and rotors that can span some or all of the Washoe Valley. We have also examined DI variability of RMSE and bias for each of the members (Figure 53). 

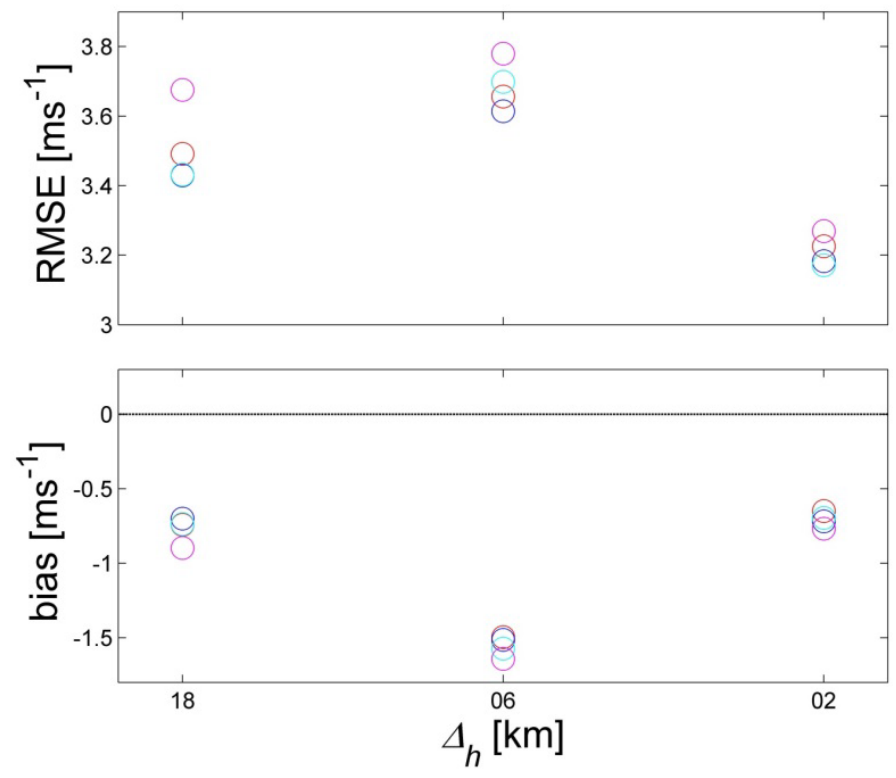

Figure 48. The WRF model RMSE (top) and bias (bottom) on WT1 at $60 \mathrm{~m}$ for all four members (\#1 red, \#2 blue, \#3 cyan, \#4 magenta) as a function of horizontal grid spacing of the domains for the period of October 6, 2012-August 12, 2013
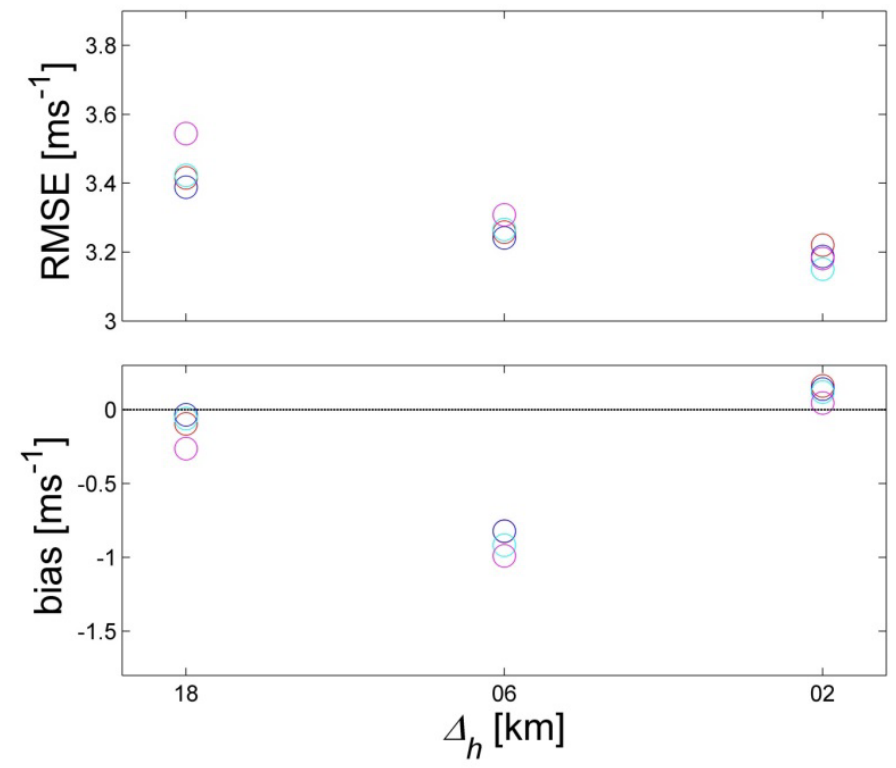

Figure 49. The WRF model RMSE (top) and bias (bottom) on WT2 at $60 \mathrm{~m}$ for all four members (\#1 red, \#2 blue, \#3 cyan, \#4 magenta) as a function of horizontal grid spacing of the domains for the period of October 6, 2012-August 12, 2013. A Y-axis range has been chosen to be consistent with the previous figure. 

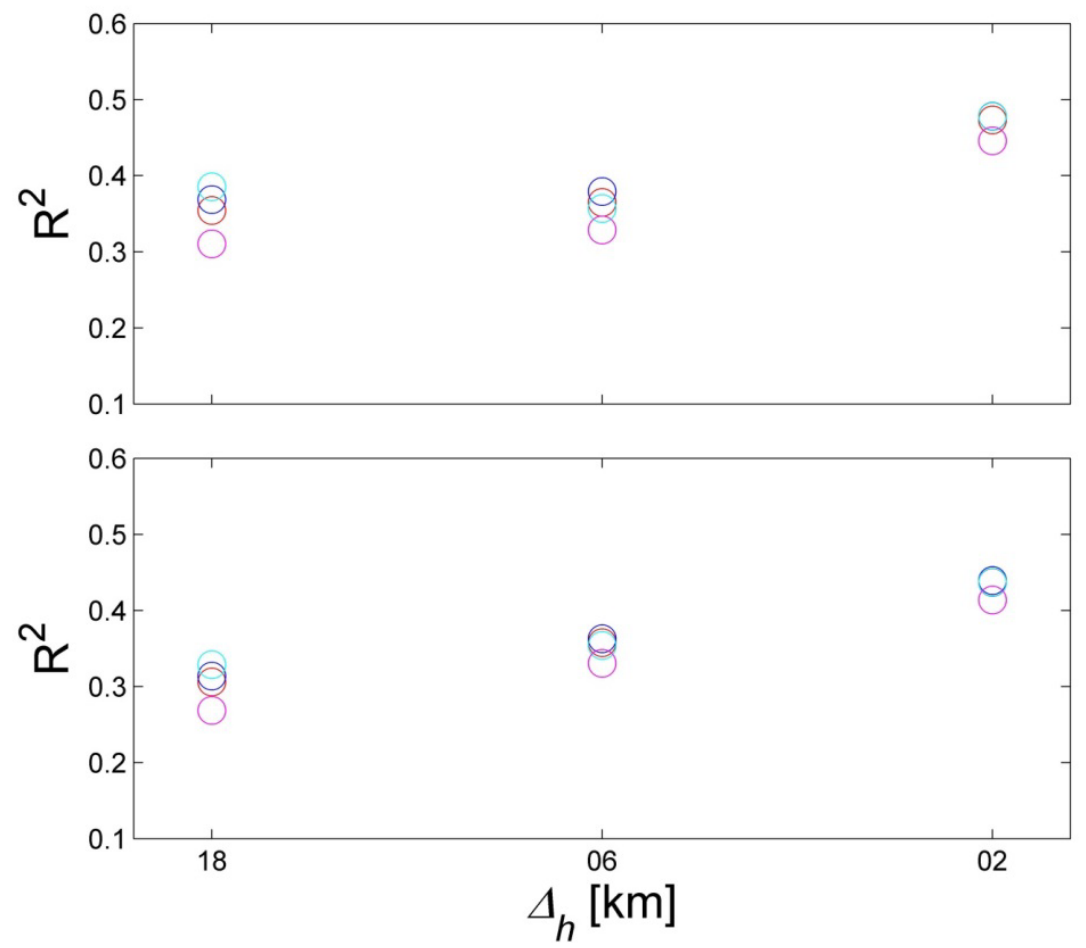

Figure 50. The WT1 (top) and tower WT2 (bottom) correlation coefficients between 60-m cup anemometer data and the WRF forecast as a function of grid spacing of the domains for all members (\#1 red, \#2 blue, \#3 cyan, \#4 magenta) for the period October 6, 2012-August 12, 2013

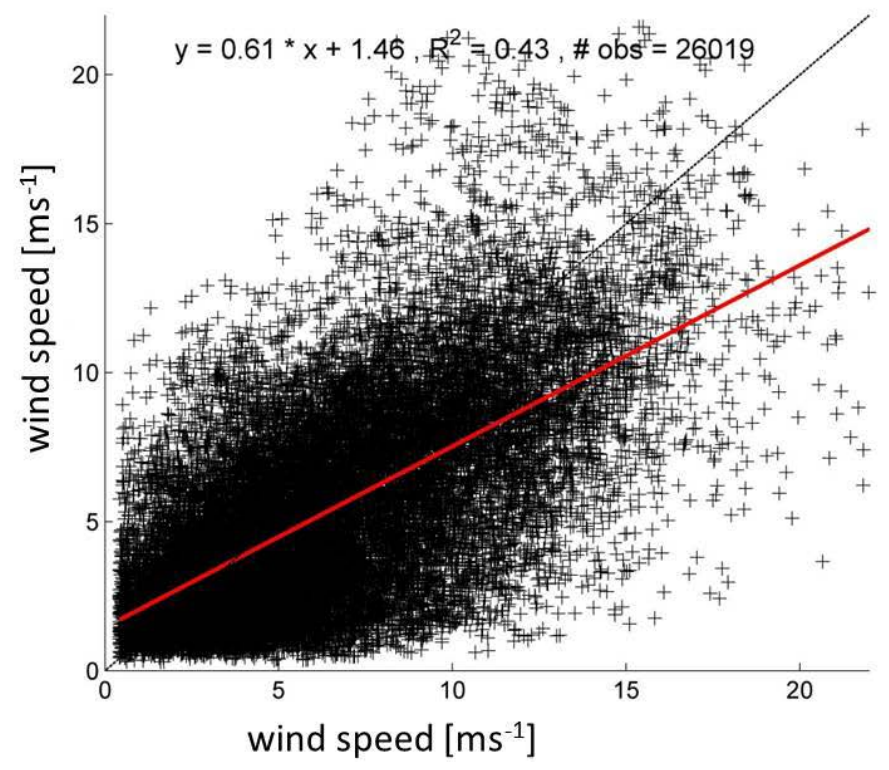

Figure 51. Scatter plot with a linear correlation of the $60-\mathrm{m}$ wind speed at tower WT1 (X-axis) and WRF forecast (Y-axis) used to calculate the correlation coefficient for member \#1, domain \#3 ( $2 \mathrm{~km}$ resolution) for the period of October 6, 2012-August 12, 2013 


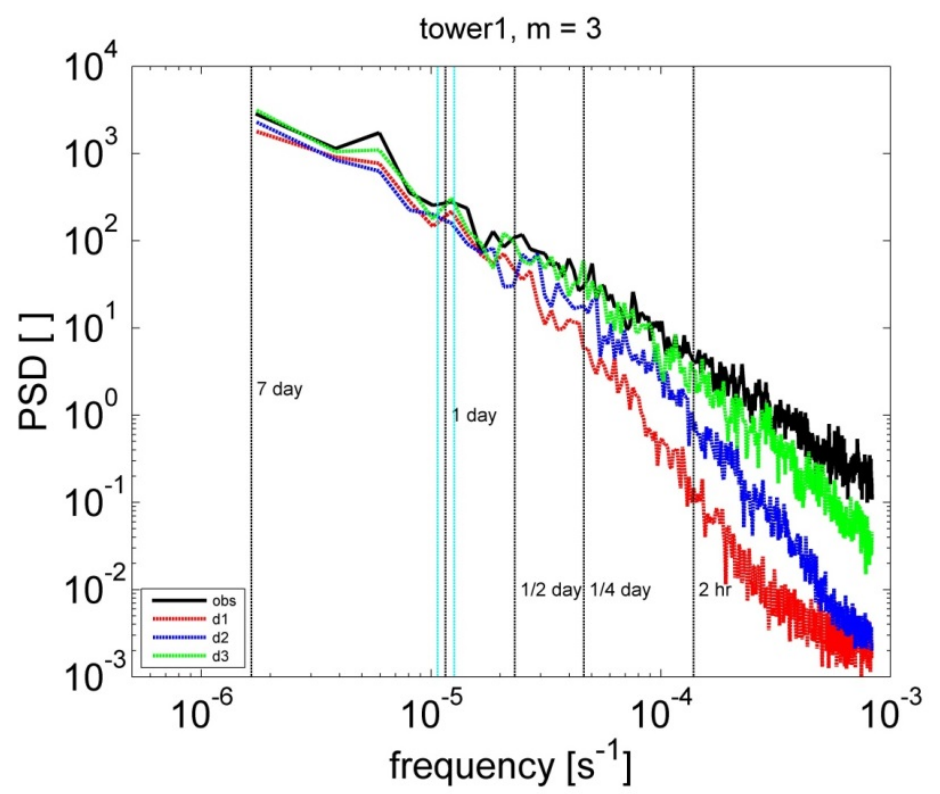

Figure 52. PSD of the 60-m wind speed from the WT1 cup anemometer data (black) and WRF domains 1 (red $18 \mathrm{~km}$ ), 2 (blue $6 \mathrm{~km}$ ) and 3 (green $2 \mathrm{~km}$ resolution) at $60 \mathrm{~m}$ for the period of October 6, 2012-August 12, 2013 for the WRF member $3(m=3)$ (MO Janjić Eta PBL option).

Vertical black lines indicate periods of 1 week, 1 day, and aliased integer multiples of 1 day; and the vertical cyan lines indicate periods of 1 day \pm 2 hours.
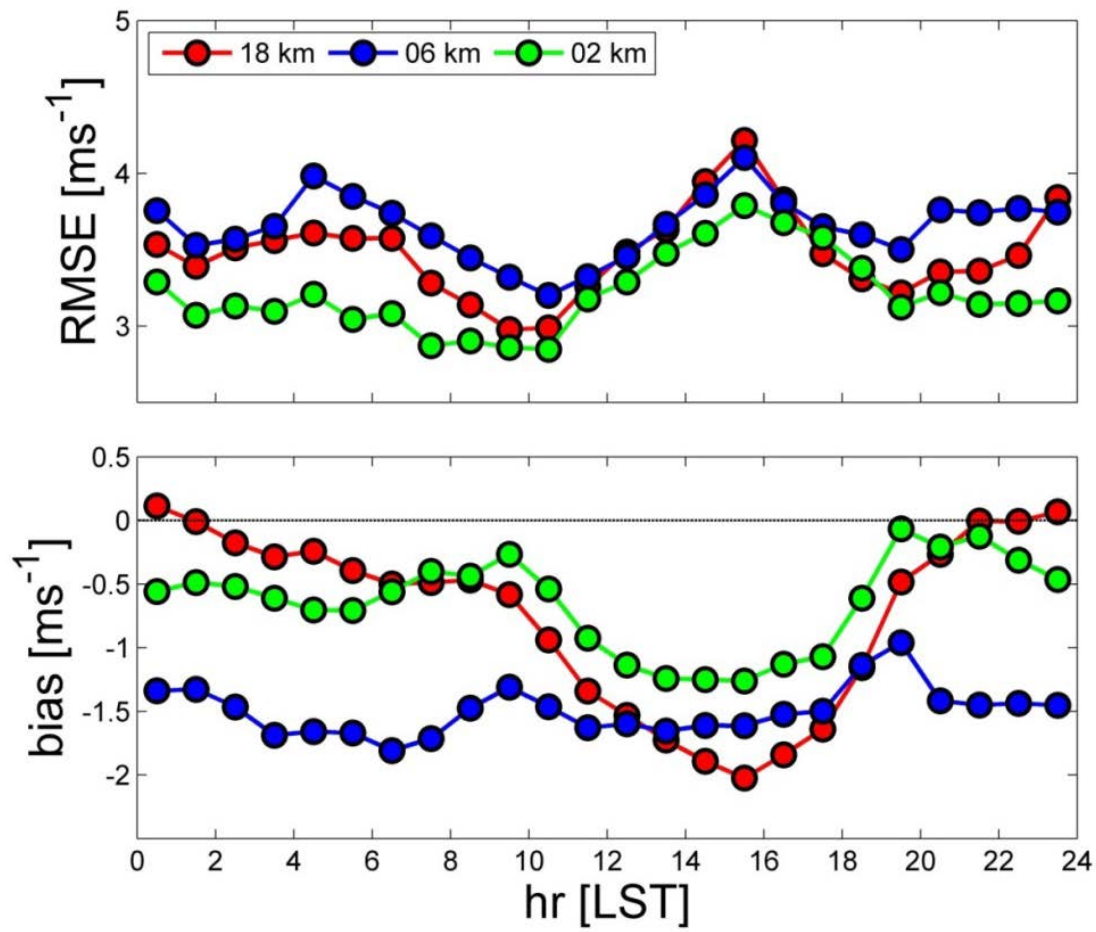

Figure 53. DI variability of the RMSE (top) and bias (bottom) at $60 \mathrm{~m}$ on tower WT1 for member \#1 for all three domains (grid spacings of $18 \mathrm{~km}$ (red), $6 \mathrm{~km}$ (blue), and $2 \mathrm{~km}$ (green) resolution) for the period of October 6, 2012-August 12, 2013 


\section{Additional Analyses}

\subsection{Subkilometer Dynamical Downscaling of Near-Surface Winds in Complex Terrain Using Weather Research and Forecasting and Mesoscale Model 5}

Subkilometer dynamical downscaling was performed using the WRF and MM5 models. The models were configured with horizontal grid spacing ranging from $27 \mathrm{~km}$ in the outermost telescoping to $333 \mathrm{~m}$ in the innermost domains and verified with data collected at four $50-\mathrm{m}$ towers in west-central Nevada during the previous NREL project (Belu and Koračin 2009; 2013) during July and December 2007. Here we show results for all stations and mainly for July 2007, while other results may be found in the attached article (Horvath et al. 2012).

The questions that we are addressing are:

1. What is the accuracy of the sub-kilometer dynamical downscaling of near-surface wind speed over complex terrain using the WRF and MM5 mesoscale models?

2. Does a uniform mesh refinement in mesoscale models uniformly enhance the accuracy of the near-surface wind speed estimates, and what is the grid spacing required for obtaining a reliable estimate of the near-surface wind statistics over complex terrain?

3. How equivalent are the moment-based and spectral verification metrics in assessing the models' performance?

4. What is the potential accuracy improvement with increasing horizontal resolution?

5. What are the strengths and weaknesses of dynamical downscaling using mesoscale models and what are the rationales and/or hypotheses that can be attributed to the sources of errors?

The comparison of measured and simulated wind speed distributions, as a part of the momentbased verification, suggests that results are similar at both $10 \mathrm{~m}$ and $50 \mathrm{~m}$ (here only $10 \mathrm{~m}$ results and only for July are shown). During July, MM5 results were less accurate than WRF results during the daytime and more accurate during the nighttime. The major difference resulting from the moment-based verification was that WRF showed larger magnitudes of the mean wind speeds than MM5 for all domains (Figure 54).

Figure 55 shows that MM5 underestimated mean wind speeds at the sub-kilometer grids by about $-18 \%$ at $10 \mathrm{~m}$ AGL and $-14 \%$ at $50 \mathrm{~m}$ above-ground level (AGL) in July and by about $26 \%$ at $10 \mathrm{~m}$ AGL and $-20 \%$ at $50 \mathrm{~m}$ AGL in December. In contrast, WRF overestimated mean wind speeds by about $13 \%$ at $10 \mathrm{~m}$ AGL and $10 \%$ at $50 \mathrm{~m}$ AGL in July and by about $11 \%$ at 10 $\mathrm{m} \mathrm{AGL}$ and $10 \%$ at $50 \mathrm{~m}$ AGL in December. As seen from the above values, MBIAS, the percentage ratio of modeled to observed mean wind speed, from both models for the verified months was higher at $10 \mathrm{~m}$ than at $50 \mathrm{~m}$ AGL. Finally, the systematic errors did not generally show monotonic decreases with the increased resolution in either model. 

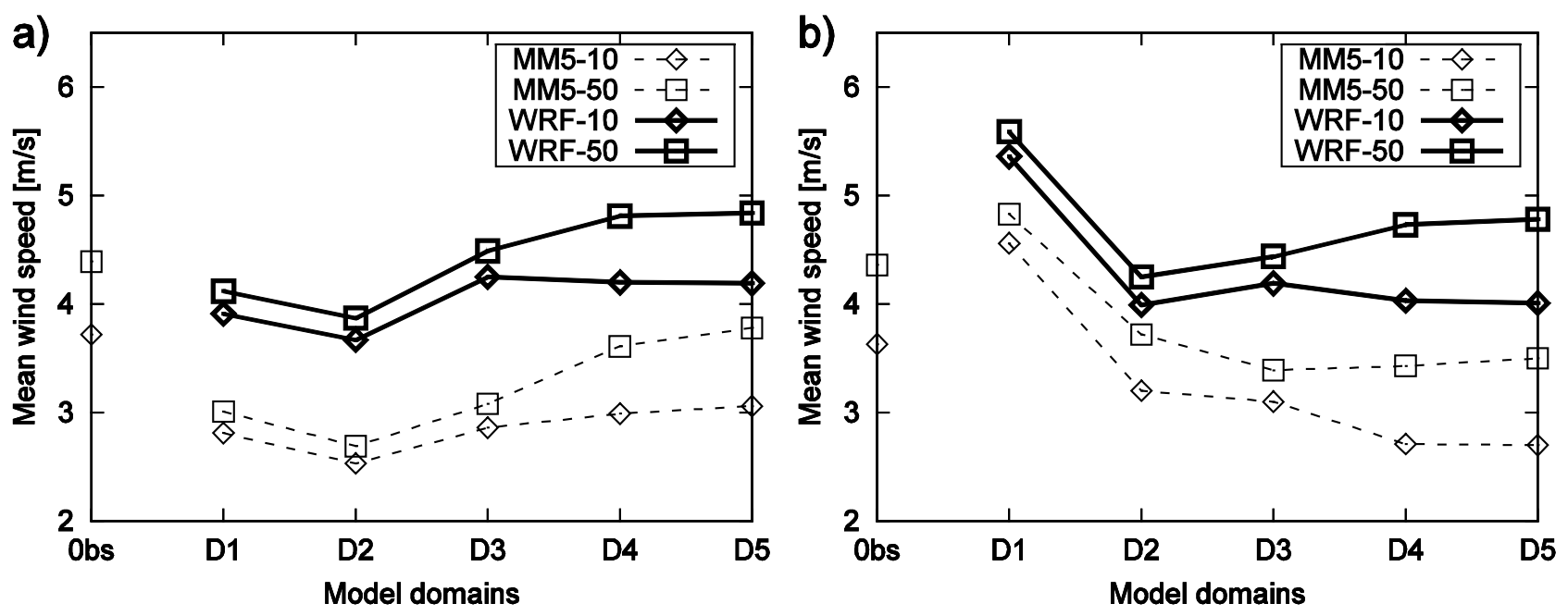

Figure 54. Mean wind speed in (a) July and (b) December 2007 for all model domains for the MM5 and WRF models. On the X-axis in a) and b), "Obs" denotes observed values.
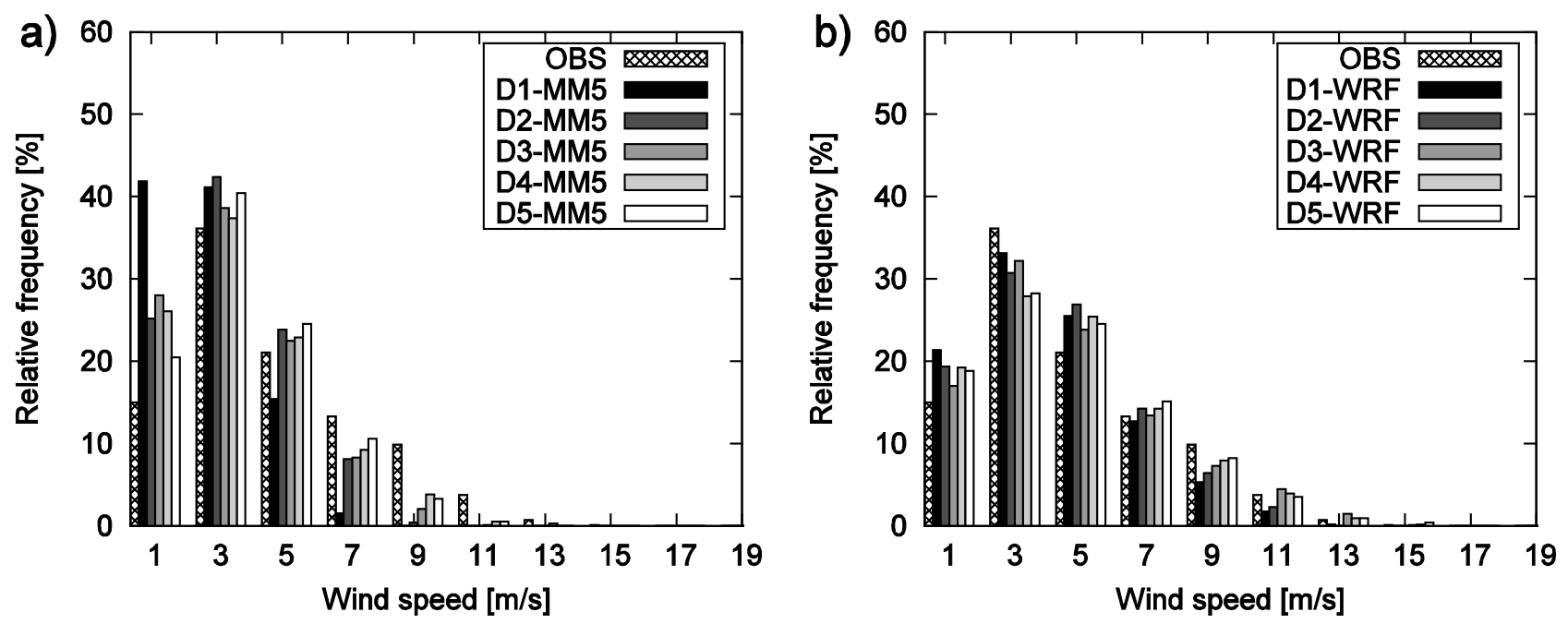

Figure 55. Histograms of observed and modeled wind speed at $10 \mathrm{~m}$ AGL during daytime for (a) MM5 and (b) WRF in July 2007. D1 denotes domain \#1, D2 domain \#2, D3 domain \#3, D4 domain \#4, and D5 domain \#5.

Figure 56 shows frequency of the measured and simulated (all five domains) wind speed at $10 \mathrm{~m}$ during daytime in July.

The most notable feature for MM5 is a considerable underestimation of the frequency of stronger daytime winds (wind speed $>6 \mathrm{~m} \mathrm{~s}^{-1}$ ) on the finest grids and overestimation of low winds for the coarsest domain. Note that higher resolution WRF domains show better agreement with measurements for higher winds; however, WRF largely overestimated the frequency of the stronger winds during the nighttime (figure not shown). 

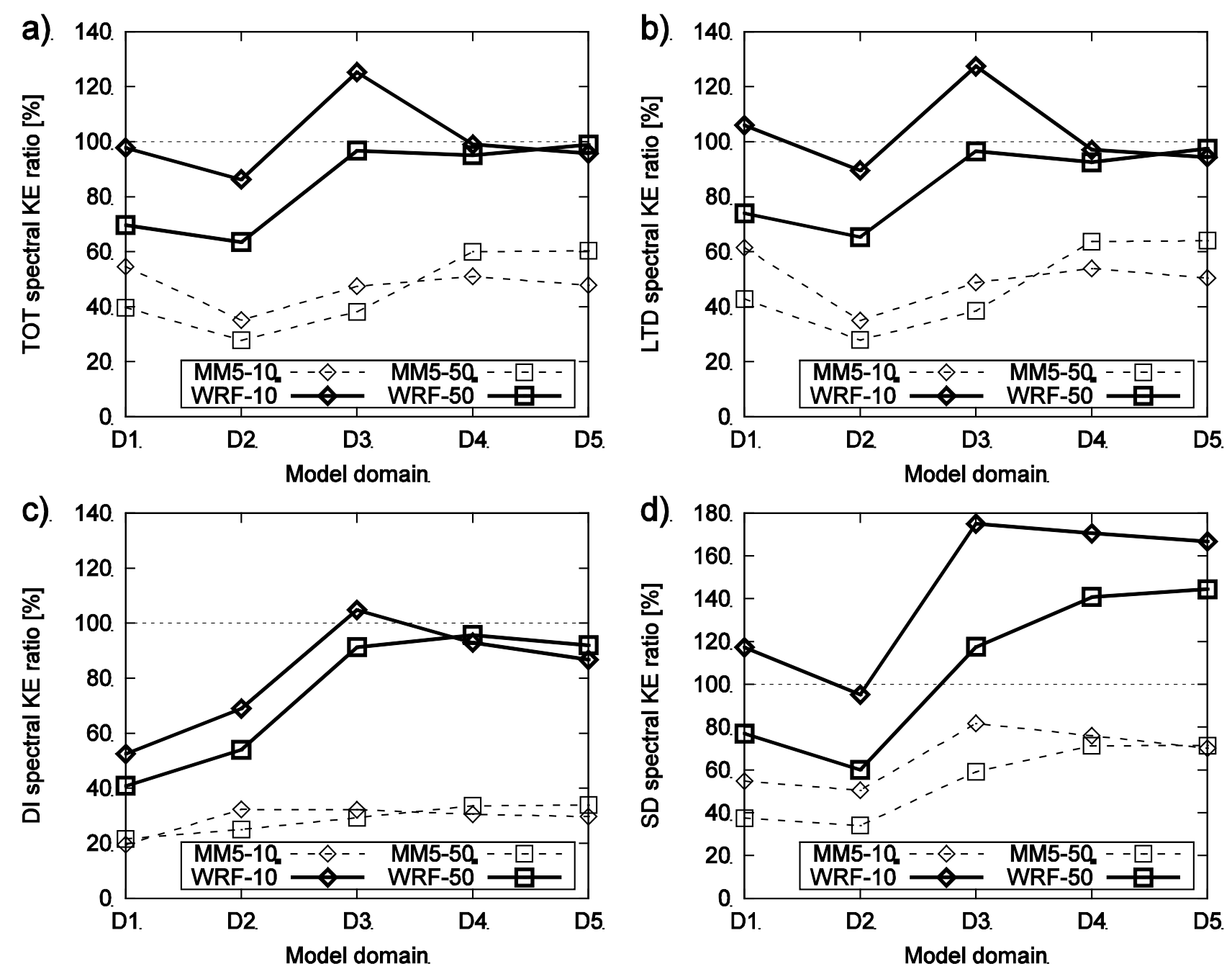

Figure 56. Variability of the ratio (\%) of the modeled and observed integrated spectral kinetic energy (horizontally averaged over all measurements stations) for all computational domains for MM5 and WRF in (a) total range of frequencies (total, 2 hours $<t<7$ days), (b) longer-than-diurnal range (LTD, 26 hours $<t<7$ days), (c) DI (22 hours $<t<26$ hours), and (d) SD (2 hours $<t<22$ hours) at $10 \mathrm{~m}$ and $50 \mathrm{~m}$ AGL for July 2007 . A perfect match $(100 \%)$ is plotted as a short-dashed line.

For the scale-selective quantitative spectral verification, we divide the motion spectrum into SD ( 2 hours $<\mathrm{T}<22$ hours), DI (22 hours $<\mathrm{T}<26$ hours), and longer-than-diurnal (LTD, 26 hours $<\mathrm{T}<7$ days) classes. We also studied the total range of frequencies. For brevity, here we show only results for July (Figure 57).

For the higher resolution domains (grid spacing of $3 \mathrm{~km}, 1 \mathrm{~km}, 0.333 \mathrm{~km}$, respectively) the energy contained in the total, LTD and DI frequency bands was close to observations for WRF. MM5 contained approximately $50 \%$ of the observed spectral kinetic energy at $10 \mathrm{~m}$ AGL in the total and LTD frequency bands and about 35\% in the DI frequency band.

On the other hand, the energy of the SD motions (which, however, carries only $4 \%$ of the energy variance in July) in the higher resolution domains was overestimated by about $70 \%$ at $10 \mathrm{~m}$, 
whereas it was underestimated by about $30 \%$ of the observed value at both levels in MM5. Generally, increasing the horizontal grid resolution in July showed a considerable benefit for both models, which was more evident in simulated winds at $50 \mathrm{~m}$ than at $10 \mathrm{~m}$ AGL.

\subsection{Dynamical Downscaling of Wind Shear: Observational Analysis and Comparison of Mesoscale Model 5 and Weather Research and Forecasting Mesoscale Model Performance}

Subkilometer dynamical downscaling of wind speed and wind shear was performed using the WRF and MM5 models. The models were configured with horizontal grid spacing ranging from $27 \mathrm{~km}$ on the outermost telescoping to $333 \mathrm{~m}$ on the innermost domain. They were verified with measurements collected at four 50-m towers (measurements of the wind speed at each $10 \mathrm{~m}$ ) in west-central Nevada during July and December 2007. Here we briefly summarize results, whereas more extensive analysis may be found in the article by Horvath et al. (2012).

The principal questions addressed in this study were:

1. What is the accuracy of the sub-kilometer dynamical downscaling of the near-surface wind shear over complex terrain using the WRF and MM5 mesoscale models?

2. Does a uniform mesh refinement in mesoscale models uniformly increase the accuracy of the near-surface wind shear estimates?

3. What is the grid spacing required for obtaining a reliable estimate of the near-surface wind shear over complex terrain?

4. How equivalent are the moment-based and spectral-based verification metrics in assessing the model's performance and the potential accuracy improvement with increasing the horizontal resolution?

5. What are the strengths and weaknesses of dynamical downscaling of wind shear using mesoscale models and what are the rationales and/or hypotheses that can be attributed to the sources of errors?

Wind shear was calculated as $\partial V / \partial z$, where $V$ is the wind speed and $z$ is the height. Unless specified otherwise, the wind shear is scaled by a factor of 100 in graphical presentations. Wind shear is calculated among all levels with $10 \mathrm{~m}$ and $20 \mathrm{~m}$ vertical differences due to uncertainties related to wind shear calculation over thin layers. While for specific wind energy studies wind shear at low wind speeds and low altitudes (below $30 \mathrm{~m}$ ) can be less relevant, we analyze the wind shear at lower heights and lower wind speeds to understand the properties of wind regime in the area. This understanding is helpful for an interpretation of observations and modeling results.

The mean wind speed profiles show an expected general increase with height at all analyzed wind towers (Figure 58). 

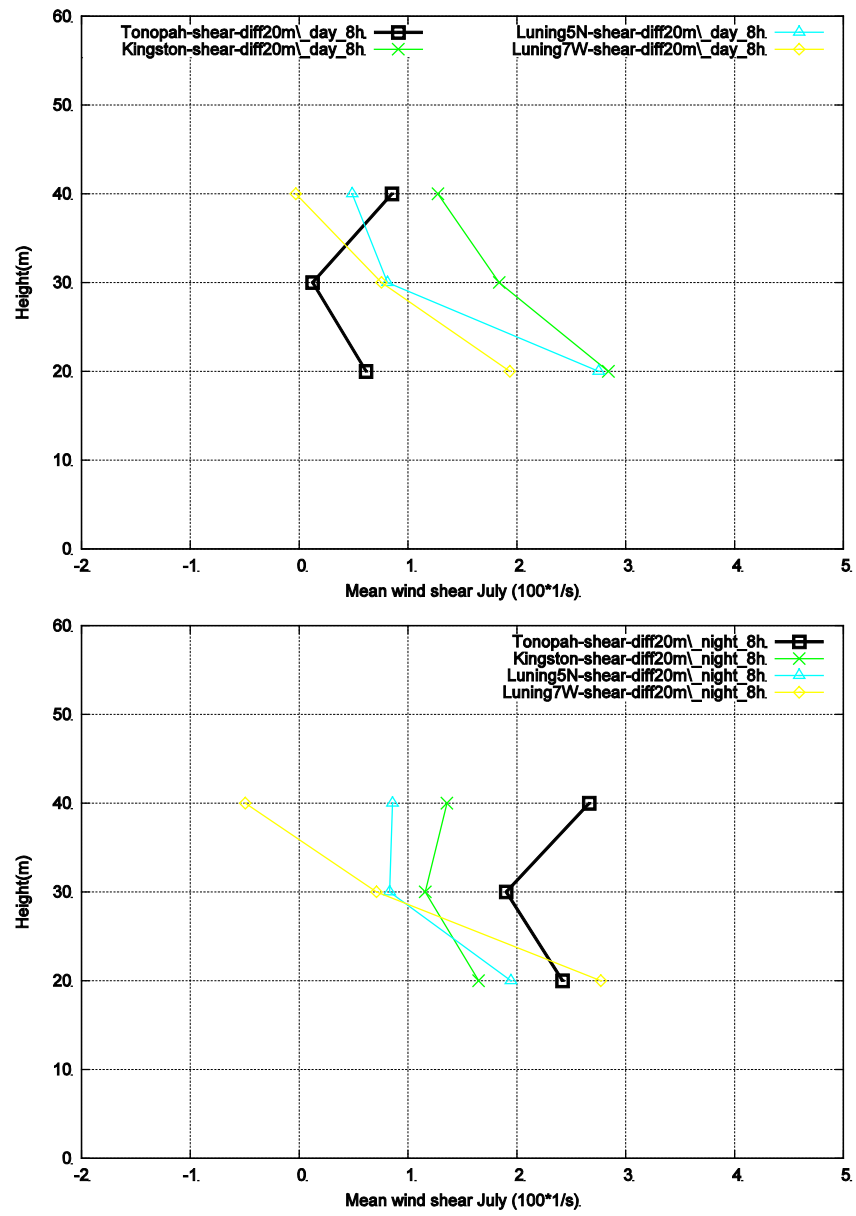

Figure 57. Time series of the measured mean wind shear for July 2007 during the daytime (top) and nighttime (bottom) at Tonopah, Kingston, Luning5N, and Luning7W towers for $20 \mathrm{~m}$ vertical separation between levels

Figure 58 shows that the magnitude of wind shear decreases with height during daytime, however, during the nighttime the wind shear between $30 \mathrm{~m}$ and $50 \mathrm{~m}$ is stronger than the wind shear between the $20 \mathrm{~m}$ and $40 \mathrm{~m}$ heights. This suggests that wind shear during the nighttime generally does not change monotonically with height and indicates possible shallow nocturnal flows. 

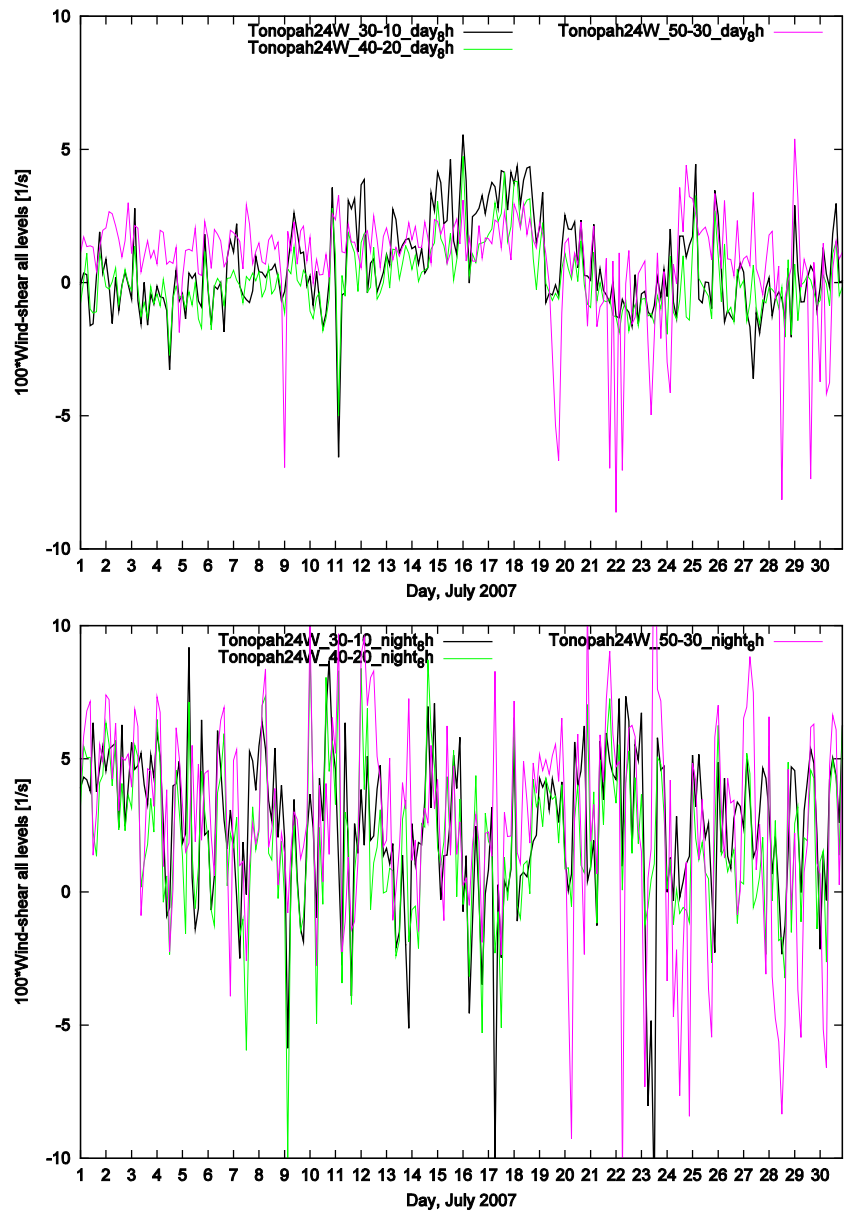

Figure 58. Time series of the measured wind shear during daytime (top) and nighttime (bottom) for July 2007 at the Tonopah 24-W tower

Time series of wind shear at the Tonopah tower reveals that, although the mean wind shear values are similar throughout the daily cycle, wind shear variability is much greater during the nighttime (Figure 59). 

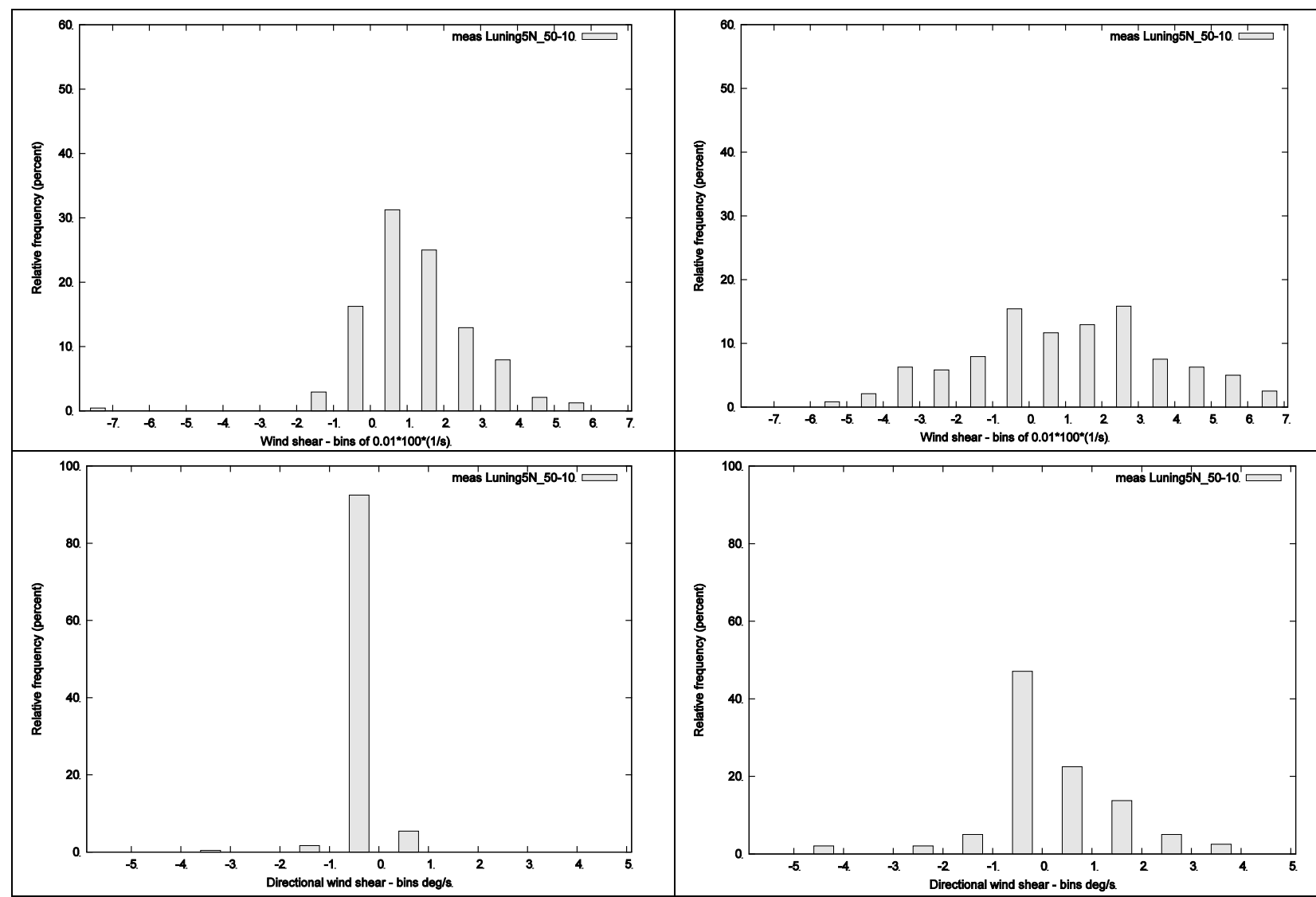

Figure 59. Histograms of the measured wind shear (top row) and the directional wind shear (bottom row) between $50 \mathrm{~m}$ and $10 \mathrm{~m}$ measurement levels during daytime (left column) and nighttime (right column) for July 2007 at the Luning $5 \mathrm{~N}$ tower

The wind shear distributions appear to be quite different between the daytime and nighttime. For all analyzed towers the daytime wind shear and directional wind shear distributions have less spread and smaller frequencies of negative shear events (Figure 60). Finally, spectral analysis suggests that there are important differences between the wind shear and wind shear PSDs, such as in magnitude and existence of the DI peak in the spectrum. 


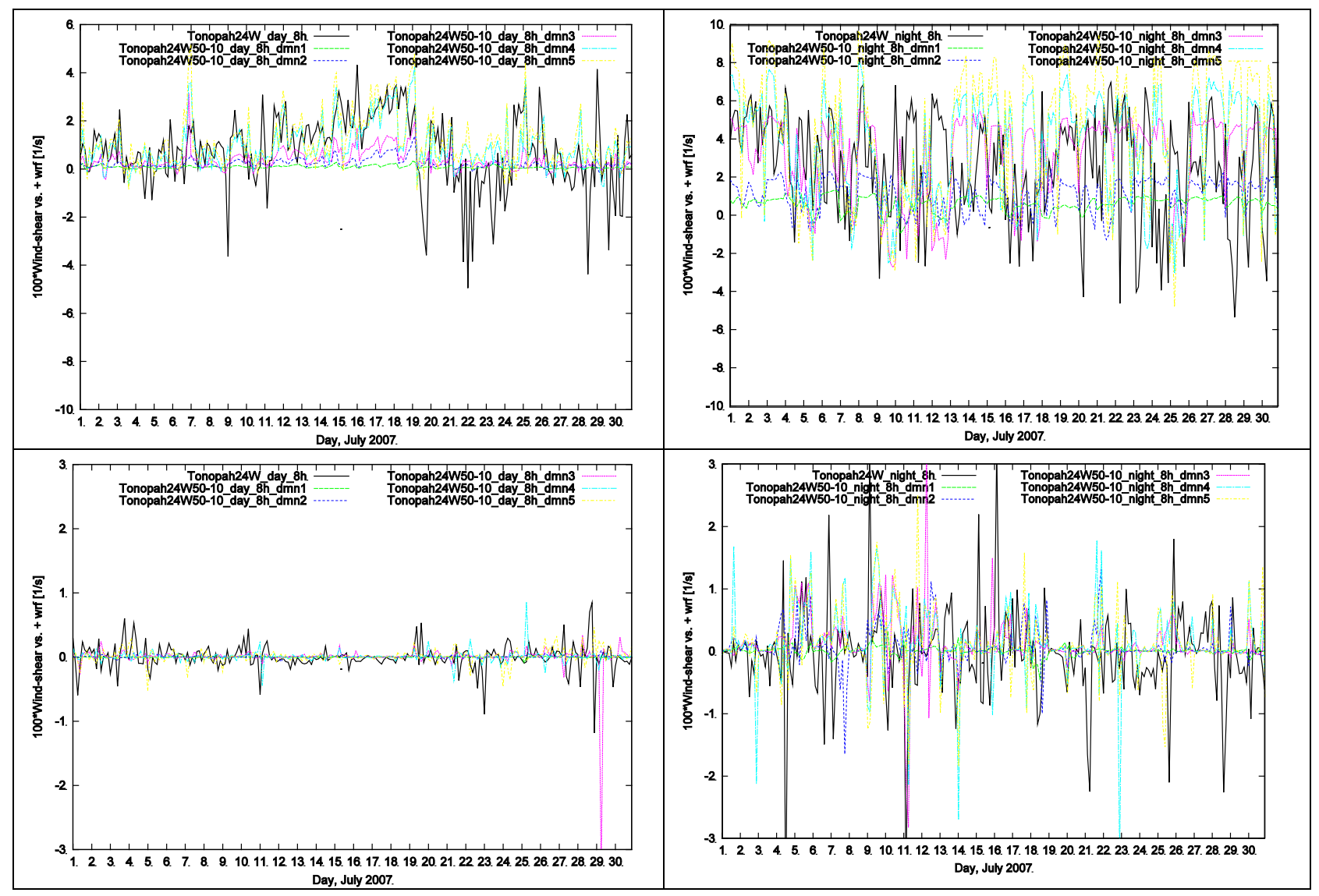

Figure 60. Measured, WRF-simulated (top), and MM5-simulated (bottom) time series of the wind shear during daytime (left column) and nighttime (right column) during July 2007 for the Tonopah tower. The models' results include five domains with different grid spacing ranging from $27 \mathrm{~km}$ to $333 \mathrm{~m}$.

Figure 61 shows that the simulated variability of the wind shear and the directional wind shear is underestimated in the lower resolution domains $(27 \mathrm{~km}, 9 \mathrm{~km}, 3 \mathrm{~km}$ grid spacing). The underestimation is more pronounced during the daytime. In the higher resolution domains, the intensity of positive wind shear and positive directional wind shear (clockwise turning with altitude) is more comparable to observations, while the intensity and variability of negative wind shear and directional wind shear are generally underestimated for all four wind towers for both WRF and MM5 (not shown here). This suggests that the current mesoscale models have considerable constraints in representing negative near-surface wind shear. Finally, events with negative wind shear are better represented in the WRF model than in the MM5, suggesting weaker vertical diffusion in WRF than in the MM5. Whether this variability exists at the right time can be studied in more details with statistical scores of the model success.

Mean measured wind shear and its standard deviation as well as basic statistical scores for all five domains for July 2007 at Tonopah and for both models are shown in Table 17. The simulated mean wind shear tends to grow with increasing resolution toward the observed values, while generally the RMSE is similar for both models. Finally, correlations are generally rather small (around 0.5 and smaller) suggesting that only part of wind shear variability is explained in the models. Finally, statistical scores for the directional wind shear (e.g., correlations) are worse 
than for the wind shear, suggesting that neither model successfully represents the measured directional wind shear.

Table 17. Statistics of the a) MM5 and b) WRF Simulated Wind Shear for the Tonopah Tower During July 2007*

a) MM5

\begin{tabular}{|c|c|c|c|c|c|c|}
\hline Source of Data & $\begin{array}{c}\text { Mean } \\
\left(10^{2} s^{-1}\right)\end{array}$ & $\begin{array}{c}\text { Standard } \\
\text { Deviation } \\
\left(10^{2} s^{-1}\right)\end{array}$ & $\begin{array}{l}\text { Covariance } \\
\quad\left(10^{4} s^{-2}\right)\end{array}$ & $\begin{array}{c}\text { Correlation } \\
\text { (no unit) }\end{array}$ & $\begin{array}{l}\text { RMSE } \\
\left(10^{2} s^{-1}\right)\end{array}$ & $\begin{array}{l}\text { NRMSE } \\
\text { (no unit) }\end{array}$ \\
\hline Measurements & 1.68310 & 2.43770 & - & - & - & - \\
\hline Domain 1 & 1.51690 & 1.60570 & 1.36330 & 0.34829 & 2.41120 & 1.43260 \\
\hline Domain 2 & 0.97700 & 0.88657 & 0.59384 & 0.27477 & 2.45600 & 1.45920 \\
\hline Domain 3 & 1.58920 & 1.66700 & 1.37450 & 0.33823 & 2.44400 & 1.45210 \\
\hline Domain 4 & 2.39670 & 2.01690 & 1.67220 & 0.34010 & 2.67700 & 1.59050 \\
\hline Domain 5 & 2.94470 & 2.53120 & 2.11830 & 0.34331 & 3.11340 & 1.84990 \\
\hline
\end{tabular}

* Wind shear is calculated as $\partial \mathrm{V} / \partial \mathrm{z}$ and scaled (multiplied) with a factor 100 . Statistics presents mean measured values $\left(10^{2} \mathrm{~s}^{-1}\right)$ and standard deviations $\left(10^{2} \mathrm{~s}^{-1}\right)$ for both measurements and model domains $1\left(\Delta_{\mathrm{x}}=27 \mathrm{~km}\right), 2\left(\Delta_{\mathrm{x}}=9\right.$ $\mathrm{km}), 3\left(\Delta_{\mathrm{x}}=3 \mathrm{~km}\right), 4\left(\Delta_{\mathrm{x}}=1 \mathrm{~km}\right), 5\left(\Delta_{\mathrm{x}}=333 \mathrm{~m}\right)$, and covariance $\left(10^{4} \mathrm{~s}^{-2}\right)$, correlation (no unit), root-mean-square error (RMSE, $10^{2} \mathrm{~s}^{-1}$ ) and root-mean-square error normalized with measured mean value (NRMSE, no unit).

b) WRF

\begin{tabular}{lcccccc}
\hline $\begin{array}{c}\text { Source of } \\
\text { Data }\end{array}$ & $\begin{array}{c}\text { Mean } \\
\left(\mathbf{1 0}^{\mathbf{2}} \mathbf{s}^{-1}\right)\end{array}$ & $\begin{array}{c}\text { Standard } \\
\text { Deviation } \\
\left(\mathbf{1 0}^{\mathbf{2}} \mathbf{s}^{-1}\right)\end{array}$ & $\begin{array}{c}\text { Covariance } \\
\left(\mathbf{1 0}^{\mathbf{4}} \mathbf{s}^{-\mathbf{2}}\right)\end{array}$ & $\begin{array}{c}\text { Correlation } \\
(\text { no unit) }\end{array}$ & $\begin{array}{c}\text { RMSE } \\
\left(\mathbf{1 0}^{\mathbf{2}} \mathbf{s}^{-1}\right)\end{array}$ & $\begin{array}{c}\text { NRMSE } \\
\text { (no unit) }\end{array}$ \\
\hline Measurements & 1.68310 & 2.43770 & - & - & - & - \\
\hline Domain 1 & 0.32040 & 0.36091 & 0.28422 & 0.32305 & 2.71170 & 1.61120 \\
\hline Domain 2 & 0.66217 & 0.75872 & 0.59024 & 0.31913 & 2.52440 & 1.49990 \\
\hline Domain 3 & 1.72580 & 1.94370 & 1.56690 & 0.33071 & 2.56500 & 1.52400 \\
\hline Domain 4 & 2.34440 & 2.36320 & 1.93890 & 0.33657 & 2.84190 & 1.68850 \\
\hline Domain 5 & 2.61390 & 2.84240 & 2.07150 & 0.29896 & 3.27590 & 1.94640 \\
\hline
\end{tabular}

Generally, both models on average reproduce too frequently a weak wind shear and lack representing events with stronger wind shear and directional wind shear, either positive or negative (Figure 62). This is more pronounced during the daytime and is similarly found for all wind towers. 

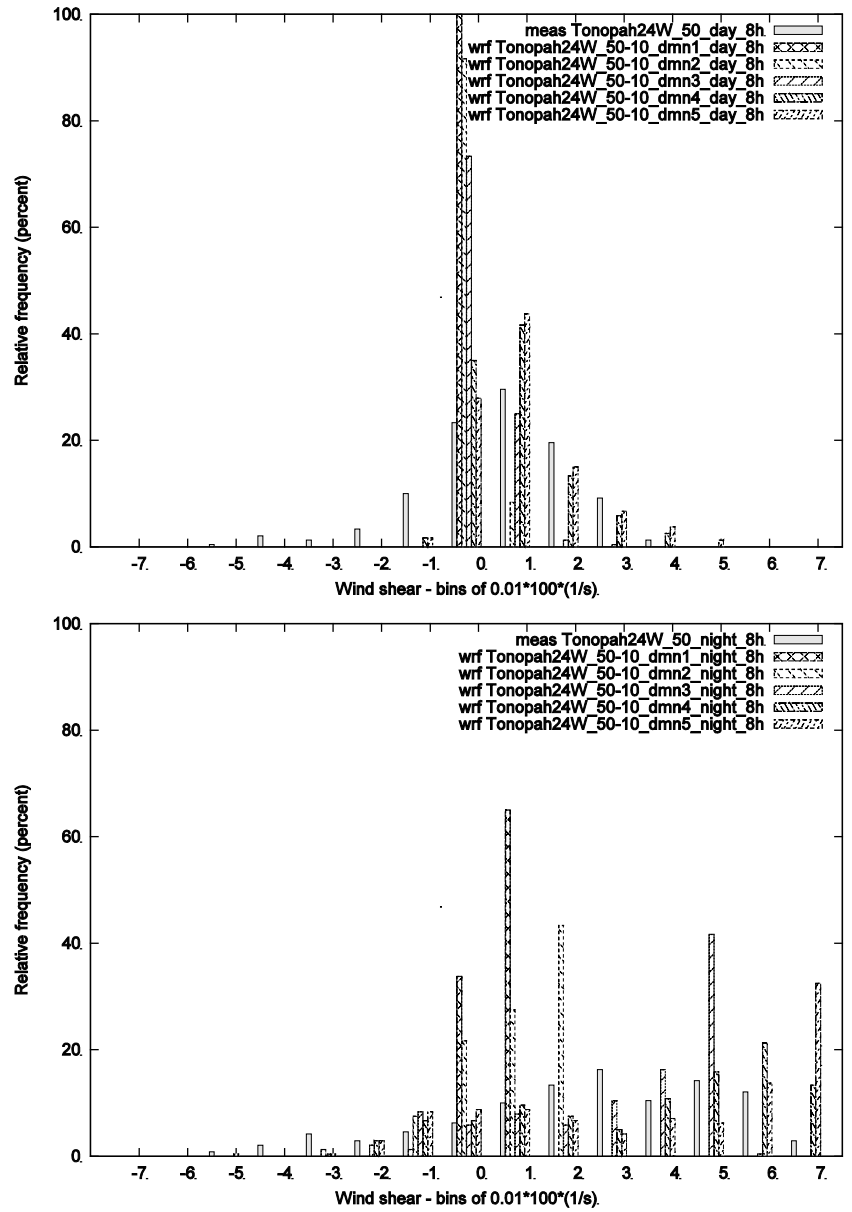

Figure 61. Histograms of the measured and simulated wind shear for WRF and all five model domains for July 2007 during daytime (top) and nighttime (bottom) for the Tonopah tower

The spread and asymmetry of the distributions are better represented for positive (directional) wind shear. For both models, the results generally tend to improve with resolution, though with some exceptions.

Power spectral densities of the observed and simulated directional wind shear are analyzed for all four wind towers, both models, all five model domains, and $40 \mathrm{~m}$ separation between levels (50$10 \mathrm{~m}$ ). Both models well represent the wind shear in total, LTD, DI, and even SD frequency bands, while insufficient energy was simulated by the lower resolution domains. On the other hand, both models were less successful in simulating the energy variance of the directional wind shear, with the exception of WRF higher-resolution simulations in the LTD frequency band, which is accurately simulated. 


\section{Conclusions}

The main objective of this project was to provide year-long wind tower and acoustic sounder measurements and evaluate two regional/mesoscale models. During the field program campaign in the complex terrain of western Nevada we deployed two 60-m towers and an acoustic sounder over the ridges of the Virginia Hills near Reno. The towers were separated horizontally by 2,700 $\mathrm{m}$ and vertically by $140 \mathrm{~m}$. They were instrumented with cup (at 20,40, and $60 \mathrm{~m}$ ) and sonic (20 and $60 \mathrm{~m}$ ) anemometers. Additionally, surface meteorological measurements were conducted at the main tower (located at a higher elevation). The acoustic sounder (sodar) was co-located with the main tower and provided wind measurements within the range from 40 to $200 \mathrm{~m}$ height and vertical resolution of $10 \mathrm{~m}$. Although it was proposed to have a one-year measurement period, the field campaign was conducted from October 5, 2012, through February 24, 2014, to cover for data loss or other data collection and communication problems.

Data from the two towers and sodar were uploaded to the DRI-WRCC website and they are publicly accessible. Links to the websites are:

- http://www.wrcc.dri.edu/cgi-bin/rawMAIN.pl?nvncs1 McClellan Peak tower (tower WT1)

- http://www.wrcc.dri.edu/cgi-bin/rawMAIN.pl?nvncs2 McClellan north saddle tower (tower WT2)

- http://www.wrcc.dri.edu/cgi-bin/rawMAIN.pl?nvncs4 Sodar data from McClellan Peak.

Besides being a data depository, the website lets the user interactively process the data online, produce statistics, and create and save plots and tables.

A three-way comparison (tower/cup, tower/sonic, and sodar) shows that the highest correlation is between sonic and cup anemometers. Considering the cup-anemometer measurements as a reference, sonic appears to overestimate wind speed for lower range of speeds and underestimate the winds for a higher range of speeds. When selecting only data with the recommended $\mathrm{QC}=$ $90 \%$, the correlation between the sodar and cup as well as sonic anemometers reaches 0.91 and 0.90 , respectively. It should be mentioned that sodar shows some overestimation for almost the entire range of wind speeds.

The analysis shows that both towers have very similar DI variation of the wind speed. The difference of $140 \mathrm{~m}$ in elevation results in an almost uniform small difference among the corresponding mean hourly values of less than $1 \mathrm{~m} \mathrm{~s}^{-1}$. The difference is slightly larger in more stratified nocturnal flows and slightly smaller during daytime mixing. The greatest mean wind speed values are in the late afternoon hours with well-developed upslope flows over the ridges.

High values of TI occur mainly for low wind speeds when the wind direction is more variable with a large standard deviation. For wind speeds greater than about $5 \mathrm{~m} \mathrm{~s}^{-1}$, the intensity is mainly between $10 \%$ and $15 \%$. The intensity is somehow larger for WT2, which has lower speeds and more complexity in the surrounding ridges. During lower wind speeds, the intensity is greatest for the lowest level, while for higher wind speeds the intensity is quite similar with height. The $k$ coefficient drops with height more uniformly for sodar than the cup anemometers 
while the $c$ coefficient increases with height. The analysis revealed seasonal effects in the behavior of the $k$ and $c$ Weibull parameters. The winter season is characterized by low wind speeds and by the lowest $k$ and highest $c$ coefficients. An opposite effect is for high spring cases - the $k$ coefficient is the highest and the $c$ coefficient is the lowest.

Regarding the sodar data, the recovery rate quickly decreases beyond $60 \mathrm{~m}$, and above $100 \mathrm{~m}$ the recovery rate is well below $50 \%$ for all QCs. In summary, data recovery rates from the sodar, using the manufacturer-recommended QC minimum of $90 \%$, are low and biased with respect to mean wind speed from the sonic anemometer and time of day. The recovery rate is optimal during low and medium winds. One of the sodar's characteristics appears to be a rapid drop in the recovery rate for winds greater than $10 \mathrm{~m} \mathrm{~s}^{-1}$. This can have significant implications for the assessment of the wind power density. It is interesting to note that, considering all observations, the sodar overestimates wind speed during low wind speeds, but to some extent underestimates wind speeds during high winds. According to the autocorrelation analysis, the sodar shows more wind speed consistency in the shorter period of time with higher autocorrelation coefficients compared to the towers' data.

A preliminary calculation of the wind power density showed that WT1 has the highest potential. The mean value of the wind power density at $60 \mathrm{~m}$ for the entire period is $220 \mathrm{~W} \mathrm{~m}^{-2}$ for WT1 compared to only $131 \mathrm{~W} \mathrm{~m}^{-2}$ for WT2. There is a strong seasonal variability of the wind power density with the highest values at $60 \mathrm{~m}$ in spring (WT1: $309 \mathrm{~W} \mathrm{~m}^{-2}$; WT2: $198 \mathrm{~W} \mathrm{~m}^{-2}$ ) and fall (WT1: $310 \mathrm{~W} \mathrm{~m}^{-2}$; WT2: $166 \mathrm{~W} \mathrm{~m}^{-2}$ ). At the same height, sodar shows lower values (mean: 202, spring: 165 , and fall: $172 \mathrm{~W} \mathrm{~m}^{-2}$ ). According to the sodar, the mean wind power density increases from $571 \mathrm{~W} \mathrm{~m}^{-2}$ at $100 \mathrm{~m}$ to $972 \mathrm{~W} \mathrm{~m}^{-2}$ at $120 \mathrm{~m}$. The value at $140 \mathrm{~m}$ is roughly double the value at $120 \mathrm{~m}$.

The second objective of the project was to evaluate high-resolution models with fixed (WRF) and adaptive (OMEGA) grid structures.

The WRF and OMEGA models were set up for western Nevada centered on the area with towers and the sodar. The models were evaluated using the data collected at the field site. During the first part of the study, additional analysis and modeling studies using MM5 and WRF were conducted utilizing data from the prior NREL-supported tower field program in western Nevada. This part of the study investigated DI and seasonal wind properties in complex terrain and uncertainties and errors in simulations.

Key conclusions from the OMEGA numerical experiments follow:

1. The first set of experiments over southwestern Nevada produced promising results in which OMEGA was competitive with other numerical models in simulating the evolution of low-level wind fields. The second set of numerical simulations over northwestern Nevada was less successful.

2. OMEGA performed much better at simulating low-level winds in the cold season than in the warm season.

3. OMEGA performed better at simulating low-level wind direction relative to wind velocity. 
4. OMEGA significantly under-simulated the magnitude of the wind velocity, particularly when DI forcing from the ground surface was important during the warm season.

5. The 667-m grid resolution version of OMEGA performed much better than the 2-km grid resolution version during both seasons.

6. The main source of error in the OMEGA PBL code was its inability to replicate the DI cycle of mixing, turbulence kinetic energy, and surface fluxes, all associated with the accurate simulation of near surface temperature.

To simulate atmospheric conditions on various scales, WRF was set up with multiple nested grids for a large span of horizontal resolutions. WRF was run in a hindcast mode and also as an ensemble forecasting system. The forecasting system included up to six interactive domains, and the number of domains within a run depended on the availability of the computer resources. Horizontal grid spacing ranged from $108 \mathrm{~km}$ on the coarsest to $444 \mathrm{~m}$ on the innermost domain. The evaluations were performed using data from the towers and the sodar at the Virginia Hills site.

The key conclusions regarding WRF simulations and evaluations using the towers and the sodar data follow:

- Generally, the WRF evaluations indicate favorable comparison with measurements during the afternoon speed up events; however, WRF has problems with rapid decrease of the wind speed and variable wind direction.

- Forecasts of winter storms are satisfactory, but frequently the wind speed peaks are overestimated. An initial WRF ensemble system for probabilistic forecasting was of limited size because the computer power was dictating the number of the ensemble members. However, ensemble forecasting techniques still represent an avenue that will be most likely followed in the future: replacement of deterministic single-result forecasts with probability density functions of the meteorological parameters including wind speed components. There are ongoing efforts in ensemble forecasting that are being applied to regional and mesoscale forecasts (e.g., Stensrud 2000; Koračin et al. 2014).

- WRF was able to forecast the high vertical velocities associated with the downslope windstorm and the valley rotor. On the western side of the valley there is a dominant incoming westerly wind component, while further to the east there are near-zero and negative $u$ component velocities.

A long WRF forecast run from January 1 to August 1, 2013, was completed during the project period. This run provided a basis for a statistical analysis of four ensemble members of WRF at nested horizontal grid spacing of 12-, 6-, and 2-km resolutions. The linear correlation coefficient between the cup anemometer data and WRF results at $60 \mathrm{~m}$ monotonically increases with respect to increased horizontal grid resolution, while the behavior of RMSE and bias is not so clear. However, the smallest RMSE and close to the smallest bias are generally seen in the innermost domain $(2 \mathrm{~km})$, because this domain can capture small-scale, topographically forced motions. The moderate correlation coefficient also indicates that WRF has had some success in reproducing sudden increases in the wind speed (wind ramps), which are difficult phenomena to forecast in complex terrain. 
Regarding the MM5 and WRF downscaling and comparison with data from four 50-m towers in western Nevada, significant characteristics were revealed in the spectral space. The LTD motions carry the largest share of energy variance, followed by the DI band. Results vary slightly between $10 \mathrm{~m}$ and $50 \mathrm{~m}$ AGL, and generally DI flows, forced by surface inhomogeneities, are slightly more pronounced at $10 \mathrm{~m}$ than at $50 \mathrm{~m}$ AGL. The major difference resulting from moment-based verification was that WRF showed larger magnitudes of mean wind speeds than MM5 in all domains. MM5 underestimated mean wind speeds at sub-kilometer grids. In contrast, WRF overestimated mean wind speeds by about $10 \%$ or so at 10 and $50 \mathrm{~m}$ AGL for both July and December. It should be noticed that the errors did not generally show monotonous decrease with the increased resolution for either model. MM5 shows a considerable underestimation of the frequency of stronger daytime winds on the finest grids. On the other hand, WRF largely overestimated the frequency of the stronger winds during the nighttime. Thus, the positive WRF bias results predominantly from overestimation of the frequency of stronger winds during the nighttime. Generally, increasing the horizontal grid resolution in July showed a considerable benefit for both models, which was more evident in simulated winds at $50 \mathrm{~m}$ than $10 \mathrm{~m}$ AGL.

Regarding the wind shear analysis, mean wind speed profiles show an expected general increase with height at all analyzed wind towers. During the daytime, the magnitude of wind shear decreases with height, but during the nighttime the wind shear between $30 \mathrm{~m}$ and $50 \mathrm{~m}$ is stronger than the wind shear between $20 \mathrm{~m}$ and $40 \mathrm{~m}$. This suggests that wind shear during the nighttime generally does not change monotonically with height, indicating a potential presence of shallow nocturnal flows. Similar results are found for all towers and for directional wind shear. This demonstrates the basic characteristics of the wind shear climate at the analyzed towers. For all analyzed towers the daytime wind shear and directional wind shear distributions have less spread and smaller frequency of negative shear events. Finally, spectral analysis suggests that there are important differences between wind shear and wind shear spectra, such as in magnitude and existence of the DI peak in the spectrum. Mean wind shear tends to grow with increasing resolution towards the observed values. Generally, RMSE is similar for MM5 and WRF. Finally, correlations are generally rather small (around 0.5 and smaller) suggesting that only a part of wind shear variability is explained by the models. Statistical scores for the directional wind shear are worse than for wind speed shear, suggesting that neither of the models is successful in representing the measured directional wind shear.

It should be emphasized that the data collected for almost 17 months at two $60-\mathrm{m}$ towers and one year of sodar data represent a great resource for wind power density assessment in complex terrain as well as for many subsequent data analysis and model evaluation studies. The evaluated models will lead to improved estimates of the wind power density in Nevada and will provide guidance for wind facilities development. 


\section{References}

Bacon, D. P.; Ahmad, N.N.; Boybeyi, A.; Dunn, T.J.; Hall, M.S.; Lee, P.C.S.; Sarma, R.A.; Turner, M.D.; Waight, K.T. III; Young, S.H.; Zack J.W. (2000). “A Dynamically Adapting Weather and Dispersion Model: The Operational Multiscale Environment Model with Grid Adaptivity (OMEGA).” Monthly Weather Review (128); pp. 2044-2076.

Basumatary H; Sreevalsan, E; Sai, K.K. (2005). "Weibull Parameter Estimates - A Comparison of Different Methods.” Wind Engineering (29); pp. 309-315.

Belu, R.; Koračin, D. (2009). "Wind Characteristics and Wind Energy Potential in Western Nevada.” Renewable Energy (34); pp. 2246-2251.

Belu R.G.; Koračin, D. (2013). "Statistical and Spectral Analysis of Wind Characteristics Relevant to Wind Energy Assessment Using Tower Measurements in Complex Terrain." Journal of Wind Energy (739162); doi:10.1155/2013/739162. http://dx.doi.org/10.1155/2013/739162.

Christofferson, R.D.; Gillete D.A. (1987). "A Simple Estimator of the Shape Factor of the TwoParameter Weibull Distribution." Journal of Climate and Applied Meteorology (26), pp. 323325.

Condrasen K.; Nielsen, L.; Prahm, L. (1984). "Review of Weibull Statistics for Estimation of Wind Speed Distribution." Journal of Climate and Applied Meteorology (23); pp. 1173-1183.

Cowen. G. (1998). Statistical Data Analysis. Oxford University Press.

Deaves, D.M.; Lines, I.G. (1997). "On the Fitting of Low Mean Wind Speed Data to the Weibull Distribution." Journal of Wind Engineering and Industrial Aerodynamics (65); pp. 169-178.

Hawkins D. (1980). Identification of Outliers. Chapman \& Hall.

Horvath, K.; Koračin, D.; Vellore, R.K.; Jiang, J.; Belu, R. (2012). "Sub-kilometer Dynamical Downscaling of Near-Surface Winds in Complex Terrain Using WRF and MM5 Mesoscale Models." Journal of Geophysical Research (117:D11111). doi:10.1029/2012JD017432.

Jiménez, P. A.; Dudhia, J. (2012). "Improving the Representation of Resolved and Unresolved Topographic Effects on Surface Wind in the WRF Model." Journal of Applied Meteorology and Climate (51), pp. 300-316.

Koračin, D.; Belu, R.; Canadillas, B.; Horvath, K.; Vellore, R.; Smith, C.; Jiang, J.; McCord, T. (2014). "A Review of Challenges in Assessment and Forecasting of Wind Energy Resources." Croat. Met. Journal. (47), pp. 13-33.

Monahan, A.H. (2006). "The Probability of Sea Surface Wind Speeds, Part I: Theory and Sea Winds Observations.” Journal of Climate (19), pp. 497-520.

Ott, R.; Longnecker, M. (2008). An Introduction to Statistical Methods and Data Analysis. Cengage Learning. 
Rothamsted, V.; Barnett, V.; Lewis, T. (1994). Outliers in Statistical Data. Wiley.

Seguro, J.V.; Lambert, T.W. (2000). "Modern estimation of the parameters of the Weibull wind speed distribution for wind energy analysis." Journal of Wind Engineering and Industrial Aerodynamics (85); pp. 75-84.

Skamarock, W.C., and Co-authors (2008). A description of the Advanced Research WRF Version 3, NCAR TN-475+STR, 113 pp.

Smith, C. M.; Koračin, D.; Horvath, K. (2014). "Forecast timing errors associated with the Washoe Zephyr. Part1: Dispersion metrics." Submitted to Weather and Forecasting.

Stevens, M.J.M.; Smulders, P.T. (1979). "The Estimation of the Parameters of the Weibull Wind Speed Distribution for Wind Energy Utilization Purposes." Wind Engineering (3), pp. 132-145. 


\section{Appendix: List of Measured and Processed Parameters from Data Measured at WT1 and WT2 and the Sodar}

Specifications of positions and orientations of the wind sensors on the towers are:

\section{Wind Tower \#1}

20-m height sensors

Cup anemometer \#1 - north side of tower (orientation $345^{\circ}$ )

Cup anemometer \#2 - south side of tower (orientation $158^{\circ}$ )

Sonic anemometer - west side of tower (orientation $252.5^{\circ}$ )

Wind direction - west side of tower (orientation 252.5 ) (located at $2 \mathrm{ft}$ below sonic)

40-m height sensors

Cup anemometer \#1 - north side of tower (orientation $342^{\circ}$ )

Cup anemometer $\# 2$ - south side of tower (orientation $155^{\circ}$ )

60-m height sensors

Cup anemometer \#1 - north side of tower (orientation $335^{\circ}$ )

Cup anemometer $\# 2$ - south side of tower (orientation $150^{\circ}$ )

Sonic anemometer - west side of tower (orientation $244.5^{\circ}$ )

Wind direction - west side of tower (orientation 244.5') (located at $2 \mathrm{ft}$ below sonic)

\section{Wind Tower \#2}

20-m height sensors

Cup anemometer \#1 - north side of tower (orientation $355^{\circ}$ )

Cup anemometer \#2 - south side of tower (orientation $178^{\circ}$ )

Sonic anemometer - west side of tower (orientation $268.5^{\circ}$ )

Wind direction - west side of tower (orientation 268.5 ) (located at $2 \mathrm{ft}$ below sonic)

40-m height sensors

Cup anemometer \#1 - north side of tower (orientation $352^{\circ}$ )

Cup anemometer \#2 - south side of tower (orientation $175^{\circ}$ )

60-m height sensors

Cup anemometer \#1 - north side of tower (orientation $355^{\circ}$ )

Cup anemometer $\# 2$ - south side of tower (orientation $180^{\circ}$ )

Sonic anemometer - west side of tower (orientation $263.5^{\circ}$ )

Wind direction - west side of tower (orientation 263.5 ) (located at $2 \mathrm{ft}$ below sonic)

In all lists below, the locations and orientations "\#1" are shown as defaults without "\#1" notations while the locations and orientations " $\# 2$ " specified above are stated at the end of the specification line. 


\section{List of Measured and Processed Parameters (WT1)}

WIND SPEED 20M

WIND VECTOR MAGNITUDE 20M

WIND DIRECTION 20M

STANDARD DEVIATION WIND DIRECTION 20M

STANDARD DEVIATION WIND SPEED 20M

MINIMUM WIND SPEED 20M

MAXIMUM WIND SPEED 20M

WIND SPEED 20M \#2

STANDARD DEVIATION WIND SPEED 20M \#2

MINIMUM WIND SPEED 20M \#2

MAXIMUM WIND SPEED 20M \#2

WIND SPEED 40M

STANDARD DEVIATION WIND SPEED 40M

MINIMUM WIND SPEED 40M

MAXIMUM WIND SPEED 40M

WIND SPEED 40M \#2

STANDARD DEVIATION WIND SPEED 40M \#2

MINIMUM WIND SPEED 40M \#2

MAXIMUM WIND SPEED 40M \#2

WIND SPEED 60M

WIND VECTOR MAGNITUDE 60M

WIND DIRECTION 60M

STANDARD DEVIATION WIND DIRECTION 60M

STANDARD DEVIATION WIND SPEED 60M

MINIMUM WIND SPEED 60M

MAXIMUM WIND SPEED 60M

WIND SPEED 60M \#2

STANDARD DEVIATION WIND SPEED 60M \#2

MINIMUM WIND SPEED 60M \#2

MAXIMUM WIND SPEED 60M \#2

AVERAGE TEMPERATURE THERMOCOUPLE 20M

AVERAGE TEMPERATURE THERMOCOUPLE 40M

AVERAGE TEMPERATURE THERMOCOUPLE 60M

AVERAGE AIR TEMPERATURE

STANDARD DEVIATION OF AIR TEMPERATURE

MAXIMUM AIR TEMPERATURE

MINIMUM AIR TEMPERATURE

MAXIMUM BAROMETRIC PRESSURE

MINIMUM BAROMETRIC PRESSURE

BAROMETRIC PRESSURE

STANDARD DEVIATION OF ATMOSPHERIC PRESSURE

UX AVERAGE 20M SONIC

UY AVERAGE 20M SONIC 
UZ AVERAGE 20M SONIC

20M SONIC TEMPERATURE AVERAGE

UX MAXIMUM 20M SONIC

UY MAXIMUM 20M SONIC

UZ MAXIMUM 20M SONIC

20M SONIC TEMPERATURE MAXIMUM

UX MINIMUM 20M SONIC

UY MINIMUM 20M SONIC

UZ MINIMUM 20M SONIC

20M SONIC TEMPERATURE MINIMUM

UX AVERAGE 60M SONIC

UY AVERAGE 60M SONIC

UZ AVERAGE 60M SONIC

60M SONIC TEMPERATURE AVERAGE

UX MAXIMUM 60M SONIC

UY MAXIMUM 60M SONIC

UZ MAXIMUM 60M SONIC

60M SONIC TEMPERATURE MAXIMUM.

UX MINIMUM 60M SONIC

UY MINIMUM 60M SONIC

UZ MINIMUM 60M SONIC

60M SONIC TEMPERATURE MINIMUM.

\section{List of Measured and Processed Parameters (WT2)}

WIND SPEED 20M

WIND VECTOR MAGNITUDE 20M

WIND DIRECTION 20M

STANDARD DEVIATION WIND DIRECTION 20M

STANDARD DEVIATION WIND SPEED 20M

MINIMUM WIND SPEED 20M

MAXIMUM WIND SPEED 20M

WIND SPEED 20M \#2

STANDARD DEVIATION WIND SPEED 20M \#2

MINIMUM WIND SPEED 20M \#2

MAXIMUM WIND SPEED 20M \#2

WIND SPEED 40M

STANDARD DEVIATION WIND SPEED 40M

MINIMUM WIND SPEED 40M

MAXIMUM WIND SPEED 40M

WIND SPEED 40M \#2

STANDARD DEVIATION WIND SPEED 40M \#2

MINIMUM WIND SPEED 40M \#2

MAXIMUM WIND SPEED 40M \#2

WIND SPEED 60M 
WIND VECTOR MAGNITUDE 60M

WIND DIRECTION 60M

STANDARD DEVIATION WIND DIRECTION 60M

STANDARD DEVIATION WIND SPEED 60M

MINIMUM WIND SPEED 60M

MAXIMUM WIND SPEED 60M

WIND SPEED 60M \#2

STANDARD DEVIATION WIND SPEED 60M \#2

MINIMUM WIND SPEED 60M \#2

MAXIMUM WIND SPEED 60M \#2

AVERAGE TEMPERATURE THERMOCOUPLE 20M

AVERAGE TEMPERATURE THERMOCOUPLE 40M

AVERAGE TEMPERATURE THERMOCOUPLE 60M

AVERAGE AIR TEMPERATURE

STANDARD DEVIATION AIR TEMPERATURE

MAXIMUM AIR TEMPERATURE

MINIMUM AIR TEMPERATURE

MAXIMUM BAROMETRIC PRESSURE

MINIMUM BAROMETRIC PRESSURE

BAROMETRIC PRESSURE

STANDARD DEVIATION OF ATMOSPHERIC PRESSURE

UX AVERAGE 20M SONIC

UY AVERAGE 20M SONIC

UZ AVERAGE 20M SONIC

20M SONIC TEMPERATURE AVERAGE

UX MAXIMUM. 20M SONIC

UY MAXIMUM 20M SONIC

UZ MAXIMUM 20M SONIC

20M SONIC TEMPERATURE MAXIMUM

UX MINIMUM 20M SONIC

UY MINIMUM 20M SONIC

UZ MINIMUM 20M SONIC

20M SONIC TEMPERATURE MINIMUM

UX AVERAGE 60M SONIC

UY AVERAGE 60M SONIC

UZ AVERAGE 60M SONIC

60M SONIC TEMPERATURE AVERAGE

UX MAXIMUM 60M SONIC

UY MAXIMUM 60M SONIC

UZ MAXIMUM 60M SONIC

60M SONIC TEMPERATURE MAXIMUM

UX MINIMUM 60M SONIC

UY MINIMUM 60M SONIC

UZ MINIMUM 60M SONIC

60M SONIC TEMPERATURE MINIMUM 


\section{List of Measured and Processed Parameters (Sodar)}

WIND DIRECTION 40M

WIND SPEED 40M

VERTICAL WIND SPEED 40M

SODAR QUALITY \% 40M

WIND DIRECTION 50M

WIND SPEED 50M

VERTICAL WIND SPEED 50M

SODAR QUALITY \% 50M

WIND DIRECTION 60M

WIND SPEED 60M

VERTICAL WIND SPEED 60M

SODAR QUALITY \% 60M

WIND DIRECTION 80M

WIND SPEED $80 \mathrm{M}$

VERTICAL WIND SPEED 80M

SODAR QUALITY \% 80M

WIND DIRECTION 100M

WIND SPEED 100M

VERTICAL WIND SPEED 100M

SODAR QUALITY \% 100M

WIND DIRECTION $120 \mathrm{M}$

WIND SPEED 120M

VERTICAL WIND SPEED 120M

SODAR QUALITY \% 120M

WIND DIRECTION 140M

WIND SPEED 140M

VERTICAL WIND SPEED 140M

SODAR QUALITY \% 140M

WIND DIRECTION 160M

WIND SPEED 160M

VERTICAL WIND SPEED 160M

SODAR QUALITY \% 160M

WIND DIRECTION 180M

WIND SPEED 180M

VERTICAL WIND SPEED 180M

SODAR QUALITY \% 180M

WIND DIRECTION 200M

WIND SPEED 200M

VERTICAL WIND SPEED 200M

SODAR QUALITY \% 200M

SODAR WIND TURBULENCE 40M

SODAR WIND TURBULENCE $50 \mathrm{M}$

SODAR WIND TURBULENCE 60M

SODAR WIND TURBULENCE $80 \mathrm{M}$

SODAR WIND TURBULENCE 100M 
SODAR WIND TURBULENCE 120M SODAR WIND TURBULENCE 140M SODAR WIND TURBULENCE 160M SODAR WIND TURBULENCE 180M SODAR WIND TURBULENCE 200M SODAR TURBULENCE QUALITY \% 40M SODAR TURBULENCE QUALITY \% 50M SODAR TURBULENCE QUALITY \% 60M SODAR TURBULENCE QUALITY $\% 80 \mathrm{M}$ SODAR TURBULENCE QUALITY \% 100M SODAR TURBULENCE QUALITY \% 120M SODAR TURBULENCE QUALITY \% 140M SODAR TURBULENCE QUALITY \% 160M SODAR TURBULENCE QUALITY \% 180M SODAR TURBULENCE QUALITY \% 200M 